Aus der Abteilung Hämatologie und Onkologie

(Prof. Dr. med. L. Trümper)

Im Zentrum Innere Medizin

der Medizinischen Fakultät der Universität Göttingen

\title{
Die Bedeutung von Dishevelled in der Wnt-5a-induzierten Signaltransduktion
}

\author{
INAUGURAL-DISSERTATION \\ zur \\ Erlangung des Doktorgrades \\ der Medizinischen Fakultät \\ der Georg-August-Universität zu \\ Göttingen
}

vorgelegt von

\section{Christina Charlotte Dicke}

aus Krefeld

Göttingen 2011 
Dekan:

I. Berichterstatterin:

II. Berichterstatter/in:

III. Berichterstatter/in:

Tag der Mündlichen Prüfung:
Prof. Dr. med. Frömmel Prof. Dr. med. Binder Prof. Dr. rer. nat. Wodarz Prof. Dr. med. Oppermann

13. Dezember 2011 



\section{Inhaltsverzeichnis}

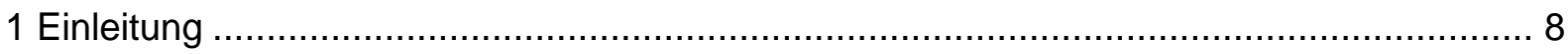

1.1 Epidemiologie und Bedeutung von Krebserkrankungen ................................ 8

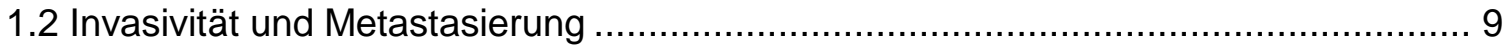

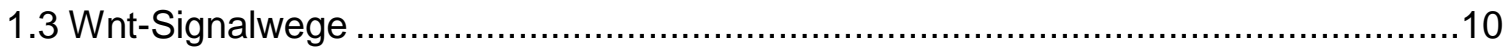

1.3.1 Der kanonische Wnt/ $\beta$-Catenin-Signalweg ................................................ 12

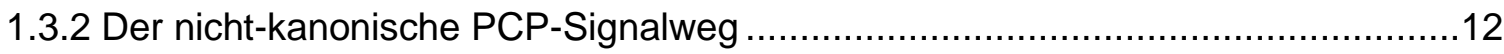

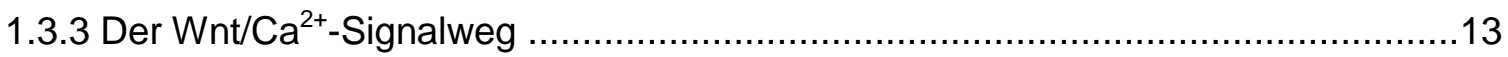

1.3.4 Ein weiterer Wnt-Signalweg über Ror 2 .....................................................14

1.3.5 Interaktionspartner der Wnt-Signalwege .......................................................14

1.4 Dishevelled - Das Schaltprotein in den Wnt-Signalwegen................................15

1.5 Wnt 5a beeinflusst die Invasivität von Tumorzellen .........................................17

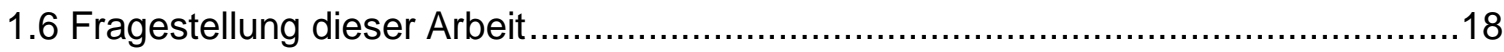

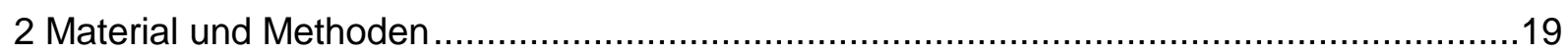

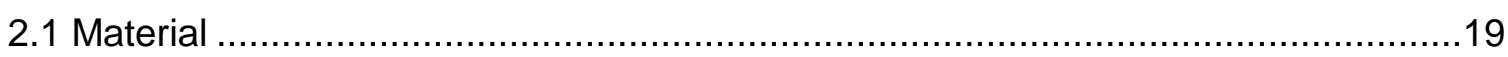

2.1.1 Chemikalien und Reagenzien ............................................................... 19

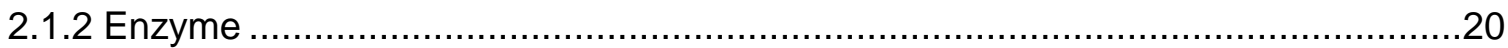

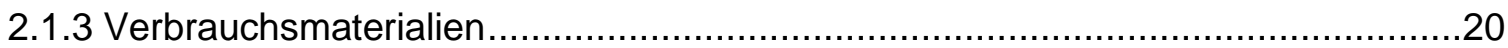

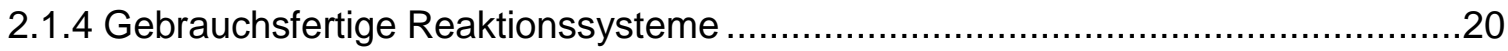

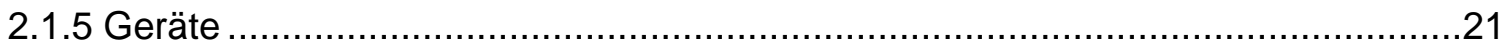

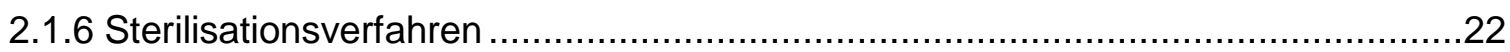

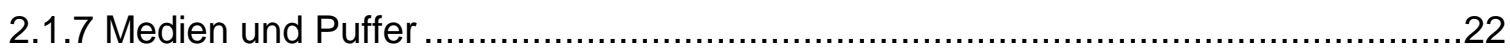

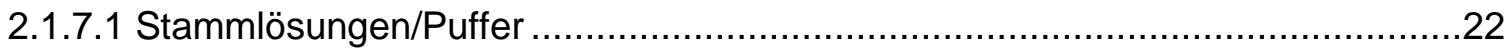

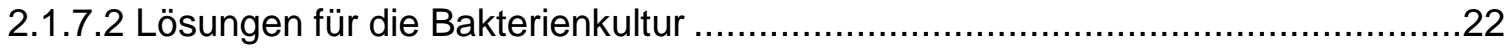

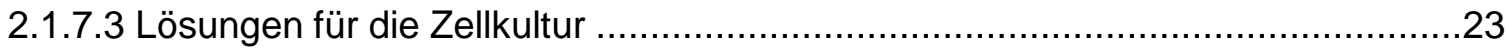

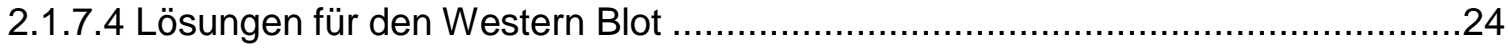

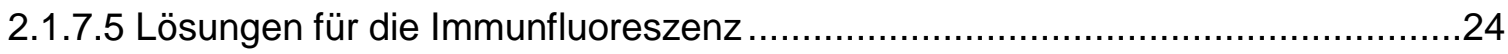

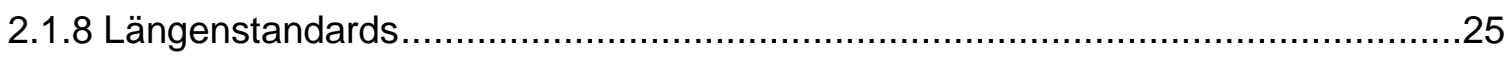




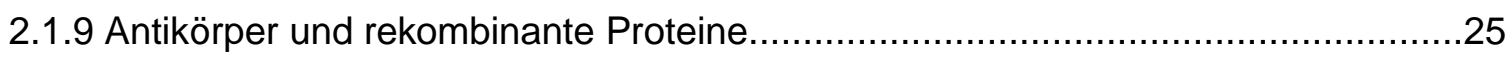

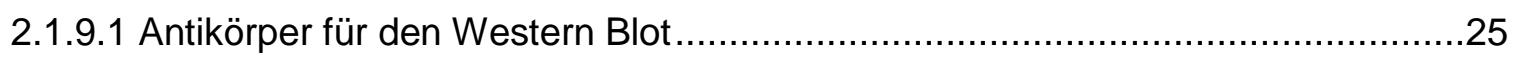

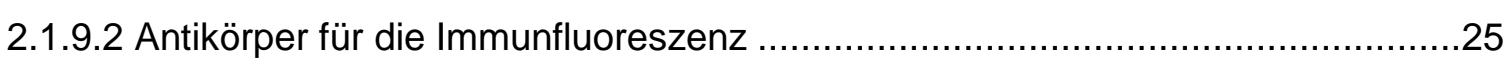

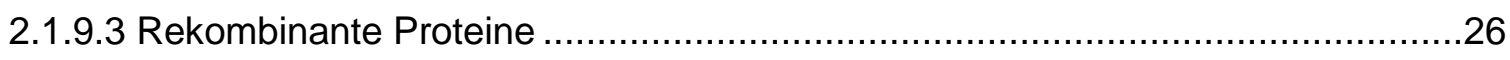

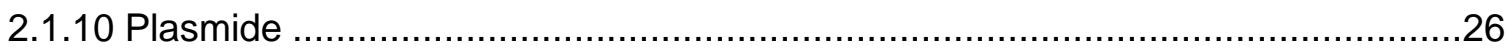

2.1.10.1 Aufbau der verwendeten Dishevelled-Plasmide........................................26

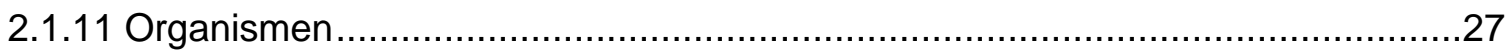

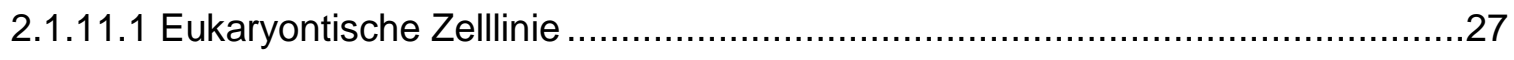

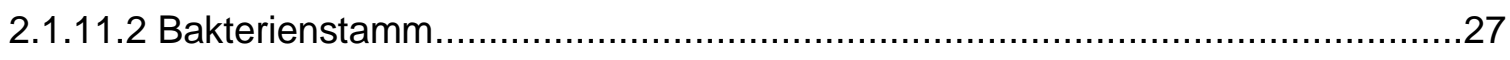

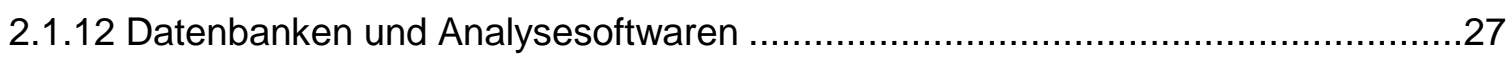

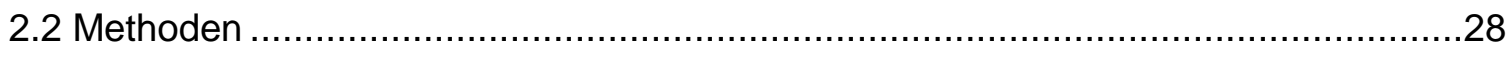

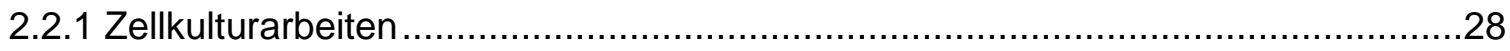

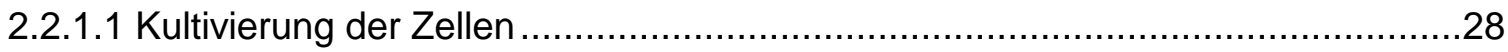

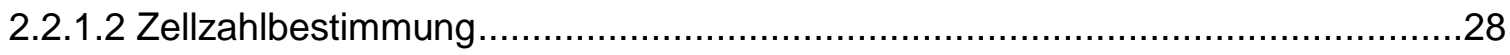

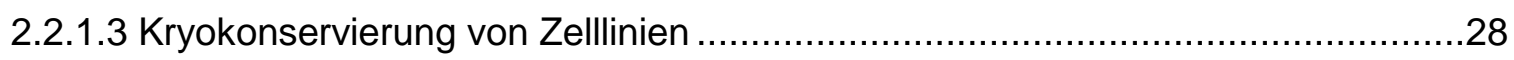

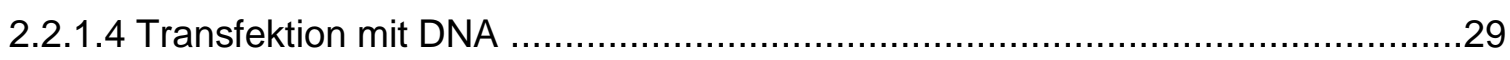

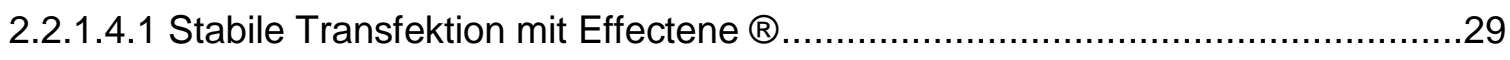

2.2.1.4.2 Transiente Transfektion mit Nanofectin $₫$..................................................29

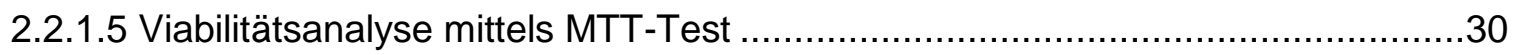

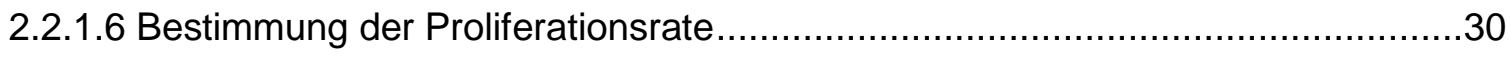

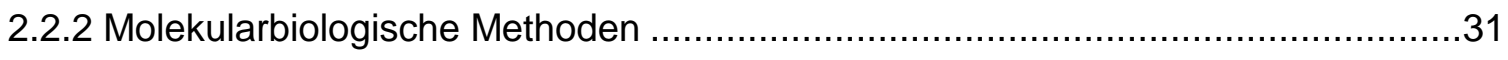

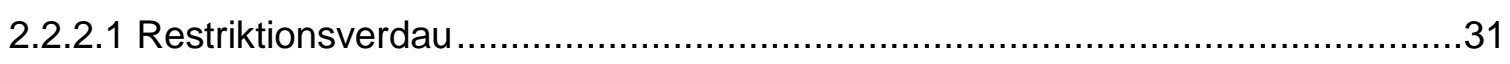

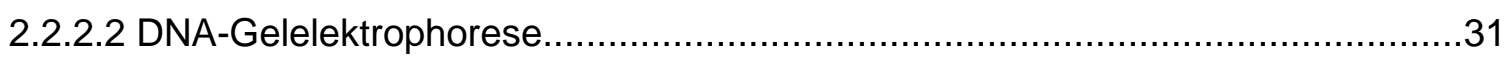

2.2.2.3 Transformation kompetenter Bakterienzellen.......................................... 31

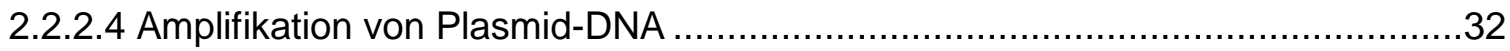

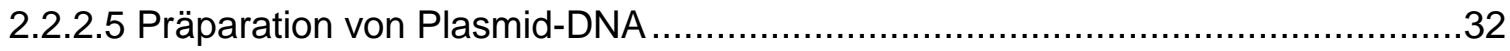

2.2.2.6 Konzentrationsbestimmung von Nukleinsäuren .........................................

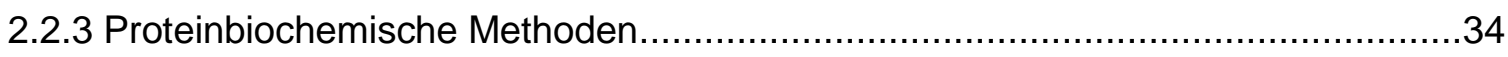


2.2.3.1 Herstellung von Zelllysaten für den Western Blot...........................................34

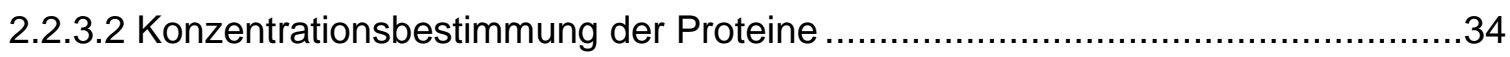

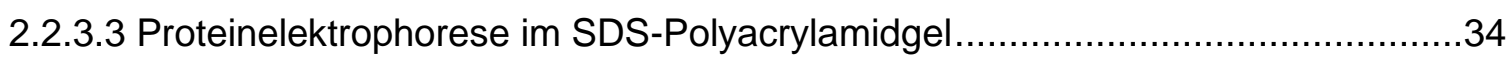

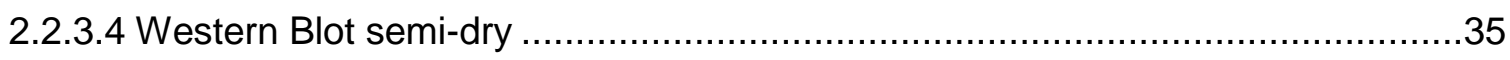

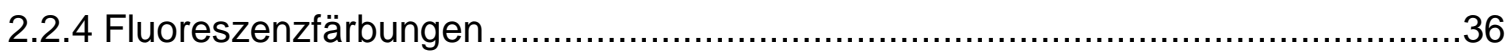

2.2.4.1 Indirekte Einfach-Immunfluoreszenzfärbung ..............................................

2.2.4.2 Indirekte Einfach-Immunfluoreszenzfärbung von Wnt-5a-stimulierten Zellen .....36

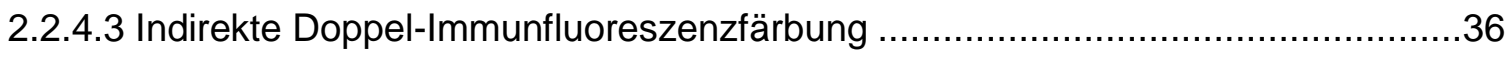

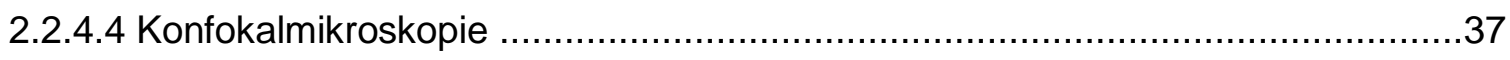

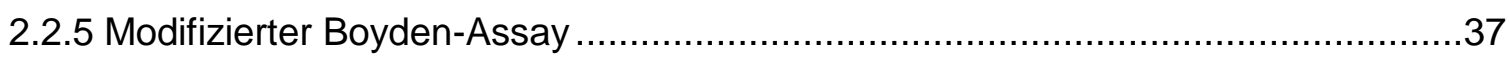

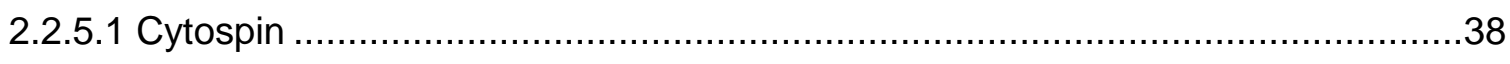

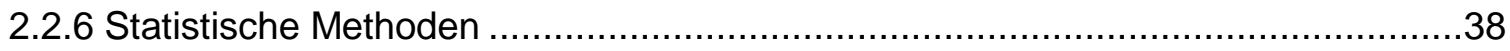

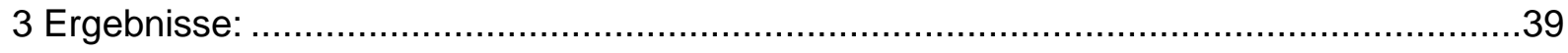

3.1 Herstellung geeigneter Klone für den Boyden-Assay.........................................39

3.1.1 Amplifikation und Konzentrationsbestimmung der Plasmid-DNA ........................39

3.1.2 Transfektionseffizienz der transienten Transfektion .....................................40

3.1.3 Expression der transient transfizierten Konstrukte .........................................41

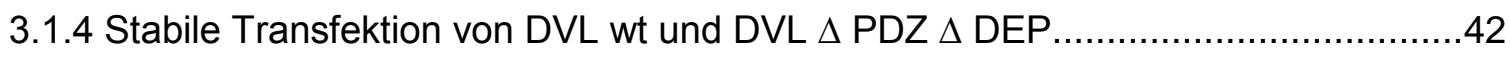

3.1.5 MTT-Assay der stabil transfizierten Zellen ..................................................43

3.1.6 Zellzählung der stabil transfizierten Zellen ................................................... 44

3.2 Einsatz der Zellen in der modifizierten Boyden-Kammer ..................................45

3.3 Subzelluläre Lokalisation der einzelnen Dishevelled-Konstrukte .........................46

3.3.1 Cytospin-Färbung der Wnt 5a-stimulierten Zellen nach Durchlaufen der Boyden-

Kammer . .46

3.3.2 Subzelluläre Lokalisation der DVL-Konstrukte in stabil transfizierter MCF-7. .46

3.3.3 Subzelluläre Lokalisation der einzelnen DVL-Konstrukte in transient transfizierten

Zellen .48

3.3.4 Subzelluläre Lokalisation der Konstrukte nach Wnt 5a - Stimulation. .50 
3.3.5 Expression von exogenem Konstrukt und endogenem DVL-3 in stabil transfizierten

Zellklonen. .51

3.3.6 Gleichzeitige Lokalisation von endogenem DVL-3 und exogenem Konstrukt........52

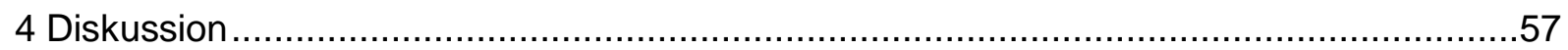

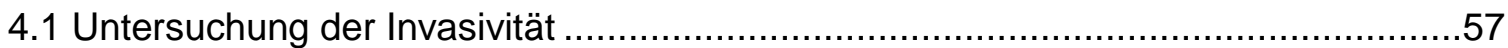

4.2 Ursache und Konsequenz der Zelllokalisationen .............................................58

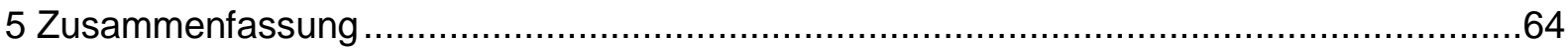

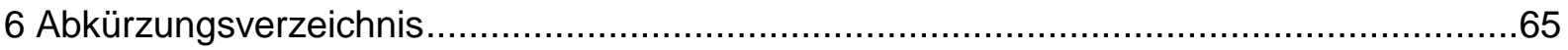

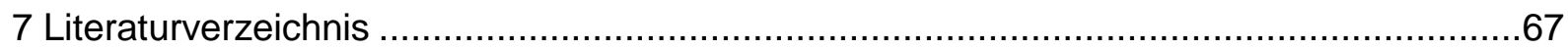




\section{Einleitung}

\subsection{Epidemiologie und Bedeutung von Krebserkrankungen}

2006 gab es in Europa 3,2 Millionen Krebs-Neuerkrankungen sowie 1,6 Millionen durch Krebs bedingte Todesfälle. Damit sind Krebserkrankungen nach Erkrankungen des HerzKreislauf-Systems die zweithäufigste Todesursache in Europa (Coleman et al. 2008). Nach Schätzungen des Robert-Koch-Instituts (2010) wurden 2006 in Deutschland 426.800 Krebs-Diagnosen gestellt. Die Inzidenz von Krebserkrankungen in Deutschland hat seit 1980 bei Frauen um $35 \%$, bei Männern um mehr als $80 \%$ zugenommen. Im Gegensatz dazu ist die Krebs-Mortalität in Deutschland zurückgegangen: Altersstandardisiert sanken die Sterberaten für Männer und Frauen seit 1980 um etwa 20 \%. Mögliche Ursachen für diese Entwicklung sind in der veränderten Altersstruktur der Bevölkerung und in der höheren durchschnittlichen Lebenserwartung $z u$ suchen. Zudem haben verbesserte Früherkennungsmaßnahmen und Therapiemöglichkeiten Inzidenz und Mortalität zahlreicher Krebserkrankungen beeinflusst (Robert-Koch-Institut 2010).

Der häufigste maligne Tumor in Deutschland ist bei der Frau das Mamma-Karzinom. Beim Mann dominiert das Prostata-Karzinom, die zweit- und dritthäufigsten Krebsarten sind bei beiden Geschlechtern das kolorektale Karzinom und das Bronchial-Karzinom. In der Mortalität ist sowohl beim Mann als auch bei der Frau das Bronchial-Karzinom führend (Robert-Koch-Institut 2010). Als maligner Tumor wird in der Onkologie eine abnorme und schnell wachsende Gewebsmasse definiert. Diese wächst unabhängig von physiologischen Stimuli und zeichnet sich durch einen Kontrollverlust von Mechanismen aus, die normalerweise Proliferation, Differenzierung und Apoptose im Zellverband regulieren (Hanahan und Weinberg 2000). Die Klassifikation in maligne oder benigne bestimmt die Prognose einer Krebserkrankung und wird anhand von mikroskopisch und makroskopisch nachweisbaren Eigenschaften gestellt: Benigne Tumoren bestehen aus hochdifferenzierten Zellen, die denen des Ursprungsgewebes in Aussehen und Funktion ähneln. Die meisten benignen Tumoren wachsen langsam und bleiben lokal begrenzt. Ihnen fehlt die Fähigkeit, umgebendes Gewebe zu infiltrieren und Metastasen in die Körperperipherie zu streuen. Im Gegensatz zu benignen Tumoren zeigen maligne Tumoren einen unterschiedlich starken Verlust der zellulären und geweblichen Differenzierung. Dazu gehören bestimmte Charakteristika wie eine ausgeprägte Zell- und Kernpolymorphie, vermehrte Mitosefiguren, eine starke funktionelle Abweichung vom Ursprungsgewebe und eine zunehmende Gewebsautonomie (Kumar et al. 2007). Maligne Tumoren zeichnen sich durch invasives und destruierendes Wachstum aus. Tumorzellen können sich über Körperhöhlen, Blut- und Lymphgefäße in andere Gewebe absiedeln und dort Metastasen bilden (Kumar et al. 2007). 


\subsection{Invasivität und Metastasierung}

Die prognostisch wichtigste Eigenschaft eines malignen Tumors ist seine Fähigkeit, invasiv zu wachsen und Metastasen zu bilden. Generell gilt: Je geringer die Differenzierung und je größer der Primärherd bei Diagnosestellung, desto höher ist die Wahrscheinlichkeit einer Metastasierung (Kumar et al. 2007).

Voraussetzung für die Entstehung eines malignen Tumors sind Mutationen in verschiedenen

Klassen von Genen, die Zellwachstum beeinflussen oder Apoptose- und Reparaturmechanismen von Zellen regulieren (Hanahan und Weinberg 2000). Durch diese genetischen Veränderungen besitzen Tumorzellen ein unbegrenztes Replikationspotential; sie sind unabhängig von Wachstumssignalen und entgehen dem programmierten Zelltod, der unter physioloschen Bedingungen die Lebensdauer einer Zelle bestimmt. Der Beginn der Kanzerogenese ist somit durch Vorgänge innerhalb der betroffenen Zelle gekennzeichnet; die nachfolgende Absiedlung von Metastasen in die Körperperipherie erfolgt durch Interaktionen mit dem die Tumorzellen umgebenden Stroma. Der komplexe Prozess der Invasivität und Metastasierung besteht aus einer Sequenz mit vier Zwischenschritten:

1. Infiltration von benignen Strukturen im Primärtumor, 2. Intravasation, 3. Extravasation,

4. Kolonisation entfernter Gewebe. Nachdem aus einer transformierten Zelle ein expandierender Tumorzellklon entstanden ist, beginnen die ersten Zellen, sich aus dem Zellverband zu lösen. Dies geschieht durch Funktionsverlust der Haftstrukturen in Zell-zuZell-Kontakten, die durch E-Cadherin-Interaktionen gebildet werden (Aplin et al. 1998). Wird die Expression von E-Cadherin unterbunden oder E-Cadherin durch den Bindungspartner $\beta$ Catenin inaktiviert, kann die Tumorzelle aus dem Zellverband ausbrechen (Hanahan und Weinberg 2000). Im nächsten Schritt der Invasion findet die temporäre Auflösung der den Tumorzellklon umgebenden Extrazellulärmatrix (ECM) aus Kollagenen, Glykoproteinen und Proteoglykanen statt (Kumar et al. 2007). Die hierfür verantwortlichen proteolytischen Enzyme werden entweder von Tumorzellen sezerniert oder nach Induktion in Stromazellen wie z.B. Fibroblasten oder Tumor-assoziierten Makrophagen (TAMs) gebildet (Lukashev und Werb 1998). Zu den bekanntesten Enzymen gehören Matrix-Metalloproteasen (MMPs), besonders MMP-9, Cathepsin D und Urokinase-Plasminogen-Aktivatoren (Chiang und Massague 2008). Der nächste Schritt in der Metastasierung ist die Migration der Tumorzelle durch die degradierte ECM zu Blut- oder Lymphgefäßen. Sowohl Tumor- als auch Stromazellen lenken die Migration durch die Sekretion bestimmter Chemokinmuster. Ebenso besitzen Abbauprodukte der ECM eine chemotaktische Aktivität (Steeg 2006). Eine systemische Dissemination erfolgt, sobald eine einzelne Tumorzelle oder ein ganzer Zellverband ein Blut- oder Lymphgefäß erreicht hat, in dieses eindringt (Intravasation) und über Blut- oder Lymphbahn in die Peripherie gelangt (Kumar et al. 2007). Laut der „Homing“Theorie erkennen die zirkulierenden Tumorzellen ihr Zielgewebe durch im Blut gelöste 
Chemokine und durch Expression von bestimmten Adhäsionsrezeptoren wie z.B. Selektinen auf den Endothelzellen und verlassen die Blutbahn (Extravasation) (Kaplan et al. 2005). Günstige Wachstumsbedingungen im Zielgewebe sind für eine erfolgreiche Absiedlung notwendig. Besonders TAMs fördern die Ausbreitung eines Tumors, indem sie Wachstumsfaktoren für Angiogenese und Lymphangiogenese produzieren. Dazu gehören VEGF (vascular endothelial growth factor) und zahlreiche Proteasen wie die zuvor schon erwähnte MMP-9 (DeNardo et al. 2008). Eine ausreichende Blutversorgung sichert das Wachstum und Überleben von Metastasen im ortsfernen Gewebe und hilft bei der Rekrutierung weiterer Entzündungszellen. Somit ist die Interaktion von Tumor- und Entzündungszellen erforderlich für die Invasivität und Metastasierung eines Tumors.

\subsection{Wnt-Signalwege}

Wnt-Gene kodieren für eine Familie von 19 humanen sekretorischen Glykoproteinen. Über Oberflächenrezeptoren aktivieren sie verschiedene Signalwege und beeinflussen dadurch die Proliferation, Migration und Ausrichtung von Zellen in Zellverbänden. Dadurch spielen Wnt-Proteine einerseits eine physiologische Rolle in Embryogenese und Gewebsorganisation, andererseits eine pathologische Rolle in Tumorprogression und -invasion.

Wnt-Signalwege sind hochkonservierte Signalkaskaden, deren Bezeichnung sich aus dem Drosophila-Segment-Polaritäts-Gen Wingless und dem dazugehörigen Vertebraten-Homolog integrated oder int-1 zusammensetzt (Komiya und Habas 2008). Sharma und Chopra fanden 1976 heraus, dass durch Ausschalten des bis dahin unbekannten Wnt-Gens auf dem linken Arm des zweiten Chromosoms ein flügelloser Phänotyp von Drosophila Melanogaster entstand (Sharma und Chopra 1976). Zu den durch Wht ausgelösten Signalkaskaden werden der kanonische Wnt/ $\beta$-Catenin-Signalweg, der nicht-kanonische Planar-Cell-PolaritySignalweg (PCP) und der Wnt/Ca ${ }^{2+}$-Signalweg gezählt (Logan und Nusse 2004). Im kanonischen Wnt/ $\beta$-Catenin-Signalweg wird eine Akkumulation von B-Catenin im Zytoplasma induziert, die nach Transfer in den Zellkern die Aktivierung zahlreicher zellulärer Prozesse zur Folge hat. So beeinflusst der kanonische Wnt/ $\beta$-Catenin-Signalweg die Zelldetermination in der frühen Embryogenese (Cadigan und Nusse 1997). Zu den zwei bekanntesten Auswirkungen dieses Signalwegs gehören die Ausbildung einer doppelten Achse im Krallenfrosch Xenopus und die Transformation, d.h. morphologische Veränderung vom Ursprungsgewebe, muriner Brustdrüsenzellen (Du et al. 1995; Shimizu et al. 1997). Neben der Regulierung der anterioren und posterioren Achsenentwicklung im Embryo spielt der kanonische Signalweg zudem eine wichtige Rolle bei der Organogenese von Herz, Lungen, Nieren, Haut und Knochen. Weiterhin wurde eine Beteiligung bei der Selbsterneuerung von Stammzellen nachgewiesen (Reya und Clevers 2005). Die nicht-kanonischen Signalwege unterscheiden sich vom kanonischen Signalweg durch eine von ß-Catenin unabhängige Signaltransduktion und durch die innen fehlende Fähigkeit, die Bildung der doppelten Achse 
im Krallenfrosch zu induzieren (McDonald und Silver 2009). Der PCP-Signalweg ist für die Zellpolarität in Drosophila und Konvergenz-Extensions-Bewegungen in Xenopus und Zebrafisch zuständig. Durch den $\mathrm{Wnt} / \mathrm{Ca}^{2+}$-Signalweg werden Zellbewegung und Zelladhäsion gesteuert (Schambony und Wedlich 2007; Wallingford und Habas 2005; Wallingford et al. 2000). Die genannten Signalwege sind eng miteinander verschaltet und können sich gegenseitig beeinflussen. Ihre Aktivierung scheint weniger durch eine spezifische Ligandenzuordnung als vielmehr durch bestimmte Kombinationen von Rezeptorkomplexen stattzufinden, an die Wnt bindet (He et al. 1997; Liu, G. et al. 2005; Liu, G. et al. 2003; Mikels und Nusse 2006b; Tamai et al. 2004). Allen den voran genannten Signalwegen ist gemeinsam, dass sie über das zytoplasmatische Protein Dishevelled weitergeleitet werden. Im Folgenden werden die einzelnen in Abbildung 1.1 dargestellten Signalwege genauer erläutert.

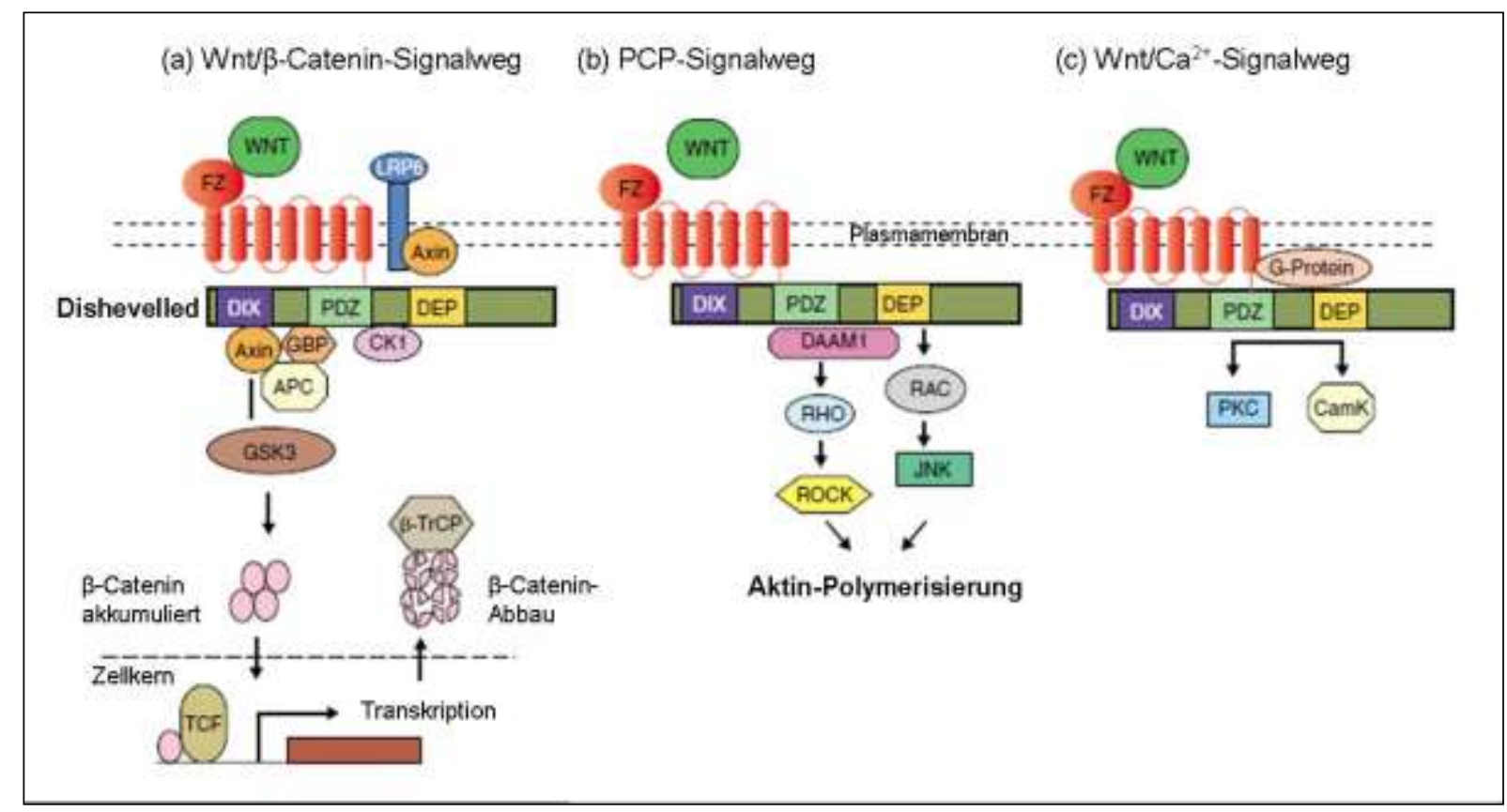

Abbildung 1.1: Die einzelnen Wnt-Signalwege nach Wallingford und Habas (Wallingford und Habas 2005, S. 4422). a) Der kanonische Wnt/ק-Catenin-Signalweg. Wnt bindet an Fz und LRP 5/6. Das Signal wird über die DIX- und PDZ-Domänen von Dishevelled weitergeleitet; dieses hemmt daraufhin einen großen Proteinkomplex im Zytoplasma, der unter anderem aus APC und GSK-3 $\beta$ aufgebaut ist und für den Abbau von $\beta$-Catenin zuständig ist. $\beta$-Catenin transferiert in den Zellkern und aktiviert dort über TCF/LEF die Transkription von Wnt-Zielgenen. b) Der nicht-kanonische PCPSignalweg. Wnt bindet an Fz und aktiviert über die PDZ- und DEP-Domäne von DVL die kleinen GTPasen Rho und Rac. Zielprodukte sind ROCK und JNK (Jun-N-Terminale Kinase JNK), die durch Veränderungen am Aktin-Zytoskelett die Zellbewegungen beeinflussen. c) Der Wnt/Ca ${ }^{2+}$-Signalweg. Wnt aktiviert den Wnt/Ca ${ }^{2+}$-Signalweg nach Bindung an Fz. Wie zuvor beim PCP-Signalweg reguliert Dishevelled über PDZ und DEP die Aktivierung von Proteinkinase $C$ und der Calmodulin-abhängigen Kinase 3, die weitere Substrate phosphorylieren. Bei allen drei Wegen muss Dishevelled an die Zellmembran binden, um das Wnt-Signal zu empfangen. 


\subsubsection{Der kanonische Wnt/ $\beta$-Catenin-Signalweg}

Wichtigster Bestandteil des kanonischen Signalwegs ist $\beta$-Catenin, das in unstimulierten Zellen transkriptionell inaktiv ist und an die Zellmembran lokalisiert, wo es am Aufbau des Zytoskeletts mittels E-Cadherin beteiligt ist (Siehe Abbildung 1.1.a.).

Nach Aktivierung des kanonischen Signalweges induziert $\beta$-Catenin unter anderem die Transkription von Zielgenen, die für Kanzerogenese und Invasivität zuständig sind (Komiya und Habas 2008). Der kanonische Signalweg wird durch Bindung von Wnt-1-Liganden (Wnt 1, Wnt 3, Wnt 8) an einem Rezeptorkomplex aktiviert, der aus dem Frizzled-Rezeptor (Fz) und dem Co-Rezeptor LRP 5/6 (Lipoprotein-Receptor-Related Protein 5/6) aufgebaut ist (van Amerongen et al. 2008). Der Wnt-Ligand bindet dabei an die extrazelluläre $\mathrm{N}$-terminale cysteinreiche Domäne des Frizzled-Rezeptors und bewirkt dadurch die Aktivierung von Dishevelled durch einen bisher unbekannten Mechanismus, möglicherweise über dessen Phosphorylierung. Aktiviertes Dishevelled inhibiert über seine DIX- und PDZ-Domänen einen großen Proteinkomplex im Zytoplasma, bestehend aus dem Adenomatosis-Polyposis-ColiProtein (APC), Protein-Phosphatase 2A (PP2A), Axin, Casein-Kinase 1a (CK1 $\alpha)$ und Glykogen-Synthase-Kinase-3 $\beta$ (GSK-3 $\beta$ ) (Gordon und Nusse 2006; He et al. 2004). In unstimulierten Zellen führt dieser Proteinkomplex zur Phosphorylierung von freiem $\beta$ Catenin, welches daraufhin ubiquitiniert und proteolysiert wird (Aberle et al. 1997). Im kanonischen Signalweg kann $\beta$-Catenin durch den Proteinkomplex nicht mehr abgebaut werden. Hypophosphoryliertes und damit stabiles $\beta$-Catenin transloziert in den Zellkern, wo es an Transkriptionsfaktoren der T-Cell-Factor/Lymphocyte-Enhancer-Factor (TCF/LEF)Familie bindet und dadurch die Transkription von Zielgenen initiiert. Dazu gehören Gene, die für die Bildung von Organisatoren in der Embryogenese benötigt werden wie z.B. Siamosis und Twin als auch Proto-Onkogene wie C-myc, Cyclin D1 und die Matrix-Metalloprotease Matrilysin (mmp-7) (Crawford et al. 1999; Pukrop et al. 2006). Die genannten ProtoOnkogene beeinflussen die Proliferation und Ausbreitung von Tumoren. Myc-Proteine binden an die Zell-DNA und aktivieren die Transkription von weiteren Genen, die für das Tumorwachstum eine Rolle spielen. Dazu gehören die Cycline, die in den Zellzyklus eingreifen und die autonome Replikation der Tumorzelle bewirken. Matrix-Metalloproteasen lösen wie unter 1.2 beschrieben die den Tumor umgebende Extrazellulärmatrix auf und fördern so dessen invasives Wachstum und Dissemination in die Peripherie (Westermarck und Kahari 1999).

\subsubsection{Der nicht-kanonische PCP-Signalweg}

Planar Cell Polarity bezeichnet die gerichtete Orientierung von fast allen Zelltypen und Geweben. Dabei zeigen nicht nur die einzelnen epithelialen Zellen eine Ausrichtung entlang 
der apikal-basolateralen Achse; tatsächlich ist im gesamten Zellverband eines epithelialen Gewebes oder Organs eine Polarität zu erkennen (Wallingford und Habas 2005).

Wnt 4, Wnt 5a und Wnt 11 aktivieren den PCP-Signalweg durch Bindung an den FrizzledRezeptor (Komiya und Habas 2008). Wie in Abbildung 1.1.b) zu sehen, findet die Signaltransduktion ab Dishevelled über zwei parallel geschaltete, voneinander unabhängige Signalwege statt. Diese führen zur Aktivierung der Rho-ATPasen RhoA und Rac (Axelrod et al. 1998; Wallingford und Habas 2005). Im ersten Signalweg bindet Dishevelled an DAAM-1 und bewirkt über RhoA die Induktion der Rho-assoziierten Kinase ROCK, welche wie Rac für die zytoskeletale Reorganisation über Aktin-Filamente zuständig ist (Habas et al. 2003). Im zweiten Signalweg wird über Rac die Jun-N-Terminale Kinase JNK aktiviert. Diese phosphoryliert C-Jun und aktiviert dadurch AP-1 (Nateri et al. 2005). AP-1 ist ein Transkriptionsfaktor, der die Expression von Zielgenen für Differenzierung, Proliferation und Apoptose von Zellen reguliert. Zugleich hat AP-1 eine wichtige Bedeutung als Tumorpromotor durch Induktion mehrerer onkogener Faktoren, unter anderem von SerinProteasen und Matrix-Metallo-Proteasen. Diese konnten wie zuvor unter 1.2. beschrieben bei malignen Prozessen mit zellulärer Invasion in Zusammenhang gebracht werden (Le Floch et al. 2005). Der PCP-Signalweg wurde zuerst in Drosophila melanogaster sowie in dem Käfer Oncopeltus fasciatus entdeckt. Durch Ausknocken von Genen des PCPSignalwegs entwickelte Drosophila eine unorganisierte Flügelbehaarung anstatt des typischen polarisierten, vom distalen Scheitel der Zellen ausgehenden Haarmusters (Adler 1992). Zu den weiteren Aufgaben des PCP-Wegs gehören die Regulierung des mitotischen Spindelapparates bei Wirbellosen als auch Konvergenz-Extensionsbewegungen, NeuralrohrVerschluss, Innenohrentwicklung und Ziliogenese bei Wirbeltieren und die Haarorientierung bei Säugetieren (Simons und Mlodzik 2008).

\subsubsection{Der Wnt/Ca ${ }^{2+}$-Signalweg}

Im nicht kanonischen Wnt/Ca ${ }^{2+}$-Signalweg induziert Wnt 5a nach Bindung an Frizzled eine $\mathrm{Ca}^{2+}$-Mobilisation aus endogenen Speichern sowie die Aktivierung der beiden Kinasen Proteinkinase C (PKC) und Calmodulin-abhängige Kinase C (CamKII). Die Weiterleitung erfolgt über die beiden Dishevelled-Domänen PDZ und DEP und ist von einem heterotrimeren G-Protein abhängig. Dieses ist membranständig und bewirkt über seine $\mathrm{Ga}_{\mathrm{t}^{-}}$ Untereinheit durch Aktivierung von Phosphodiesterase 6 (PDE6) einen Abbau des intrazellulären, zyklischen Guanosinmonophosphats (cGMP) zu GMP. Niedrige intrazelluläre Spiegel von cGMP wiederum inhibieren die Aktivität der cGMP-abhängigen Proteinkinase $G$ (PKG) (Wang et al. 2004). Über seine GßY-Untereinheit aktiviert das heterotrimere G-Protein Phospholipase C; diese spaltet membranständiges $\mathrm{PIP}_{2}$ (Phosphatidylinositol-4,5bisphosphat) in $\mathrm{IP}_{3}$ (Inositol-1,4,5-trisphosphat) und DAG (Diacylglycerin). Letzteres aktiviert Proteinkinase $\mathrm{C}(\mathrm{PKC})$, während $\mathrm{IP}_{3}$ einen Ausstrom von $\mathrm{Ca}^{2+}$-lonen aus endogenen 
Speichern bewirkt. Die Höhe und Geschwindigkeit der $\mathrm{Ca}^{2+}$-Wellen regulieren die Aktivierung der Proteinkinase $\mathrm{C}$ und der Calmodulin-abhängigen Kinase 3, die weitere Substrate phosphorylieren (De Koninck und Schulman 1998; Dolmetsch et al. 1998; Slusarski et al. 1997; Slusarski und Pelegri 2007). Ein wichtiges Effektorprotein des Wnt/ Ca ${ }^{2+}$-Signalwegs ist der Nuclear Factor of Activated T-Cells (NFAT), der in den Zellkern transloziert und dort die Calcineurin-abhängige Expression bestimmter Zielgene anregt (Saneyoshi et al. 2002). Neuere Studien zeigen eine pro-onkogene Funktion von NFAT in soliden und hämatologischen Malignomen. So wurde zum Beispiel eine hohe Expression von NFAT bei Invasivem Duktalen Mamma-Karzinom, Pankreas-Karzinom und Non-Hodgkin-B-Zell- und -T-Zell-Lymphomen nachgewiesen (Medyouf und Ghysdael 2008).

\subsubsection{Ein weiterer Wnt-Signalweg über Ror 2}

Neben den bisher bekannten Wnt-Signalwegen gibt es noch einen weiteren Signalweg, dessen Effektorprotein JNK ist. Es werden weder $\beta$-Catenin noch der TCF/LEFTranskriptionsfaktor aktiviert, weswegen diese Kaskade zu den nicht-kanonischen Signalwegen gezählt wird. Der Signalweg wird - wie der PCP-Signalweg - durch Wnt 5a induziert, läuft aber über einen anderen Rezeptormechanismus ab, den Tyrosin-KinaseRezeptor Ror 2 (Yamamoto et al. 2007). Wnt 5a bindet in diesem Fall an die extrazelluläre cysteinreiche Domäne von Ror 2 und bewirkt unter Umgehung von Dishevelled und der kleinen GTPase Rho die Aktivierung von JNK. Wie im PCP-Signalweg aktiviert JNK c-jun und AP-1 und dadurch die Transkription der gleichen Gene, die auch beim PCP-Signalweg für die Pathogenese bei invasiven Vorgängen eine herausragende Rolle spielen (Liu, Y. et al. 2008; Oishi et al. 2003; Schambony und Wedlich 2007). Eine kanzerogene Rolle des durch Wnt 5a-induzierten Signalwegs über Ror 2 wurde in murinen NIH3T3-Zellen nachgewiesen, bei denen nach Stimulation Migration und Invasion induziert wurde (Nomachi et al. 2008).

\subsubsection{Interaktionspartner der Wnt-Signalwege}

Wnt-Proteine werden über eine Vielzahl an Bindungspartnern positiv oder negativ reguliert. $\mathrm{Zu}$ den extrazellulären Inhibitoren gehören sFRPs (soluble Frizzled-related proteins) und WIFs (Wnt inhibitory factor), die an Wnt (und im Fall von sFRP zusätzlich an den FrizzledRezeptor) binden und dadurch sowohl den kanonischen Signalweg als auch $\beta$-Cateninunabhängige Signalwege antagonisieren (MacDonald et al. 2009). Die Dkk-Familie (Dickkopf) wirkt durch Bindung an LRP 5/6 modulierend auf die Wnt-gesteuerten Signalwege ein, je nach Ligand aktivierend oder inhibierend. So hemmt Dkk-1 den kanonischen WntSignalweg und kann ebenso die B-Catenin-unabhängigen Signalwege antagonisieren, während Dkk-2 unter entsprechenden Rezeptorkonstellationen unterschiedliche Funktionen ausübt: Bei hoher LRP-6-Dichte hat Dkk-2 eine aktivierende Funktion, bei niedriger 
Rezeptoranzahl wirkt Dkk-2 wie Dkk-1 und Dkk-4 als Antagonist des kanonischen Signalwegs (Niehrs 2006). Norrin ist ein spezifischer Ligand für Frizzled-4 und kann dadurch den kanonischen Signalweg in Abwesenheit von Wnt aktivieren (MacDonald et al. 2009). Diese Beispiele verdeutlichen die komplexen Wechselwirkungen zwischen den einzelnen Signalwegen, die je nach Ligand und Rezeptorkonstellation in unterschiedlicher Weise beeinflusst werden können.

\subsection{Dishevelled - Das Schaltprotein in den Wnt-Signalwegen}

Allen Signalwegen - außer dem Ror-Signalweg - ist gemeinsam, dass sie über das zytoplasmatische Protein Dishevelled weitergeleitet werden. Während die Schritte bis zu Dishevelled in allen Signalkaskaden ähnlich sind, laufen sie ab Dishevelled mit unterschiedlichen Effektorproteinen weiter. Dishevelled kann somit als Schaltprotein in den Wnt-Signalwegen bezeichnet werden (Wallingford und Habas 2005). Es gibt mehrere Theorien, durch welche Mechanismen Dishevelled die einzelnen Signalwege unterscheidet und weiterleitet. So soll einerseits die Verwendung verschiedener Proteindomänen von Dishevelled bei der Signaltransduktion eine Rolle spielen. Andererseits scheint aber auch die Verteilung von Dishevelled im Zytoplasma Auswirkungen auf die Aktivierung einzelner Signalwege $\mathrm{zu}$ haben. Auf beide Hypothesen wird im Folgenden näher eingegangen (Axelrod et al. 1998; Habas und Dawid 2005).

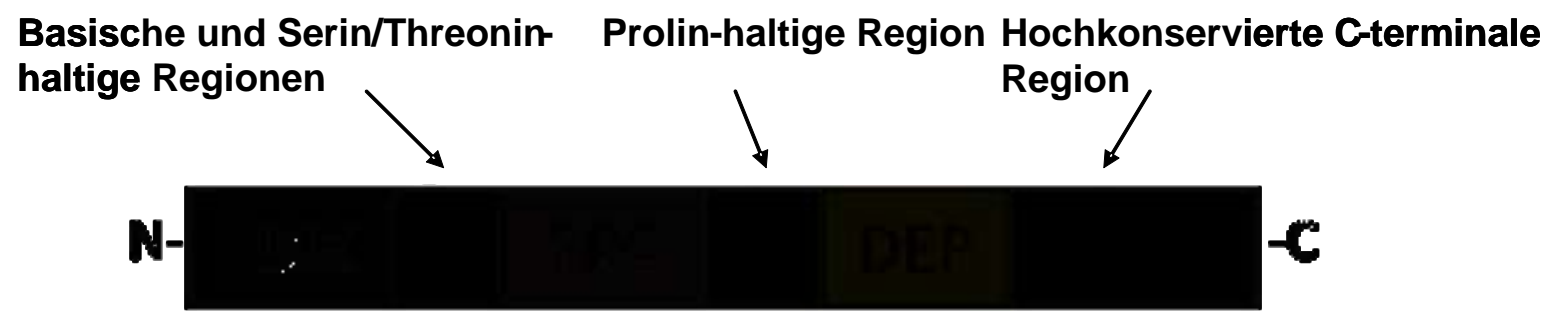

Abbildung 1.2: Das Dishevelled-Protein nach Wallingford und Habas (Wallingford und Habas 2005), S. 4423). Am N-Terminus von Dishevelled befindet sich die DIX-Domäne, die für die Weiterleitung des kanonischen Wnt/ $\beta$-Catenin-Signalwegs zuständig ist. Dagegen regulieren PDZ und DEP den Wnt/Ca ${ }^{2+}$-Signalweg und den PCP-Signalweg.

Dishevelled bedeutet übersetzt „ungekämmt“, „durcheinander“ und beschreibt damit die erste Entdeckung im Zusammenhang mit diesem wichtigen Schaltprotein bei der Weiterleitung der Wnt-Signalwege. Fahmy und Fahmy fanden 1959 heraus, dass bei einer Mutation im Drosophila-Genom die Fliegen eine unorganisierte und unpolarisierte Kopf- und Flügelbehaarung aufwiesen. Damit waren die ersten Dishevelled-Allele identifiziert (Fahmy und Fahmy 1959). Das erste Dishevelled-Homolog bei Wirbeltieren wurde in Mäusen entdeckt, danach folgte die Bestimmung eines Xenopus-DSH, zwei weiterer Dishevelled- 
Proteine im Maus-Genom (DVL-1, DVL-2) und im weiteren Verlauf drei humane DishevelledGene: Humanes Dishevelled 1-3 (Wallingford und Habas 2005). Die in der wissenschaftlichen Literatur verwendete Abkürzung für Dishevelled orientiert sich am Ursprungsorganismus: Ein Xenopus-Dishevelled wird mit DSH abgekürzt, DishevelledProteine von Wirbeltieren erhalten die Kurzbezeichnung DVL (Wallingford und Habas 2005). Dishevelled-Proteine sind aus 500 - 600 Aminosäuren aufgebaut und bestehen aus den drei hochkonservierten Domänen DIX (für Dishevelled und Axin-Proteine), PDZ (für $\underline{\text { PSD-95, }}$ Disc-large und ZZO-1-Proteine) und DEP (für Dishevelled, EGL-10 und Pleckstrin-Proteine). Die Verwendung der verschiedenen Domänen beeinflusst den weiteren Verlauf der Signalkaskade (Axelrod et al. 1998; Wallingford und Habas 2005). Über die DIX-Domäne wird der kanonische Signalweg reguliert, während DEP den nicht-kanonischen PCPSignalweg und den $\mathrm{Wnt} / \mathrm{Ca}^{2+}$-Signalweg weiterleitet. PDZ scheint dagegen in allen drei Signalwegen eine Rolle zu spielen (Capelluto et al. 2002; Wong et al. 2000). Für die WntSignaltransduktion transloziert das zytoplasmatische Protein Dishevelled an die Zellmembran. Neuere Studien zeigen, dass Dishevelled an der Membran phosphoryliert wird. Für die Phosphorylierung kommen mehrere Kinasen in Betracht, von denen die beiden

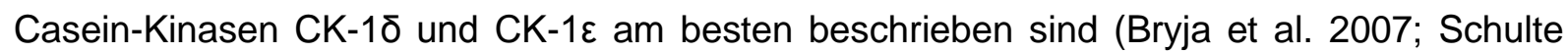
und Bryja 2007). Im kanonischen Signalweg bindet die n-terminale DIX-Domäne an Axin, ein Bestandteil des großen $\beta$-Catenin-Destruktionskomplexes. Somit wird dieser inaktiviert. Stabilisiertes $\beta$-Catenin kann daraufhin im Zytoplasma akkumulieren und in den Zellkern translozieren. Für die nicht-kanonischen Signalwege konnte bisher keine direkte Beteiligung von DIX nachgewiesen werden. Die PDZ-Domäne ist an allen drei Signalwegen beteiligt und bewirkt die Bindung von Dishevelled an den Frizzled-Rezeptor (Wong et al. 2003). Die am CTerminus befindliche DEP-Domäne ist für die Transduktion vom PCP- und $\mathrm{Wnt} / \mathrm{Ca}^{2+}$ Signalweg zuständig. Zudem spielt sie wie PDZ eine Rolle bei der Membranbindung (Axelrod et al. 1998; Boutros et al. 2000; Wong et al. 2003; Wong et al. 2000). Eine weitere Theorie zur Signaltransduktion via Dishevelled basiert auf dessen Verteilung an der Plasmamembran: Rekrutierung von Dishevelled an die apikale Plasmamembran scheint den PCP-Weg zu induzieren, während der kanonische Wnt-Signalweg möglicherweise mit der Translokation von Dishevelled zu den basolateralen Anteilen der Membran verbunden ist (Wu et al. 2004). Dishevelled ist an zahlreichen biologischen Prozessen beteiligt: Angefangen von der segmentären Polarität bei Drosophila, der dorsoventralen Achsenausrichtung und der Gastrulation bei Wirbeltieren, der gerichteten Migration von Zellen innerhalb von Zellverbänden, der polarisierten Zellteilung bis zum Neuralrohrverschluss und der neuronalen Entwicklung bei Vertebraten. Die Vielzahl an Entwicklungsprozessen, auf die Dishevelled einwirkt, verdeutlicht dessen komplexe Bedeutung als Schaltstelle für die einzelnen Signalwege (Wallingford und Habas 2005). 


\subsection{Wnt 5a beeinflusst die Invasivität von Tumorzellen}

Hagemann et al. konnten 2004 zeigen, dass Kokulturen der Brustkrebszelllinie MCF-7 mit humanen Makrophagen die Invasivität der Tumorzellen steigern. Dies geschieht über Induktion von Matrix-Metalloproteasen und TNF- $\alpha$ (Hagemann et al. 2004). Nachfolgende Untersuchungen durch Pukrop et al. haben ergeben, dass die bei den Invasivitätsexperimenten eingesetzten Tumor-assoziierten Makrophagen (TAMs) Wnt $5 \mathrm{a}$ hochregulieren; ein gleicher, die Invasivität von MCF-7 fördernder Effekt wird durch rekombinantes Wnt 5a erzeugt, wenn es in Abwesenheit von Makrophagen zu den Zellen gegeben wird (Pukrop et al. 2006). Wnt 5a konnte hochreguliert in Gewebsschnitten von zahlreichen aggressiven Malignomen nachgewiesen werden. Dazu gehören Karzinome des Nasopharynx sowie Bronchial-, Mamma-, und Prostata-Karzinome. Je bösartiger und höhergradiger das Tumorstadium - zum Beispiel bei Melanomen der Haut -, desto höher war die ermittelte Wnt-5a-Konzentration im Gewebe. Zudem zeigte sich die höchste Dichte von Wnt 5a oft in der invasiven Front der Karzinome. Wnt 5a wurde dabei nicht nur in den Tumorzellen selber nachgewiesen, sondern auch in den im Tumorstroma enthaltenen Makrophagen (Pukrop und Binder 2008).

Die vorausgegangen Experimente unserer Arbeitsgruppe haben gezeigt, dass die Invasivität von MCF-7 unter Wnt-5a-Stimulation deutlich zunahm. Nach Wnt-5a-Gabe stiegen die AP-1Promotor-Aktivität und die c-Jun-Phosphorylierung rasant an; beides Endprodukte des PCPSignalweges. Zudem wurden mmp-7 und TNF- $\alpha$ hochreguliert. Dagegen wurde der unter Wnt 5a induzierte Invasivitätsanstieg durch Zugabe von Dickkopf-1 (Dkk-1) oder dem JNKInhibitor 1 antagonisiert. Dkk-1 ist ein bekannter Antagonist des kanonischen Signalwegs, kann aber auch die B-Catenin-unabhängigen Signalwege inhibieren (Lee et al. 2004; Mikheev et al. 2004). Ein leichter additiver Effekt der Invasivität trat auf, wenn zusätzlich der kanonische Signalweg durch Inhibition des GSK-3- $\beta-K o m p l e x e s$ in den Tumorzellen aktiviert wurde. Wurde der kanonische Signalweg hingegen ausgeschaltet, konnte keine Invasivität mehr nachgewiesen werden. Dieser Effekt konnte erreicht werden, indem der TCF/LEFTranskriptionsfaktor als Ziel des kanonischen Signalwegs durch ein dominant-negatives LEF-1-Konstrukt antagonisiert wurde (Pukrop und Binder 2008).

Zusammengefasst zeigen die gewonnenen Ergebnisse, dass durch nicht-kanonisches Wnt5a-Signaling die Invasivität von MCF-7 ansteigt. Durch Inhibition an unterschiedlichen Zielpunkten in der PCP-Signalkaskade wurde die Invasivität gehemmt. Eine Hochregulation von Effektorproteinen des kanonischen Signalwegs wie zum Beispiel eine Zunahme von unphosphoryliertem $\beta$-Catenin konnte dabei nicht nachgewiesen werden. Diese Resultate verdeutlichen, dass ein intakter kanonischer Signalweg zwar Voraussetzung für eine unter Wnt 5a gesteigerte Invasivität ist, den Vorgang der gesteigerten Invasivität aber nicht ausreichend erklären kann (Pukrop et al. 2006). 


\subsection{Fragestellung dieser Arbeit}

Mit dieser Arbeit möchte ich an die Arbeit von Pukrop et al. anknüpfen, die zeigen konnten, dass Wnt 5a die Invasivität von MCF-7 höchstwahrscheinlich über den PCP-Signalweg steigert (Pukrop et al. 2006). Diese These soll nun anhand eines weiteren Versuchsaufbaus überprüft werden. Ein geeigneter Angriffspunkt für meine Fragestellung ist das Schaltprotein Dishevelled (DVL) in den Wnt-Signalwegen. Über dessen PDZ- und DEP-Domänen wird der PCP-Signalweg weitergeleitet (Wallingford und Habas 2005). Ein flag-getaggtes humanes Dishevelled-Konstrukt, bei dem genau diese beiden Domänen fehlen, soll stabil in MCF-7Zellen transfiziert werden (DVL $\triangle$ PDZ $\triangle \mathrm{DEP}$ ). Dieses soll als dominant-negatives Konstrukt in den MCF-7-Zellen überexprimiert werden und kompetitiv zum endogenen DVL wirken. Als Vergleich dazu wird außerdem ein Wildtyp-Konstrukt in eine zweite Zelllinie (DVL wt) gebracht. Falls die Wnt-5a-induzierten Signale tatsächlich in den PCP-Pfad kanalisiert werden, wäre ein Fehlen der funktionellen Auswirkungen von Wnt $5 \mathrm{a}$ in den mit dem DVL $\Delta$ PDZ $\triangle$ DEP-Konstrukt transfizierten Zellen zu erwarten. DVL wt hingegen sollte im Vergleich zur MCF-7-Kontrolle eine ähnliche Beeinflussung auf die Invasivität oder allenfalls aufgrund seines hochregulierten full-length-Konstruktes eine etwas höhere Steigerung zur Folge haben. Das invasive Verhalten der transfizierten Zellen unter Wnt-5a-Stimulation wird in einer modifizierten Boyden-Kammer untersucht. Die Ergebnisse der Versuchsreihen könnten einen weiteren Einblick in den komplizierten Prozess der Metastasierung geben. In der onkologischen Forschung ist die Bedeutung des kanonischen Signalwegs für die Invasivität von Malignomen seit langem bekannt; der PCP-Signalweg schien bisher vorwiegend in physiologischen Prozessen eine Funktion zu haben, wie zum Beispiel bei der Migration von Zellen im Rahmen der Gewebsentwicklung. Eine Involvierung des PCP-Signalwegs in der Invasivität der Brustkrebszelllinie MCF-7 ließe vermuten, dass ähnliche Prozesse bei der Metastasierung von weiteren Malignomen eine Rolle spielen. 


\section{Material und Methoden}

\subsection{Material}

Nicht aufgeführte Chemikalien wurden von der Firma Sigma-Aldrich,München bezogen.

\subsubsection{Chemikalien und Reagenzien}

\section{Substanz}

Acrylamid/Bisacrylamid $40 \%$

Albumin Fraktion V

Ampicillin

Ampicillin Agar

Dimethylsulfoxid (DMSO)

1,4- Dithiothreitol (DTT)

Effectene ${ }^{\circledR}$ Transfection Reagent

Enhanced chemiluminescence detection system (ECL)

Enhanced chemiluminescence detection system plus (ECL plus)

Ethanol

Ethidiumbromid

Ethylendiamintetraessigsäure (EDTA)

Extrazellulärmatrix (ECM)

Fluorescent mounting medium

Fetales Kälberserum (FCS)

$\mathrm{HCl}$

imMedia $^{\mathrm{TM}}$ Amp Agar

Isopropanol

6x Ladepuffer (für Gelelektrophorese)

Methanol

Nanofectin ${ }^{\circledR}$ Transfection Reagent

t- Octylphenoxypolyethoxyethanol (Triton X-100)

PBS

Phosphate buffered saline (PBS)

Ponceau-Lösung

Phosphatase-Inhibitor Phosphostop

Polyoxyethylene sorbitan monolaurate (Tween 20)

PureYield Plasmid Midi Prep System

\section{Bezugsquelle}

Roth, Karlsruhe

Biomol, Hamburg

Sigma-Aldrich, München

Invitrogen Europe, Paisly, UK

Merck, Darmstadt

Merck, Darmstadt

Qiagen, Hilden

GE Healthcare, Solingen

GE Healthcare, Solingen

Merck, Darmstadt

Sigma-Aldrich, München

Serva, Heidelberg

Sigma-Aldrich, München

Dako, CA, USA

Biochrom, Berlin

Merck, Darmstadt

Invitrogen Europe, Paisly, UK

Sigma-Aldrich, München

Fermentas, St. Leon-Rot

Merck, Darmstadt

PAA, Cölbe

Sigma,-Aldrich, München

PAN Biotech $\mathrm{GmbH}$, Aidenbach

Sigma-Aldrich, München

Sigma-Aldrich, München

Roche Diagnostics, Mannhein

Bio-Rad Laboratories, München

Promega, Mannheim 
RPMI 1640

S.O.C. Medium

Tetramethylethylendiamin (TEMED)

Tris buffered saline (TBS)

Trishydroxymethylaminomethan (Tris)

Trypsin/Ethylendiamintetraessig-säure (EDTA)

Zeocin $^{\mathrm{TM}}$
Sigma-Aldrich, München

Invitrogen Europe, Paisly, UK

Sigma-Aldrich, München

Sigma-Aldrich, München

Roth, Karlsruhe

Biochrom AG, Berlin

Invitrogen Europe, Paisly, UK

\subsubsection{Enzyme}

\section{Enzym}

Restriktionsenzyme inklusive Puffer 2

\section{Bezugsquelle}

New England Biolabs, Frankfurt a.M.

\subsubsection{Verbrauchsmaterialien}

Nicht aufgeführte Gebrauchswaren wurden von den Firmen Sarstedt, Nümbrecht oder Greiner, Solingen bezogen.

\section{Produkt}

24-Well-Platten

6-Well-Platten

96-Well-Platten

Blotting Papier

Boyden-Membran

Cell.Scraper $25 \mathrm{~cm}$

Deckgläser $\varnothing 12 \mathrm{~mm}$

High performance chemiluminescence film

HybondTM-C Extra Nitrocellulose Transfer

Insulinkanüle $1 \mathrm{ml}$

Objektträger $76 \times 26 \mathrm{~mm}$

Pipettenspitzen

Polycarbonat-Membran

Zellkulturflaschen $25 \mathrm{~cm}^{2}$

\section{Bezugsquelle}

Nunc, Wiesbaden

Nunc, Wiesbaden

Nunc, Wiesbaden

Heinemann Labortechnik, Duderstadt

Nucleopore, Pleasanton, CA, USA

Sarstedt, Nümbrecht

Carl Roth, Karlsruhe

GE Healthcare, Solingen

GE Healtthcare, Solingen

Braun Petzold, Melsungen

Waldemar Knittel, Braunschweig

Biozym, Hess. Oldendorf

Pieper Filter, Bad Zwischenahn

Nunc, Wiesbaden

\subsubsection{Gebrauchsfertige Reaktionssysteme}

\section{Kit}

BCA $^{\mathrm{TM}}$ Protein Assay Kit

\section{Bezugsquelle}

Pierce Biotechnology, Rockford, IL, USA 
Effectene ${ }^{\circledR}$ Transfection Reagent

Enhanced chemiluminescence detection

system (ECL)

Enhanced chemiluminescence detection

system plus (ECL plus)

Nanofectin ${ }^{\circledR}$ Transfection Reagent

PureYieldTM Plasmid Midi Prep System
Quiagen, Hilden

GE Healthcare, Solingen

GE Healthcare, Solingen

PAA, Cölbe

Promega, Mannheim

\subsubsection{Geräte}

\section{Gerät}

Bio Photometer (für Nukleinsäure-

Konzentrationsbestimmungen)

Blotting-Aparatur mit Power-Supply

Boyden-Kammer

Biometra T13

Dampfsterilisator Varioklav Thermo

Elektrophoresekammern für DNA

Fluoreszenzmikroskop Axiovert 200

Geldokumentationssystem

Konfokalmikroskop

Lichtmikroskop

Magnetrührer mit Heizplatte

Microplate-Spektralphotometer

Pipetten

Pipettus

Sterilwerkbank, MSC-Advantage

Wasserbad

Zentrifuge Centrifuge $5415 \mathrm{C}$

Zentrifuge Multifuge 3L-R

Zellkultur-Inkubator Sanyo

Zentrifuge Shandon 3

Zentrifuge Universal $30 \mathrm{~F}$

\section{Hersteller}

Eppendorf, Hamburg

Biometra, Göttingen

Wissenschaftliche Werkstätte,

Universitätsklinikum Göttingen

Biometra, Göttingen

Fisher Scientific,Schwerte

Biometra, Göttingen

Carl Zeiss, Hamburg

Biometra, Göttingen

Carl Zeiss, Hamburg

Carl Zeiss, Hamburg

Ikamag Reo, Staufen

Bio-Rad Laboratories, München

Eppendorf, Hamburg

Integra Bioscience, Fernwald

Thermo Scientific, Langenselbold

Gesellschaft für Labortechnik mbH (GFL)

Eppendorf, Hamburg

Heraeus Instruments, Hanau

Etten Leur, Niederlande

Thermo Fisher Scientific, Braunschweig

Krannich, Göttingen 


\subsubsection{Sterilisationsverfahren}

Sämtliche Gebrauchswaren, Lösungen und Kulturmedien - sofern nicht steril geliefert wurden bei $180^{\circ} \mathrm{C}$ und 1 Bar Überdruck mit Wasserdampf autoklaviert oder vier Stunden bei $180^{\circ} \mathrm{C}$ Kerntemperatur hitzesterilisiert. Hitzeempfindliche Lösungen wurden steril filtriert.

\subsubsection{Medien und Puffer}

\subsubsection{Stammlösungen/Puffer}

\section{Stammlösung/Puffer}

10x TBS

10x PBS

10x TBE-Puffer

\subsubsection{Lösungen für die Bakterienkultur}

\section{Medium}

LB-Medium (Luria-Broth-Medium)

S.O.C. Medium

\section{Zusammensetzung}

$0,5 \mathrm{M}$

$1,5 \mathrm{M}$

Tris/HCL

$\mathrm{NaCl}$

Auf $\mathrm{pH} 7,6$ einstellen

$\begin{array}{ll}140 \mathrm{mM} & \mathrm{NaCl} \\ 6,4 \mathrm{mM} & \mathrm{Na}_{2} \mathrm{HPO}_{4} \\ 1,4 \mathrm{mM} & \mathrm{KH}_{2} \mathrm{PO}_{4} \\ 2,7 \mathrm{mM} & \mathrm{KCl} \\ \text { Auf pH 7,4 einstellen } & \\ 890 \mathrm{mM} & \text { TRIS } \\ 890 \mathrm{mM} & \text { Borsäure } \\ 20 \mathrm{mM} & \text { EDTA (pH8) }\end{array}$

\section{Zusammensetzung}

$\begin{array}{ll}10 \mathrm{~g} / \mathrm{l} & \text { Trypton } \\ 5 \mathrm{~g} / \mathrm{l} & \text { Hefeextrakt } \\ 10 \mathrm{~g} / \mathrm{l} & \mathrm{NaCl}\end{array}$

Invitrogen Europe, Paisly, UK

Die Medien wurden mit bidestilliertem Wasser angesetzt, autoklaviert und bei $4^{\circ} \mathrm{C}$ aufbewahrt. Je nach Bedarf wurde das LB-Medium mit dem entsprechenden Antibiotikum versetzt. Zur Herstellung fester Nährböden wurde dem Fertigpräparat imMediaTM Amp Agar von Invitrogen Europe, Paisly, UK, $200 \mathrm{ml}$ destilliertes Wasser hinzugefügt. Anschließend wurde die Lösung aufgekocht und in die bereitgestellten Zellplatten gegossen. 


\subsubsection{Lösungen für die Zellkultur}

\section{Lösung}

Einfriermedium

Zellkulturmedium

MTT-Lyse-Puffer

\section{Zusammensetzung}

RPMI 1640 (Sigma, Deisenhofen)

$50 \%(\mathrm{v} / \mathrm{v})$

FCS

$5 \%(\mathrm{v} / \mathrm{v})$

DMSO

RPMI 1640 (Sigma, Deisenhofen)

$10 \%(\mathrm{v} / \mathrm{v})$

FCS

$75 \%(\mathrm{v} / \mathrm{v})$

Ameisensäure

$25 \%(v / v)$

DMSO

$5 \mathrm{mg} / \mathrm{ml}$

In PRMI 1640

(3-(4,5-Dimethylthiazol-2-yl )2,5-

diphenytetrazoliumbromid)

Selektionsmedium

Splitting Medium

Zellkultur-PBS

Zelllyse-SDS-Puffer

RIPA-Puffer
Zeocin $^{\mathrm{TM}}$ (Invitrogen Europe, Paisly, UK)

$100 \mu \mathrm{g} / \mathrm{ml}$ Zellkulturmedium

Trypsin/EDTA (Biochrom AG, Berlin)

$\begin{array}{ll}0,05 \%(w / v) & \text { Trypsin } \\ 0,02 \%(w / v) & \text { EDTA in PBS }\end{array}$

PAN Biotech $\mathrm{GmbH}$, Aidenbach

$10 \mathrm{mM}$

Tris/ $\mathrm{HCl}$

$1 \%(\mathrm{w} / \mathrm{v})$

SDS

Auf $\mathrm{pH} 7,4$ einstellen

$150 \mathrm{mM}$

$\mathrm{NaCl}$

$1 \%(w / v)$

NP40

$0,5 \%(w / v)$

Natriumdesoxychelat

$0,1 \%(w / v)$

SDS

$50 \mathrm{mM}$

Tris

Auf $\mathrm{pH} 8$ einstellen

Zu $1000 \mu$ I RIPA-Lysepuffer wurden noch 1\% (w/v) Phosphatase-Inhibitor -(Phosphostop, Roche, Diagnostics GmbH, Mannhein) - und $10 \%$ (v/v) Protease-Inhibitor-Cocktail zugegeben, um eine Verdauung der im Lysat enthaltenen Proteine durch Proteasen zu verhindern. Der RIPA-Puffer diente ebenso wie der Zelllyse-SDS-Puffer zur Gewinnung von Protein (exogenes und endogenes DVL) aus MCF-7, DVL wt und DVL $\triangle$ PDZ $\triangle$ DEP. 


\subsubsection{Lösungen für den Western Blot}

\section{Lösung}

1x Transferpuffer

Sammelgelpuffer

Trenngelpuffer

5\% Milchpulver

10x SDS-PAGE Laufpuffer

4x Lämmli-Ladepuffer

TBS-Tween

PBS-Tween

\section{Zusammensetzung}

$25 \mathrm{mM}$

Tris

$150 \mathrm{mM}$

Glycin

$20 \%(\mathrm{v} / \mathrm{v})$

Methanol

Auf $\mathrm{pH} 8,3$ einstellen

$0,5 \mathrm{M}$

Tris

$0,4 \%(w / v)$

SDS

Auf $\mathrm{PH}$ 6,6 einstellen

$1,5 \mathrm{M}$

Tris

$0,4 \%(w / v)$

SDS

Auf $\mathrm{pH} 8.8$ einstellen

$5 \%$

Magermilchpulver

Jeweils gelöst in PBS, TBS, TBS-T,

PBS-T

$250 \mathrm{mM}$

$14,4 \%(w / v)$

$1 \%(w / v)$

Auf $\mathrm{pH} \mathrm{8,3} \mathrm{einstellen}$

$400 \mathrm{mM}$

Tris/HCl

$40 \%(\mathrm{v} / \mathrm{v})$

Glycerin

$8 \%(\mathrm{v} / \mathrm{v})$

SDS

$0,004 \%(v / v)$

Bromphenolblau

$20 \%(\mathrm{v} / \mathrm{v})$

$\beta$-Mercaptoethanol

Auf $\mathrm{pH}$ 6,8 einstellen

$10 \mathrm{x}$

TBS-Lösung

$1 \%(v / v)$

Tween 20

$10 \mathrm{x}$

PBS-Lösung

$1 \%(\mathrm{v} / \mathrm{v})$

Tween 20

\subsubsection{Lösungen für die Immunfluoreszenz}

\section{Lösung}

\section{Zusammensetzung}

Paraformaldehyd (PFA)

$4 \%$

In PBS/TBS

Octylphenoxypolyethoxyethanol (Triton X-100)

$0,02 \%$

In PBS/TBS

4', 6' diamino-2' phenylindol (DAPI)

$200 \mathrm{ng} / \mathrm{ml}$

In PBS/TBS 


\subsubsection{Längenstandards}

Um die Größe von DNA- und. Protein-Fragmenten auf Agarosegelen zu bestimmen, wurden folgende Längenstandards parallel mitgeführt:
Längenstandard
Bezugsquelle
Spectra multicolor broad range protein
Fermentas, St. Leon-Rot
ladder (Western Blot)
Broad-range prestained SDS-PAGE
Bio-Rad, Laboratories, München
standards Plus (Western Blot)
O'Gene Ruler ${ }^{\mathrm{TM}}$ DNA Ladder Mix
Fermentas, St. Leon-Rot

\subsubsection{Antikörper und rekombinante Proteine}

\subsubsection{Antikörper für den Western Blot}

$\begin{array}{lll}\text { Antikörper } & \begin{array}{l}\text { Verdünnung, } \\ \text { Inkubationszeit }\end{array} & \text { Bezugsquelle } \\ \text { Anti-flag polyclonal } & 1: 500,1,5 \mathrm{~h} & \text { Sigma-Aldrich, München } \\ \text { Anti-DVL 3 polyclonal } & 1: 1000,1 \mathrm{~h} & \begin{array}{l}\text { New England Biolabs, } \\ \text { Frankfurt a.M. }\end{array} \\ \text { Anti-Rabbit-lgG-HRP } & 1: 2000,1 \mathrm{~h} & \begin{array}{l}\text { Santa Cruz Biotechnology, } \\ \text { Heidelberg }\end{array} \\ \text { Anti-Mouse-IgM-HRP } & 1: 2000,1 \mathrm{~h} & \begin{array}{l}\text { Santa Cruz Biotechnology, } \\ \text { Heidelberg }\end{array}\end{array}$

\subsubsection{Antikörper für die Immunfluoreszenz}

\begin{tabular}{|c|c|c|}
\hline Antikörper & $\begin{array}{l}\text { Verdünnung, } \\
\text { Inkubationszeit }\end{array}$ & Bezugsquelle \\
\hline Normal mouse lgG & $1: 1000,1 \mathrm{~h}$ & $\begin{array}{l}\text { Santa Cruz Biotechnology, } \\
\text { Heidelberg }\end{array}$ \\
\hline Normal rabbit lgG & $1: 1000,1 \mathrm{~h}$ & $\begin{array}{l}\text { Santa Cruz Biotechnology, } \\
\text { Heidelberg }\end{array}$ \\
\hline Anti-flag M5 monoclonal & $1: 1000,1 \mathrm{~h}$ & Sigma-Aldrich, München \\
\hline Anti-flag M2 polyclonal & $1: 500,1 \mathrm{~h}$ & Sigma-Aldrich, München \\
\hline Anti-DVL3 (N19) polylonal & $1: 50 ; 1 \mathrm{~h}$ & $\begin{array}{l}\text { Santa Cruz Biotechnology, } \\
\text { Heidelberg }\end{array}$ \\
\hline Anti-Mouse-TRITC & $1: 1000,1 \mathrm{~h}$ & Sigma-Aldrich, München \\
\hline $\begin{array}{l}\text { Anti-Goat-lgG(H+L); Alexa } \\
\text { Fluor }{ }^{\circledR} 488\end{array}$ & $1: 1000,1 \mathrm{~h}$ & $\begin{array}{l}\text { Invitrogen Europe, Paisly, } \\
\text { UK }\end{array}$ \\
\hline
\end{tabular}




\subsubsection{Rekombinante Proteine}

\section{Rekombinantes Protein}

Rekombinantes Maus Wnt 5a

\subsubsection{Plasmide}

\section{Bezeichnung}

DVL wildtyp

DVL $\Delta$ DIX

DVL $\triangle \mathrm{PDZ} \Delta \mathrm{DIX}$

DVL $\Delta$ PDZ $\Delta$ DEP

DVL $\triangle$ DEP

pEGFP

\section{Bezugsquelle}

R\&D Systems, Minneapolis, MN, USA

\section{Bezugsquelle}

Randall T. Moon, Washington D.C., USA Randall T. Moon, Washington D.C., USA Randall T. Moon, Washington D.C., USA Randall T. Moon, Washington D.C., USA Randall T. Moon, Washington D.C., USA BD Biosciences Clontech, St-Germain-enLaye, Frankreich

\subsubsection{Aufbau der verwendeten Dishevelled-Plasmide}

DVL wildtyp

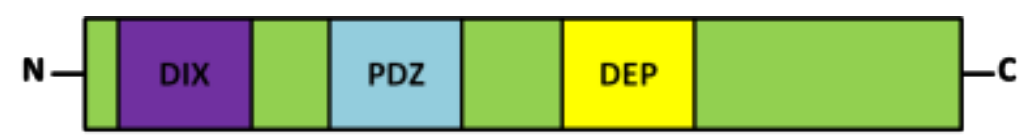

$\mathrm{DVL} \Delta \mathrm{DIX}$

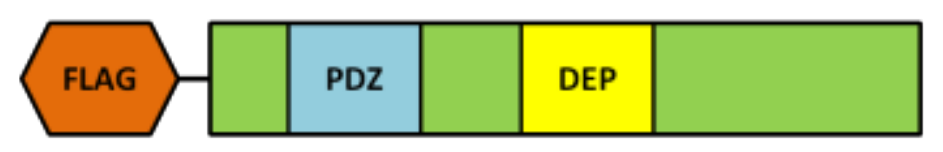

DVL $\Delta$ DIX $\Delta \mathrm{PDZ}$

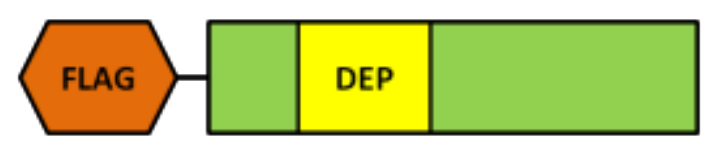

DVL $\Delta \mathrm{PDZ} \Delta \mathrm{DEP}$

DVL $\Delta$ DEP

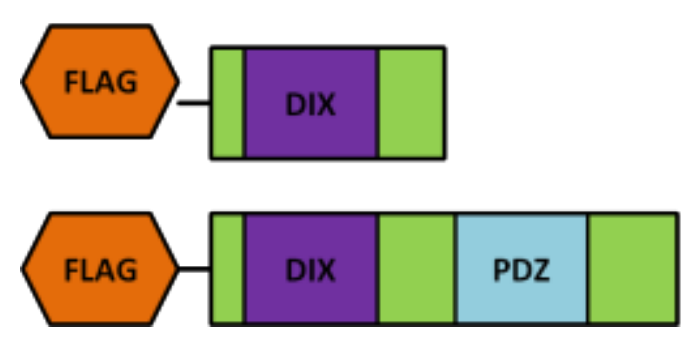




\subsubsection{Organismen}

\subsubsection{Eukaryontische Zelllinie}

$\begin{array}{llll}\text { Zelllinie } & \text { Herkunft } & \text { Typ } & \text { Bezugsquelle } \\ \text { MCF-7 } & \text { Homo sapiens } & \text { Brustkrebszellinie } & \text { HBT-22, ATCC, } \\ & \text { (Mensch) } & & \text { Rockville, MD, USA }\end{array}$

Die Zellen wurden bei $37^{\circ} \mathrm{C}$ und $95 \%$ Luftfeuchtigkeit mit 5\% CO2 inkubiert.

\subsubsection{Bakterienstamm}

\section{Bakterienstamm}

Escherichia coli (E. coli) Top 10

\section{Bezugsquelle}

Invitrogen Europe, Paisly UK

\subsubsection{Datenbanken und Analysesoftwaren}

Folgende Programme wurden zu der Analyse und Bearbeitung von Daten sowie zur Planung von Experimenten verwendet:

\section{Programm}

Axio-Vision 4.0 (Zeiss, München)

LSM Image Browser (Zeiss, München) Intas GDS (Intas, Göttingen)

GraphPad Software (La Jolla, CA, USA)

\section{Verwendung}

Software für das Axiovert 200

Fluoreszenzmikroskop

Software für das Konfokalmikroskop

Software für Geldokumentation

Statistikprogramm 


\subsection{Methoden}

\subsubsection{Zellkulturarbeiten}

\subsubsection{Kultivierung der Zellen}

Die Zellinie MCF-7 wurde unter den in 2.1.11 genannten Bedingungen gehalten. Als Zellkulturmedium wurde RPMI 1640 (Sigma, Deisenhofen) mit L-Glutamin und 10\% (v/v) hitzeinaktiviertem fetalen Kälberserum (FCS) (Sigma, Deisenhofen) verwendet, im Folgenden Zellkulturmedium genannt. Um den Selektionsdruck aufrechtzuerhalten, wurden die mit den jeweiligen Konstrukten stabil transfizierten MCF-7-Zelllinien mit dem Antibiotikum Zeocin $^{\mathrm{TM}}$ behandelt; das bei einer Konzentration von $100 \mathrm{ng} / \mathrm{ml}$ zum Zellkulturmedium gegeben wurde. Zum Waschen der Zellkultur wurde Phosphatgepufferte Salzlösung (PBS) ohne $\mathrm{Ca}^{2+}$ und $\mathrm{Mg}^{2+}$ verwendet, im Folgenden Zellkultur-PBS genannt.

Der Zellrasen wurde mit einer 1:10 Trypsin/EDTA-Lösung (0,05\% Trypsin, 0,02\% EDTA $(w / v)$ in PBS) (Biochrom, Berlin) vom Boden der Zellkulturflaschen gelöst. Die Zellen wurden anschließend im Zellkulturmedium aufgenommen und bei einer Geschwindigkeit von 850 rpm für 5 Minuten zentrifugiert. Der Überstand wurde abgenommen und das gebildete Pellet wieder in frisches Zellkulturmedium aufgenommen, resuspendiert und in eine neue, sterile Zellkulturflasche gegeben. Alle drei Tage wurde das Kulturmedium erneuert. Bei Erreichen eines konfluenten Zellrasens wurden die Zellen wieder mit Trypsin/EDTA abgelöst und 1:2 bis $1: 5$ gesplittet.

\subsubsection{Zellzahlbestimmung}

Die Zellzahl wurde mit Hilfe der Neubauer-Improved-Zählkammer bestimmt. Dabei wurde die Zellmenge in einem definierten Volumen $\left(0,4 \mathrm{~mm}^{3}\right)$ ermittelt und konnte dann in die entsprechende Konzentration (Zellzahl/ml) umgerechnet werden. Voraussetzung für eine korrekte Auswertung war eine gleichmäßige Verteilung der Zellen über das gesamte Linienraster; war dies nicht der Fall, wurde die Zellsuspension nochmal neu aufgeschüttelt.

\subsubsection{Kryokonservierung von Zelllinien}

Die stabil transfizierten Zellen wurden kryokonserviert, um sie für einen längeren Zeitraum haltbar zu machen und bei Belieben wieder in Kultur bringen zu können. Dazu wurden die Zellen in einer Konzentration von $5 \times 10^{6}$ bis $1 \times 10^{7}$ Zellen $/ \mathrm{ml}$ in ein Einfriermedium gebracht, das 50\% FCS (v/v) und 5\% DMSO (v/v) gelöst in RPMl 1640 enthielt. DMSO bewirkt, dass sich beim Einfrierprozess keine zellschädigenden Kristalle bilden. Da DMSO bei höheren Temperaturen zytotoxisch reagiert, wurde $4^{\circ} \mathrm{C}$ kaltes Medium verwendet. 
Die Zellen wurden in einer mit Isopropanol gefüllten Nalgene-Cryobox langsam bei $1^{\circ} \mathrm{C} / \mathrm{min}$ auf $-80^{\circ} \mathrm{C}$ herunter gekühlt und anschließend bei $-150{ }^{\circ} \mathrm{C}$ gelagert.

\subsubsection{Transfektion mit DNA}

Plasmid-DNA sollte transient und stabil in die MCF-7-Zelllinie gebracht werden. Je nach Vorhaben wurden zwei unterschiedliche Transfektionssysteme verwendet.

\subsection{Stabile Transfektion mit Effectene ${ }^{\circledR}$}

Für die stabile Transfektion der Plasmide DVL wt und DVL $\triangle$ PDZ $\triangle$ DEP in die MCF-7Zellen wurde das Transfektionsreagenz Effectene ${ }^{\circledR}$ verwendet. Hierbei wird die PlasmidDNA zuerst mittels eines Enhancers kondensiert und in Mizellen eines nicht-liposomalen Lipids in die Zellen transferiert.

Am Tag vor der Transfektion wurden jeweils $4-5 \times 10^{5}$ Zellen pro Well in einer 6-Well-Platte ausgesät. Bei einer Zellrasen-Konfluenz von ca. 40 - 80\% fand am folgenden Tag die Transfektion statt. Dazu wurde das alte Medium der Zellen nach einmaligem Spülen mit PBS durch frisches Medium ersetzt. 0,4 $\mu \mathrm{g}$ DNA und 3,2 $\mu \mathrm{l}$ des Enhancers wurden mit dem beigefügten EC-Puffer auf eine Gesamtmenge von $100 \mu \mathrm{l}$ zusammengegeben, kurz gevortext und für 2 bis 5 Minuten bei Raumtemperatur inkubiert. Danach wurden $10 \mu \mathrm{l}$ des Effectene-Reagenz zum DNA-Enhancer-Gemisch hinzugefügt und nach kurzem Vortexen und nachfolgender 5 bis 10 minütiger Inkubation bei Raumtemperatur in $1600 \mu \mathrm{l}$ Zellkulturmedium gelöst langsam auf die Zellen pipettiert. 24 Stunden nach Transfektion wurden die Zellen im Verhältnis 1:3 gesplittet und im entsprechenden Selektionsmedium mit dem zytotoxisch wirksamen Antibiotikum Zeocin ${ }^{\mathrm{TM}}$ kultiviert. Da das transfizierte Plasmid ein Resistenzgen für dieses Antibiotikum enthält, konnten nur diejenigen Zellen, die das Plasmid in den Kern integriert hatten, in dem Selektionsmedium überleben.

\subsection{Transiente Transfektion mit Nanofectin ${ }^{\circledR}$}

Die transiente Transfektion von MCF-7-Zellen wurde mit dem Transfektionsreagenz Nanofectin® durchgeführt.

4-5 × $10^{5}$ Zellen wurden am Vortag in 6-Well-Platten ausgesät, so dass sie am Tag der Transfektion ca. 40 - 80\% konfluent waren. $3 \mu \mathrm{g}$ DNA wurden mit Nanofectin-Puffer zu einer Gesamtmenge von $100 \mu \mathrm{l}$ aufgefüllt. Dann wurden 9,6 $\mu \mathrm{l}$ Nanofectin $(3,2 \mu \mathrm{l}$ Nanofectin/ $\mu \mathrm{g}$ DNA) mit Nanofectin-Puffer zu einer Gesamtmenge von $100 \mu$ l gelöst, auf die DNA-Lösung gegeben und für eine halbe Stunde bei Raumtemperatur inkubiert, so dass sich DNANanopartikel-Komplexe bilden konnten. Nach dieser Zeit wurde der Transfektionsansatz von nun $200 \mu \mathrm{l}$ auf die zuvor in PBS gewaschenen und mit $2000 \mu \mathrm{l}$ Zellkulturmedium 
beschichteten Zellen getropft. Um den Transfektionserfolg einzuschätzen, wurde parallel ein 6-Well mit pEGFP transfiziert; Zellen mit erfolgreich integrierter pEGFP-Plasmid-DNA leuchteten unter dem Fluoreszenzmikroskop grün auf und dienten somit als Maß für die Effizienz. Nach 3 Stunden fand ein Mediumwechsel statt, da Nanofectin zytotoxisch wirkt und sich somit nur für transiente Transfektionen eignet.

\subsubsection{Viabilitätsanalyse mittels MTT-Test}

Dieser Test beruht auf der Umsetzung des Tetrazoliumsalzes MTT (3-(4,5-Dimethylthiazol-2yl) 2,5-diphenytetrazoliumbromid, Sigma, Deisenhofen) über das mitochondriale SuccinatTetrazolium-Reduktase-System zu einem wasserunlöslichen Formazanfarbstoff. Da der Farbstoff nur von vitalen Zellen umgesetzt wird, ist die gemessene Absorption direkt proportional zur Menge der vitalen Zellen. Für den Test wurden in Triplikaten je $1 \times 10^{5}$ Tumorzellen pro Vertiefung einer 24-Loch-Platte ausgesät. In jede Vertiefung wurde anschließend das rekombinante Protein Wnt 5a zugefügt (100 ng/ml). Nach $24 \mathrm{~h}$ wurde bei allen Vertiefungen $500 \mu$ l einer zehnfach in Kulturmedium verdünnten MTT-Lösung $(5 \mathrm{mg} / \mathrm{ml})$ hinzugegeben. Nach einer weiteren Inkubation für vier Stunden im Brutschrank wurde das MTT-Medium abgesaugt und durch jeweils $500 \mu \mathrm{l}$ eines Ameisensäure-haltigen Lysepuffers ersetzt. Danach wurden $100 \mu \mathrm{l}$ des Lysats in eine 96-Well-Platte überführt. Unter dem Spektrometer erfolgte die Ausmessung des Absorptionsgrades des umgesetzten Farbstoffs in den Mikrotiterplatten bei 540 nm Filter. Es wurden die Mittelwerte der Extinktion aus den triplikaten Ansätzen gebildet und ins Verhältnis zu den unstimulierten Kontrollen gesetzt.

\subsubsection{Bestimmung der Proliferationsrate}

Jeweils $10^{5}$ Zellen wurden in Triplikation in 24-Loch-Platten ausgesät und nach 96 Stunden gezählt. Die Zellen wurden nach Ablauf der jeweiligen Stundenzahl mit einer 1:10 Trypsin/EDTA-Lösung vom Zellboden gelöst, zentrifugiert, der Überstand wurde abgenommen und das Pellet in einem definierten Volumen wieder ordentlich gelöst. Die Zellzahl in $1 \mathrm{ml}$ Lösung wurde in der Neubauer-Improved-Zählkammer ermittelt. 


\subsubsection{Molekularbiologische Methoden}

\subsubsection{Restriktionsverdau}

Für den Ansatz wurden 0,5 - $1 \mu \mathrm{g}$ der Plasmid-DNA in einem Volumen von $20 \mu \mathrm{l}$ mit jeweils $1 \mu \mathrm{l}$ der Restriktionsenzyme Eco RI, Hind III und Not I und $2 \mu$ Reaktionspuffer über Nacht bei $37{ }^{\circ} \mathrm{C}$ inkubiert. Alle Dishevelled-Plasmide enthielten eine Schnittstelle für Hind III und jeweils für Not I oder Eco RI, so dass beim Doppelverdau pro Plasmid zwei Fragmente entstanden.

$\begin{array}{lll}\text { Bezeichnung } & \text { Restr.-Enzym 1 } & \text { Restr.-Enzym 2 } \\ \text { DVL wildtyp } & \text { Hind III } & \text { Eco R I } \\ \text { DVL } \Delta \text { DIX } & \text { Hind III } & \text { Not I } \\ \text { DVL } \Delta \text { PDZ } \Delta \text { DIX } & \text { Hind III } & \text { Not I } \\ \text { DVL } \Delta \text { PDZ } \Delta \text { DEP } & \text { Hind III } & \text { Eco R } \\ \text { DVL } \triangle \text { DEP } & \text { Hind III } & \text { Eco R }\end{array}$

Tabelle 2. 1: Restriktionsenzyme

\subsubsection{DNA-Gelelektrophorese}

Zur gelelektrophoretischen Auftrennung der beim Doppelverdau entstandenen DNAFragmente wurde ein 1\% Agarose-Gel mit $0,5 \mu \mathrm{g} / \mathrm{ml}$ Ethidiumbromid in 1x TBE-Puffer verwendet. Die Proben wurden vor dem Auftragen mit 6x Probenpuffer versetzt und etwa 1 Stunde bei 100 Volt laufen gelassen. Die Nukleinsäuren werden dadurch aufgetrennt, indem die negativ geladenen Moleküle entlang des elektrischen Feldes durch die Agarose-Matrix wandern. Kleinere Moleküle bewegen sich schneller und wandern weitere als größere Moleküle. Ausgewertet wurden die Gele unter UV-Licht bei $312 \mathrm{~nm}$. Im Detail ist diese Methode bei Sambrook et al. beschrieben (Sambrook $J$ et al. 1989). Über eine Größenbestimmung der herausgeschnittenen Fragmente konnte kontrolliert werden, ob es sich um das gewünschte Plasmid handelte

\subsubsection{Transformation kompetenter Bakterienzellen}

$50 \mu \mathrm{l}$ kompetente E. coli-Bakterien (Top 10 Invitrogen) wurden auf Eis aufgetaut, mit $1 \mu \mathrm{l}$ Plasmid-DNA versetzt und für 30 Minuten auf Eis inkubiert. Durch Gabe eines „Hitzeschocks“, der für 30 Sekunden im Wasserbad bei $42^{\circ} \mathrm{C}$ erreicht wird, konnten die Bakterienzellen die Plasmid-DNA aufnehmen. Anschließend wurden die Zellen wieder für 1-2 Minuten auf Eis abgekühlt. Nach Zugabe von $500 \mu \mathrm{l}$ SOC-Medium wurden die Zellen für 1 Stunde bei $37^{\circ} \mathrm{C}$ geschüttelt. Für die anschließende Selektion wurden $20 \mu \mathrm{l}$ der Ansätze auf 
antibiotikahaltigen (Ampicillin $50 \mu \mathrm{g} / \mathrm{ml}$ ) LB-Agarplatten ausgestrichen und über Nacht bei 37 ${ }^{\circ} \mathrm{C}$ inkubiert. Auf den antibiotikahaltigen LB-Agarplatten konnten nur die transformierten Bakterienzellen wachsen, da die Dishevelled-Plasmide eine Resistenzkassette gegen Ampicillin enthielten.

\subsubsection{Amplifikation von Plasmid-DNA}

Für die Vermehrung eines transformierten Bakterienklons wurde zunächst eine Vorkultur in 3-5 ml antibiotikahaltigen LB-Medium mit Hilfe einer sterilen Impföse von einer Kolonie der Agarplatte angeimpft und für mind. $6 \mathrm{~h}$ unter Schütteln bei $37^{\circ} \mathrm{C}$ inkubiert. Daraus wurde dann eine Hauptkultur angelegt, indem 1 - 2 ml der Vorkultur in 150 - 200 ml Medium im sterilen Erlenmeyerkolben gegeben und über Nacht bei $37^{\circ} \mathrm{C}$ im Schüttler inkubiert worden sind.

\subsubsection{Präparation von Plasmid-DNA}

Die Isolierung von Plasmid-DNA erfolgte mit dem PureYieldTM Plasmid Midi Prep System (Promega, Mannheim) entsprechend der Anleitung des Herstellers. Die Bakterien wurden zunächst durch Sedimentation geerntet $\left(10 \mathrm{~min} 5000 \mathrm{xg}, 21^{\circ} \mathrm{C}\right)$ und die entstandenen Pellets in $3 \mathrm{ml}$ Cell Resuspension Solution resuspendiert. Nachfolgend wurde $3 \mathrm{ml}$ Cell Lysis Solution hinzugegeben, mehrfach vorsichtig invertiert und für 3-5 Minuten inkubiert. Es folgte die Gabe von $5 \mathrm{ml}$ Neutralization Solution. Nach mehrfachem Invertieren und einer weiteren Inkubation von 3 Minuten zeigte sich der Zell-Debris als weiße Präzipitation, die bei einer Zentrifugation mit $3000 \mathrm{~g}$ für 5 Minuten in der Pure Yield ${ }^{\mathrm{TM}}$ Clearing Column abgefiltert wurde. Das Filtrat wurde auf die Pure Yield ${ }^{\mathrm{TM}}$ Binding Column gegeben und bei $1500 \mathrm{~g}$ für 3 Minuten zentrifugiert. Während des Durchflusses band die DNA an das Säulenmaterial nach dem lonenaustauschprinzip. Als nächstes wurde die Säule mit $5 \mathrm{ml}$ Endotoxin-Free Removal Wash Solution während einer Zentrifugation mit $1500 \mathrm{~g}$ für 3 Minuten gereinigt. Nach Gabe von $20 \mathrm{ml}$ Column Wash Solution folgte eine weitere Zentrifugation bei $1500 \mathrm{~g}$ für 15 Minuten. In zwei aufeinanderfolgenden Schritten wurden dann insgesamt $1000 \mu$ l NucleaseFree-Water auf die Membranen der Säule gegeben und bei $1500 \mathrm{~g}$ für jeweils 5 Minuten abzentrifugiert. Das Filtrat wurde in einem Eppendorfhütchen gesammelt und bei $4^{\circ} \mathrm{C}$ gelagert.

\subsubsection{Konzentrationsbestimmung von Nukleinsäuren}

Die Quantifizierung der gewonnenen Plasmid-DNA wurde mittels einer photometrischen Messung im BioPhotometer 6139 (Eppendorf, Hamburg, Deutschland) durchgeführt. Dazu 
wurde die DNA 1: 50 verdünnt und gegen Wasser als Leerwert bei 260 und $280 \mathrm{~nm}$ gemessen. Eine optische Dichte (OD) von 1,0 bei einer Wellenlänge von $260 \mathrm{~nm}$ entspricht einer Konzentration von $50 \mu \mathrm{g} / \mathrm{ml}$ doppelsträngiger DNA.

Die bei der photometrischen Konzentrationsbestimmung erfassten Werte sind in Tabelle 2.20 dargestellt:

Bezeichnung

DVL wildtyp

DVL $\triangle \mathrm{DIX}$

DVL $\Delta \mathrm{PDZ} \Delta \mathrm{DIX}$

DVL $\triangle \mathrm{PDZ} \Delta \mathrm{DEP}$

DVL $\triangle$ DEP

Tabelle 2. 2: Plasmid-DNA-Konzentration

\section{Konzentration}

$0,260 \mu \mathrm{g} / \mu \mathrm{l}$

$0,209 \mu \mathrm{g} / \mu \mathrm{l}$

$0,287 \mu \mathrm{g} / \mu \mathrm{l}$

$0,235 \mu \mathrm{g} / \mu \mathrm{l}$

$0,084 \mu \mathrm{g} / \mu \mathrm{l}$ 


\subsubsection{Proteinbiochemische Methoden}

\subsubsection{Herstellung von Zelllysaten für den Western Blot}

Die mit Dishevelled-Konstrukten transient und stabil transfizierten MCF-7-Zellen wurden für die weitere Analyse mittels Western Blot lysiert. Adhärente Zellen wurden mit eiskaltem PBS gewaschen und mit Lysepuffer bedeckt. Der Zellrasen wurde mit einem Zellschaber abgekratzt, in ein Eppendorfhütchen überführt und bei $4^{\circ}$ für 10 Minuten auf Eis inkubiert. Anschließend wurde das Eppendorfhütchen mit höchster Drehzahl bei $4^{\circ}$ für 5 Minuten zentrifugiert und der Überstand mit den gewonnen Proteinen in ein neues Eppendorfhütchen gegeben. Die Lagerung der Lysate erfolgte bei $-20^{\circ}$.

\subsubsection{Konzentrationsbestimmung der Proteine}

Die Konzentrationsbestimmung von enthaltendem Protein in den Lysaten erfolgte mit dem BCA $^{\mathrm{TM}}$ Protein Assay Kit (Pierce Biotechnology) entsprechend der Anleitung des Herstellers. Bei einer Wellenlänge von $540 \mathrm{~nm}$ wird die Absorption durch die Proteinkonzentration ermittelt; die Höhe der Absorption korreliert dabei mit der Proteinkonzentration.

\subsubsection{Proteinelektrophorese im SDS-Polyacrylamidgel}

Zur elektrophoretischen Auftrennung der Proteine nach ihrem Molekulargewicht wurde die Methode nach Laemmli (Laemmli 1970) angewendet.

Ein $8 \%$ Trenngel und ein 5\% Sammelgel sind am Abend zuvor in mit Dichtungsbändern seitlich und nach unten hin verschlossenen Glaskammern (Biometra) gegossen und über Nacht in Frischhaltefolie eingewickelt bei $4^{\circ}$ gelagert worden.

Vor dem Auftragen wurden die Proteine bei $95^{\circ}$ für 5 Minuten im Lämmli-Probenpuffer denaturiert und in einer Mini-Proteingel-Kammer (Biometra) in 1x Laufpuffer für 30 Minuten bei 90 Volt und für etwa weitere 90 Minuten bei 120 Volt aufgetrennt.

$\begin{array}{lll}8 \% \text { Trenngel } & 5 \mathrm{ml} & \text { Trenngelpuffer } \\ & 5,3 \mathrm{ml} & 30 \% \text { Acrylamid mit } \\ & 0,8 \% \text { Bisacrylamid } \\ & 9,5 \mathrm{ml} & \text { Aqua bidest. } \\ 200 \mu \mathrm{l} & 10 \%\end{array}$

Ammoniumpersulfat 


\section{4\% Sammelgel}

$$
\begin{aligned}
& 630 \mu \mathrm{l} \\
& 830 \mu \\
& 3,45 \mathrm{ml} \\
& 50 \mu \mathrm{l}
\end{aligned}
$$

$5 \mu \mathrm{l}$
Sammelgelpuffer

$30 \%$ Acrylamid mit

$0,8 \%$ Bisacrylamid

Aqua bidest.

$10 \%$

Ammoniumpersulfat

(APS)

TEMED

\subsubsection{Western Blot semi-dry}

Alle gewonnenen Lysate der transient und stabil transfizierten MCF-7-Zellen wurden mittels Western Blot untersucht. Um die elektrophoretisch aufgetrennten Proteine nachzuweisen, wurden diese mit Hilfe einer Elektroblotting-Apparatur auf eine Nitrozellulose-Membran transferiert. Das Gel wurde hierzu auf eine entsprechend große Membran aufgelegt, die zuvor mit 6 in selbiger Größe zurecht geschnittenen Blotting-Papieren in Transferpuffer äquilibriert worden war. Auf die Anode der Elektroblotting-Apparatur wurden zuerst drei Blotting-Papiere geschichtet, es folgte die Membran mit dem auf ihr liegendem Gel und darauf die restlichen drei Blotting-Papiere. Durch diese Schichtung können die negativ geladenen Proteine in Richtung der Anode auf die Membran transferieren. Der entstandene Stapel wurde mit Transferpuffer großzügig bewässert und mit einer Pipette glattgerollt, um störende Luftblasen zwischen den Schichten zu vermeiden. Abschließend wurde die Elektroblotting-Apparatur durch den die Kathode enthaltenden Deckel geschlossen und mit einem Gewicht erschwert. Der Transfer dauerte 75 Minuten bei 10 Volt. Die Membran wurde danach für 60 Minuten in TBS mit $5 \%$ (w/v) Magermilchpulver geblockt. Nach dem Blocken wurde die Membran mit geeigneter Verdünnung eines spezifischen Primärantikörpers in TBS mit 0,1\% Tween 20 und je nach Protokollvorgabe $5 \%$ Milchpulver oder 5\% Rinderserumalbumin für 1-2 Stunden inkubiert. Nach dreimaligem Waschen mit TBS mit 0,1\% Tween 20 wurden die Antigen-Antikörper-Komplexe mit einer geeigneten Verdünnung eines an Meerrettich-Peroxidase (horseradish-peroxidase, HRP) gekoppelten Anti-IgGAntikörpers in PBS mit 0,1\% Tween inkubiert. Für diese Arbeit wurden anti-Maus- und antiKaninchen-Sekundärantikörper in einer Verdünnung von 1:2000 verwendet. Die Detektion der gebundenen HRP-gekoppelten Antikörper erfolgte mit ECL- und ECL plus-Reagenz nach Anleitung des Herstellers (Amersham). 


\subsubsection{Fluoreszenzfärbungen}

\subsubsection{Indirekte Einfach-Immunfluoreszenzfärbung}

Die transient und stabil transfizierten Zellen sowie MCF-7-Kontrolle wurden mittels EinfachImmunfluoreszenz angefärbt. Dafür wurden am Tag zuvor jeweils $10^{5}$ der zu überprüfenden Zellen auf runden, sterilen Deckgläschen in 24-Well-Platten ausgesät

Nach 24 Stunden wurde das Kulturmedium abgesaugt und die Deckgläschen wurden mehrfach mit eiskaltem PBS gespült. Danach wurden die Zellen für 20 Minuten mit 4\% PFA fixiert und anschließend wieder mit PBS gespült. Zur Permeabilisierung der Zellwand wurden die Zellen anschließend für 10 Minuten mit 0,2\% Triton X-100 inkubiert und dreimal mit PBS gespült. Es folgte eine Inkubation für 10 Minuten in 1\% BSA, um die Wahrscheinlichkeit unspezifischer Bindungen zu reduzieren. Anschließend wurden die Primärantikörper für 1 Stunde in der den Hersteller-Protokollen entsprechenden Konzentrationen auf die Zellen gegeben. Nach Ablauf der Inkubationszeit wurden die Zellen dreimal für 5 Minuten in PBS gespült, mit den Sekundärantikörperm unter Lichtausschluss für 1 Stunde inkubiert und wieder dreimal für 5 Minuten in PBS gespült. Im letzten Schritt wurden die Zellkerne mittels des in PBS gelösten DNA-Farbstoffs 4', 6' diamino-2' phenylindol (DAPI) sichtbar gemacht. Nach abgelaufener Inkubationszeit von 5 Minuten wurden die Deckgläschen noch einmal mit PBS gewaschen und dann mit Aqua bidest. gespült. Die Deckgläschen wurden mit einem Tropfen Fluorescent Mounting Medium (Dako, CA, USA) mit der Zellseite nach unten auf die Objektträger fixiert und für 24 Stunden bei $4^{\circ}$ getrocknet.

\subsubsection{Indirekte Einfach-Immunfluoreszenzfärbung von Wnt-5a-stimulierten Zellen}

$10^{5}$ der zu überprüfenden Zellen wurden einen Tag vor der Färbung auf runden, sterilen Deckgläschen in 24-Well-Platten ausgesät, so dass nach $24 \mathrm{~h}$ eine Konfluenz von etwa 40 $80 \%$ erreicht wurde. Rekombinantes Wnt 5a wurde mit einer Konzentration von 100 ng pro der mit $1000 \mu \mathrm{l}$ Zellkulturmedium gefüllten Wells zugegeben. Nach 30 min Inkubationszeit wurde das Medium abgesaugt und mit der Immunfluoreszenzfärbung nach 2.2.4.1. begonnen.

\subsubsection{Indirekte Doppel-Immunfluoreszenzfärbung}

Bei der Doppel-Immunfärbung wurden beide Primärantikörper gleichzeitig auf die Zellen gegeben. Für die vorherigen und nachfolgenden Schritte wurde das gleiche Protokoll wie bei der Einfach-Fluoreszenzfärbung verwendet, siehe 2.2.4.1. 


\subsubsection{Konfokalmikroskopie}

Die indirekte Immunfluoreszenz wurde mit einem konfokalen Laser-Scanning-Mikroskop LSM 510 (Carl Zeiss, Göttingen) ausgewertet. Die fluoreszierenden Sekundärantikörper wiesen folgende Extinktionswerte auf:

\section{Antikörper}

Anti-Mouse-TRITC

Anti-Goat-lgG $(\mathrm{H}+\mathrm{L})$; Alexa Fluor® 488

DAPI

\section{Anregungsfilter}

$546 \mathrm{~nm}$

$488 \mathrm{~nm}$

$350 \mathrm{~nm}$

\subsubsection{Modifizierter Boyden-Assay}

Die Invasivitätsbestimmung der Zellen erfolgte mit Hilfe der Boyden-Kammer. Diese besteht aus zwei Kammern, die durch eine mit $10 \mu \mathrm{m}$ großen Poren besetzte Membran getrennt werden. In die obere Kammer werden die zu untersuchenden Zellen gegeben. Nach Ablauf einer Inkubationszeit werden die Zellen gezählt, die in die untere Kammer gewandert sind. Anhand der ermittelten Werte kann dann eine Aussage über die Invasivität der Zellen getroffen werden.

Die beiden aus Acryl gegossenen Hälften der Boyden-Kammer wurden in den Werkstätten des Universitätsklinikums Göttingen angefertigt .Für jeden Versuch wurde eine sterile Boyden-Kammer unter der Zellbank neu angesetzt: Die aus Polycarbonat bestehende Membran wurde dafür mit ECM, das zuvor in FCS-freien Zellkulturmedium im Verhältnis 1:3 gelöst wurde, beschichtet und für 10 Minuten getrocknet. Die Vertiefungen der unteren Kammern wurden mit 2\% FCS-haltigem Zellkulturmedium gefüllt, bis sich kleine Flüssigkeitskuppeln über den Löchern bildeten. Anschließend wurde die Membran unter Vermeidung von Luftblasen auf die untere Kammer gelegt. Auf die Membran wurde dann die obere Kammer gesetzt und das System wurde mit 9 sterilen Inbusschrauben aus Edelstahl fest verschlossen. Die Wells der oberen Kammer wurden mit jeweils $500 \mu \mathrm{l} 10 \%$ FCSZellkulturmedium gefüllt. Die Boyden-Kammer wurde darauf nach oben und nach unten mit sterilen Deckeln von 24-Well-Platten verschlossen und für 30 Minuten im Brutschrank inkubiert. Für den Versuch wurden jeweils $500 \mu 10 \%$ FCS- Zellkulturmedium mit 100.000 Zellen in die oberen Wells gegeben, so dass sich für eine Lane eine Gesamtmenge von 300.000 Zellen ergab. Jede Lane entsprach dabei einem Versuchsansatz. Zwei Lanes enthielten die gleichen Zelllinien mit und ohne Wnt 5a-Inkubation. Rekombinantes Wnt 5a wurde dafür mit einer Konzentration von 100 ng pro der mit $1000 \mu$ l Zellkulturmedium gefüllten oberen Wells eingesetzt. 
Als Positivkontrolle liefen in jeder Boyden-Kammer nicht-transfizierte MCF-7-Zellen mit, deren Invasivitätsanstieg unter Wnt 5a schon durch Pukrop et al. gezeigt worden ist (Pukrop et al. 2006). Nach einer Laufzeit von $96 \mathrm{~h}$ im Brutschrank wurde die Boyden-Kammer auseinandergebaut, um das invasive Verhalten der Zellen zu bestimmen. Dazu wurde in der unteren Kammer das Medium einer Lane mit einer Pipette aufgenommen und für 5 Minuten bei 850 rpm zentrifugiert. Um eventuell abgesetzte Zellen vom Boden zu lösen, wurde zuvor mit der Pipette auf dem Wellboden geschabt. Der Überstand wurde abgeschüttet und das Pellet noch einmal in $5 \mathrm{ml}$ PBS für 5 Minuten bei 850 rpmi zentrifugiert. Danach wurde der Überstand bis auf $1 \mathrm{ml}$ abgenommen. Das Pellet wurde resuspendiert und dessen Zellmenge in einer Neubauer-Improved-Zählkammer bestimmt. Dabei wurde jeder der vier Eckquadranten einzeln gezählt und aus den Zellzahlen ein Mittelwert gebildet. Der Mittelwert der ohne Wnt $5 a$ gelaufenen Zellen wurde auf $100 \%$ gesetzt und mit dem Mittelwert der unter Wnt-5a-Inkubation gelaufenen Zelllinie verglichen. So konnte bestimmt werden, ob unter Wnt 5 a ein Invasivitätsanstieg stattgefunden hatte.

Diese Methode wurde initial durch Hagemann et al beschrieben (Hagemann et al. 2004).

\subsubsection{Cytospin}

Für den Cytospin wurden jeweils $200 \mu \mathrm{l}$ der aus der Boyden-Kammer gewonnenen Zellsuspensionen für 5 Minuten bei $800 \mathrm{xg}$ in die für die Zytospin vorgesehene Vorrichtung zentrifugiert. Der Objektträger mit dem Ausstrich wurde über Nacht bei $4^{\circ} \mathrm{C}$ getrocknet. Anschließend wurde das Präparat mit den flag-Antikörpern nach den in 2.2.4.1. beschriebenen Inkubationszeiten und Konzentrationsverhältnissen gefärbt, so dass der prozentuale Anteil der durch die Boyden-Kammer gelaufenen transfizierten Zellen im Vergleich zu den nicht-transfizierten Zellen ermittelt werden konnte.

\subsubsection{Statistische Methoden}

Die Daten werden als Mittelwert +/- Standardabweichung dargestellt. Statistische Signifikanz im Students t-test ist gegeben bei $p<0,05$. Die Auswertung und die graphische Darstellung der Ergebnisse erfolgte mithilfe des Programms GraphPad Prism (GraphPad Software, La Jolla, CA, USA). 


\section{Ergebnisse:}

\subsection{Herstellung geeigneter Klone für den Boyden-Assay}

\subsubsection{Amplifikation und Konzentrationsbestimmung der Plasmid-DNA}

Aus den verschiedenen Dishevelled-Konstrukten wurden DVL wt und DVL $\triangle \mathrm{PDZ} \triangle \mathrm{DEP}$ für die Untersuchungen zur Invasivität ausgewählt. DVL wt soll in MCF-7 ein flag-getaggtes fulllength-Konstrukt überexprimieren, DVL $\Delta \mathrm{PDZ} \triangle \mathrm{DEP}$ ist eine Deletionsmutante, dem die beiden Domänen PDZ und DEP fehlen.

Um zu überprüfen, ob die unterschiedlichen Plasmide in ihrer richtigen Form und damit in der korrekten Größe amplifiziert wurden, fand ein Restriktionsverdau statt. Auf dem Agarose-Gel in Abbildung 3.1 zeigen sich die entsprechenden Größenverhältnisse, angegeben in Basenpaaren (bp). Auf der Aufnahme erkennt man, dass die amplifizierten Plasmide - unter Berücksichtigung zusätzlicher Basenpaare durch das flag-tag - den erwarteten Größen entsprachen, wie in Tabelle 3.1 angegeben.

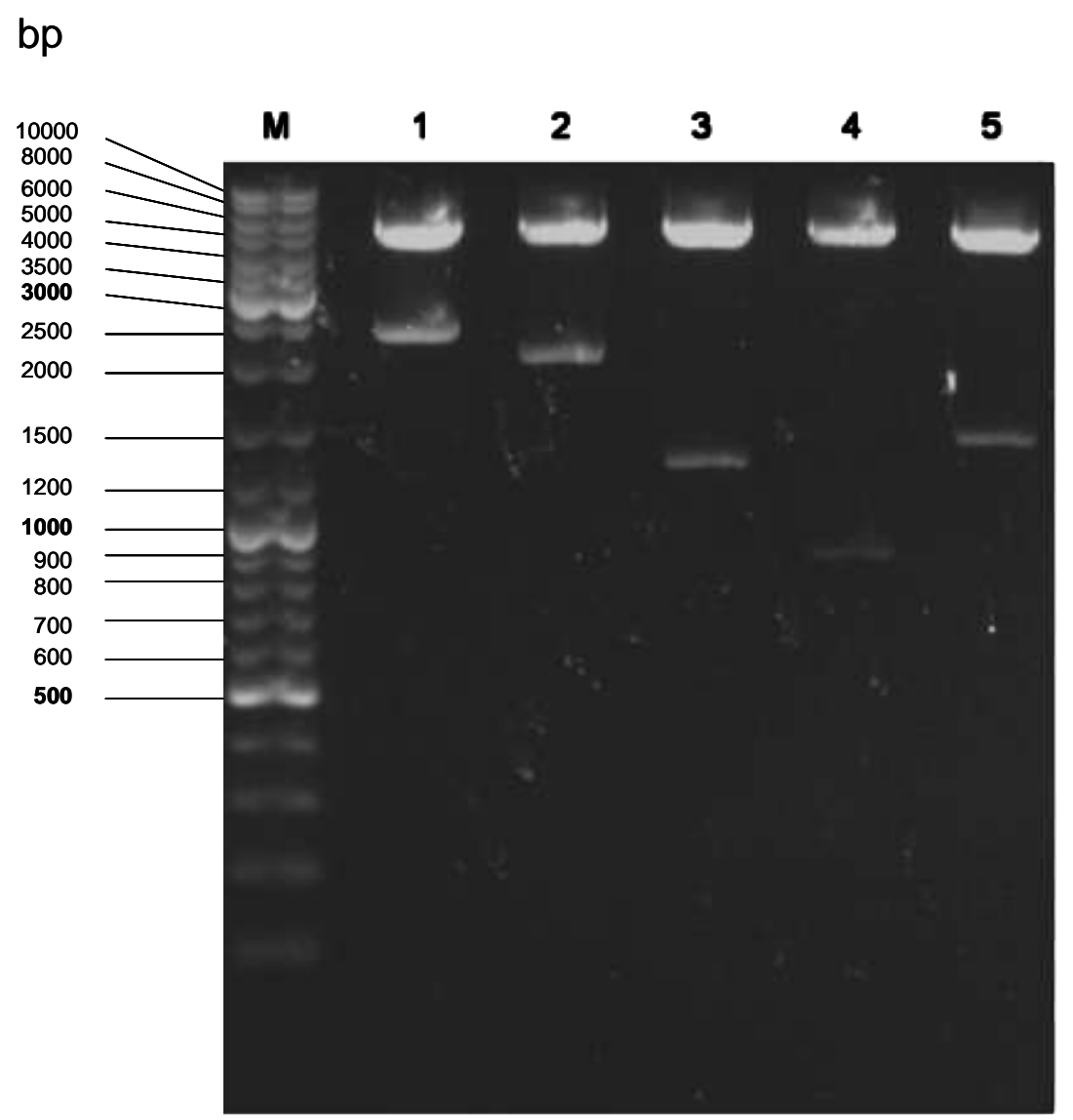

Abbildung 3.1: Fragmentgrößen der Dishevelled-Konstrukte..

Auf 1\% - Agarosegel aufgetragene Plasmide nach Restriktionsverdau. 1: DVL wt; 2: DVL $\triangle$ DIX; 3: DVL $\triangle D I X \triangle P D Z ; 4:$ DVL $\triangle P D Z \triangle D E P ; 5: D V L \triangle D E P$. Die Plasmide trennen sich entsprechend ihrer Größenverhältnisse auf dem Gel. 
Tabelle 3.1: Fragmentgrößen der Plasmide ohne flag-tag.

$\begin{array}{ll}\text { Bezeichnung } & \text { Erwartete Fragment-Größe } \\ \text { DVL wildtyp } & 2151 \mathrm{bp} \\ \text { DVL } \Delta \text { DIX } & 1905 \mathrm{bp} \\ \text { DVL } \Delta \text { DIX } \Delta \text { PDZ } & 1155 \mathrm{bp} \\ \text { DVL } \Delta \text { PDZ } \Delta \text { DEP } & 741 \mathrm{bp} \\ \text { DVL } \Delta \text { DEP } & 1266 \mathrm{bp}\end{array}$

\subsubsection{Transfektionseffizienz der transienten Transfektion}

Um den Transfektionserfolg von MCF-7 einfacher beurteilen zu können, wurde bei allen transienten Transfektionen (siehe 2.2.1.3.2) mit den Dishevelled-Plasmiden parallel eine Transfektion mit pEGFP durchgeführt. Dieses Plasmid hat den Vorteil, dass diejenigen Zellen, die das Plasmid erfolgreich aufgenommen haben, unter dem Fluoreszenzmikroskop bei einer Anregung von $488 \mathrm{~nm}$ grün fluoreszieren.

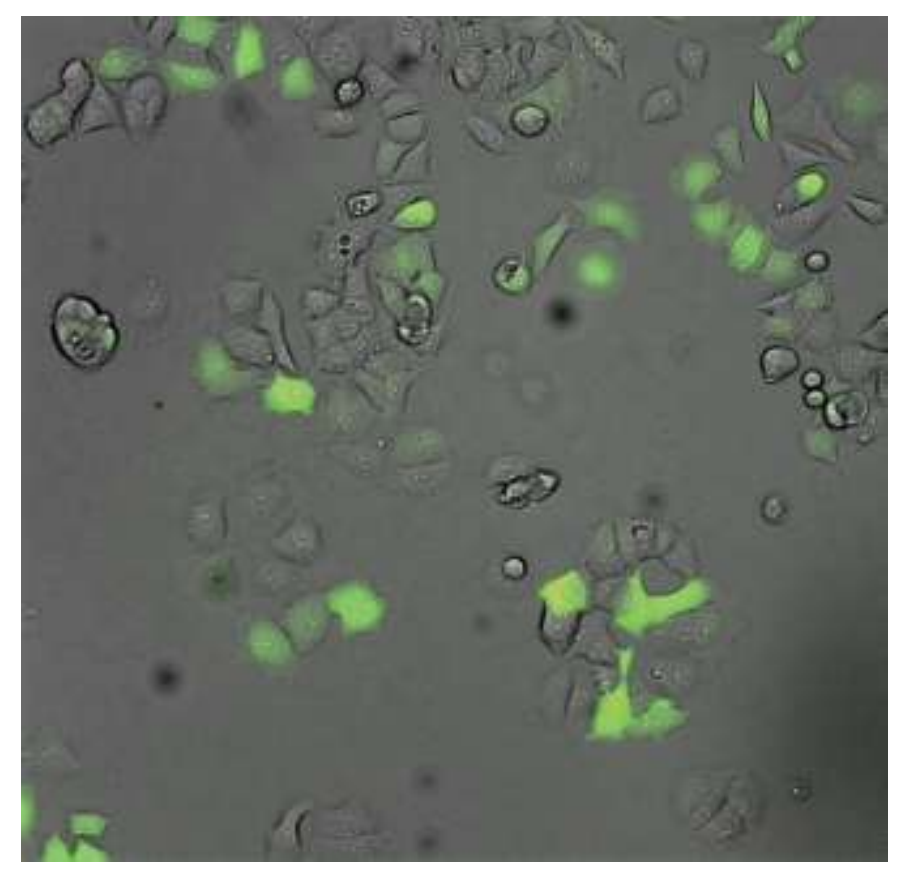

Abbildung 3.2: pEGFP transfizierte MCF-7-Zellen. Transfizierte Zellen fluoreszieren grün bei einer Wellenlänge von $488 \mathrm{~nm}$. Untransfizierte Zellen zeigen keine Fluoreszenz.

Die transfizierten Zellen wurden ausgezählt und ihr Anteil an der Gesamtzellzahl errechnet. Es wurde eine durchschnittliche Transfektionseffizienz von 14\% erreicht. Da dieser Wert für den Einsatz der Zellen in die Boyden-Kammer zu gering war, wurde parallel dazu eine stabile Transfektion mit den ausgewählten Konstrukten DVL wt und DVL $\triangle$ PDZ $\Delta$ DEP vorgenommen. 


\subsubsection{Expression der transient transfizierten Konstrukte}

Es sollte überprüft werden, ob eine Expression der Dishevelled-Proteine von DVL wt und DVL $\triangle \mathrm{PDZ} \triangle \mathrm{DEP}$ nach transienter Transfektion stattfand. Nach 24h, 36h, 48h, 72h und 96h wurden die Zellen lysiert und die Expression der flag-getaggten Plasmide mittels Western

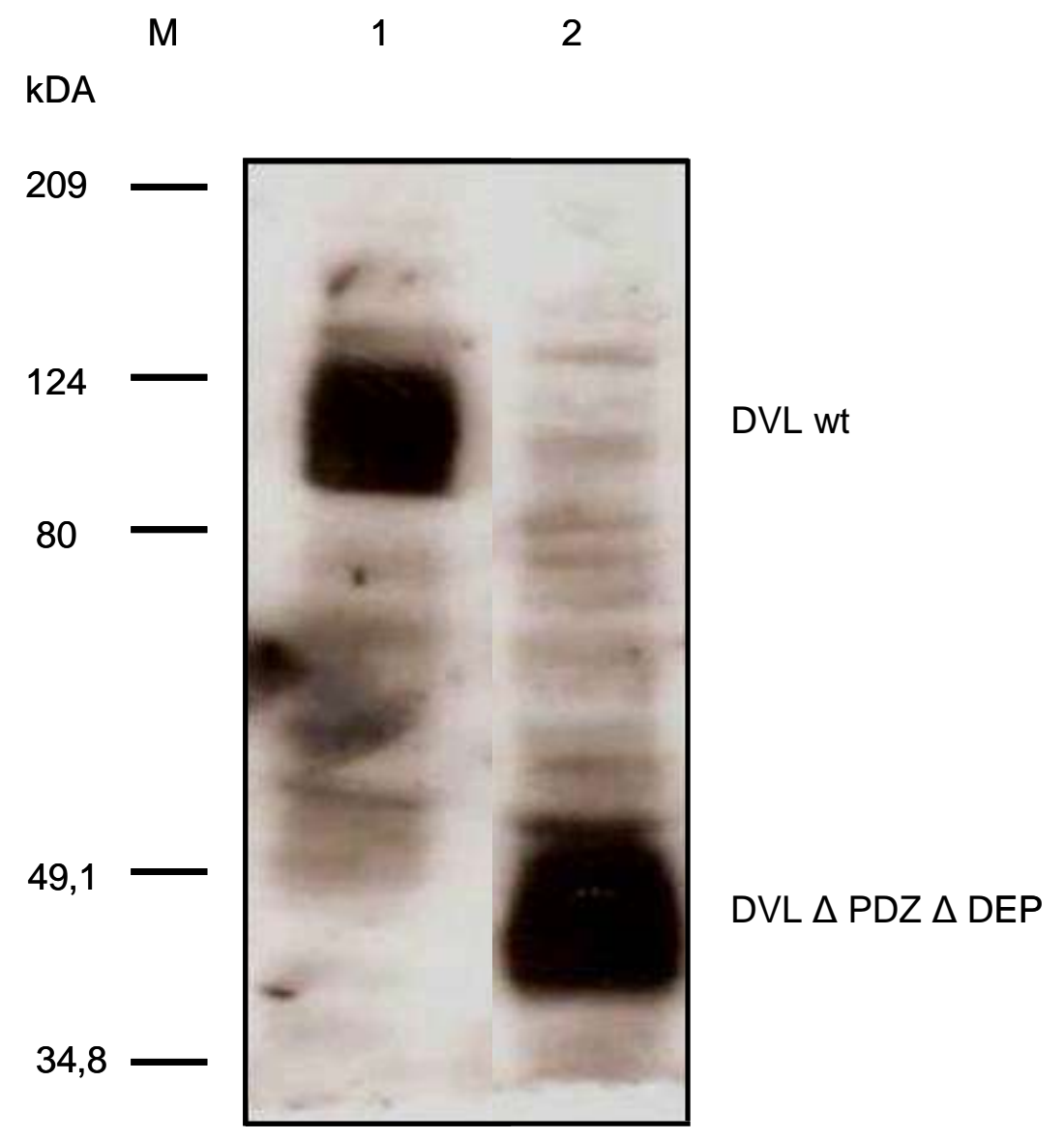

Abbildung 3.3: Expression von transient transfizierten DVL wt und DVL $\triangle$ PDZ $\triangle$ DEP in MCF-7. Anti-flag-Western Blot der Deletionsmutanten nach 96h Inkubationszeit. 8\%iges SDS-Gel. FlagAntikörper 1:500. Starke Expression der Konstrukte in den Zellklonen. 1: DVL wt, 2: DVL $\triangle$ PDZ $\Delta$ $D E P$.

Blot bestimmt. Bei beiden Konstrukten zeigte sich sowohl 24h, 48h als auch $96 \mathrm{~h}$ nach Transfektion eine Expression der flag-getaggten Proteine. In Abbildung 3.3 wird das Transfektionsergebnis nach $96 \mathrm{~h}$ gezeigt. Auffallendes Ergebnis des Western Blots ist, dass beide Konstrukte sich nicht als Einzelbande darstellen lassen. Vielmehr werden sie als mehrere aufeinanderfolgende Banden in folgenden Größenbereichen dargestellt: Die Banden von DVL wt entsprechen einem Gewicht zwischen 80 - 130 kDa.

DVL $\triangle$ PDZ $\triangle$ DEP zeigt Banden zwischen 50 - $35 \mathrm{kDa}$. Die Auftrennung der einzelnen Dishevelled-Konstrukte in mehrere Banden im Western Blot wurde schon durch Angers et al. beschrieben (Angers et al. 2006). 


\subsubsection{Stabile Transfektion von DVL wt und DVL $\triangle \mathrm{PDZ} \Delta \mathrm{DEP}$}

Für DVL wt und DVL $\triangle$ PDZ $\triangle$ DEP wurde jeweils ein stabiler Zellklon ermittelt und dessen Protein-Expression im Western Blot überprüft.

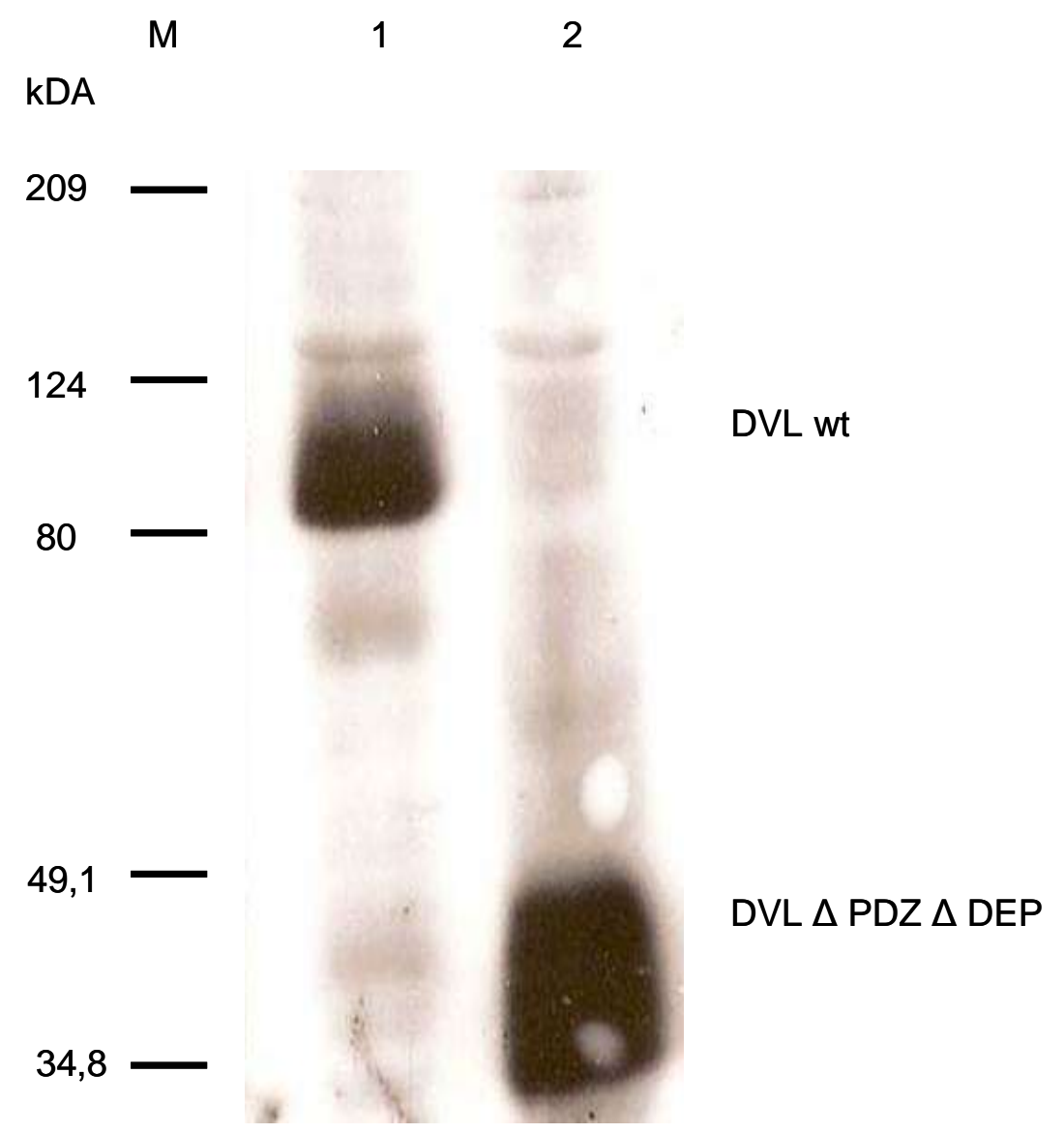

Abbildung 3.4: Expression von DVL wt und DVL $\triangle$ PDZ $\triangle$ DEP in stabilen MCF-7-Zellklonen. Anti-flag-Western Blot der Deletionsmutanten. 8\%iges SDS-Gel. Flag-Antikörper 1:500. Starke Expression der Konstrukte in den Zellklonen.1: DVL wt, 2: DVL $\triangle P D Z \triangle D E P$.

DVL wt und DVL $\triangle$ PDZ $\triangle$ DEP zeigten jeweils eine starke Expression der flag-getaggten Dishevelled-Proteine. Da die Zellen mit Zeocin ${ }^{\mathrm{TM}}$ behandelt wurden, konnte sichergestellt werden, dass sich im Zellklon nur die Zellen befanden, die mit dem Plasmid auch die Resistenzkassette gegen das Antibiotikum aufgenommen hatten. Beide Klone eigneten sich somit für die nachfolgenden Versuche. 


\subsubsection{MTT-Assay der stabil transfizierten Zellen}

Um herauszufinden, ob das Stimulans Wnt 5a die Proliferation der Zellen und damit die Ergebnisse in den Invasivitätsuntersuchungen beeinflusst, wurde ein MTT-Assay durchgeführt. Die Messung des MTT-Einbaus in die drei Zelllinien unter Stimulation mit Wnt $5 a$ konnte zeigen, dass es bei MCF-7 und den stabilen Zellklonen DVL wt und DVL $\triangle$ PDZ $\Delta$ DEP keine signifikanten Unterschiede in der Viabilität zwischen unstimulierter Kontrolle und den stimulierten Zellen gab. Auch Zeocin ${ }^{\mathrm{TM}}$ schien keinen signifikanten Effekt auf die Viabilität der Zellklone auszuüben.

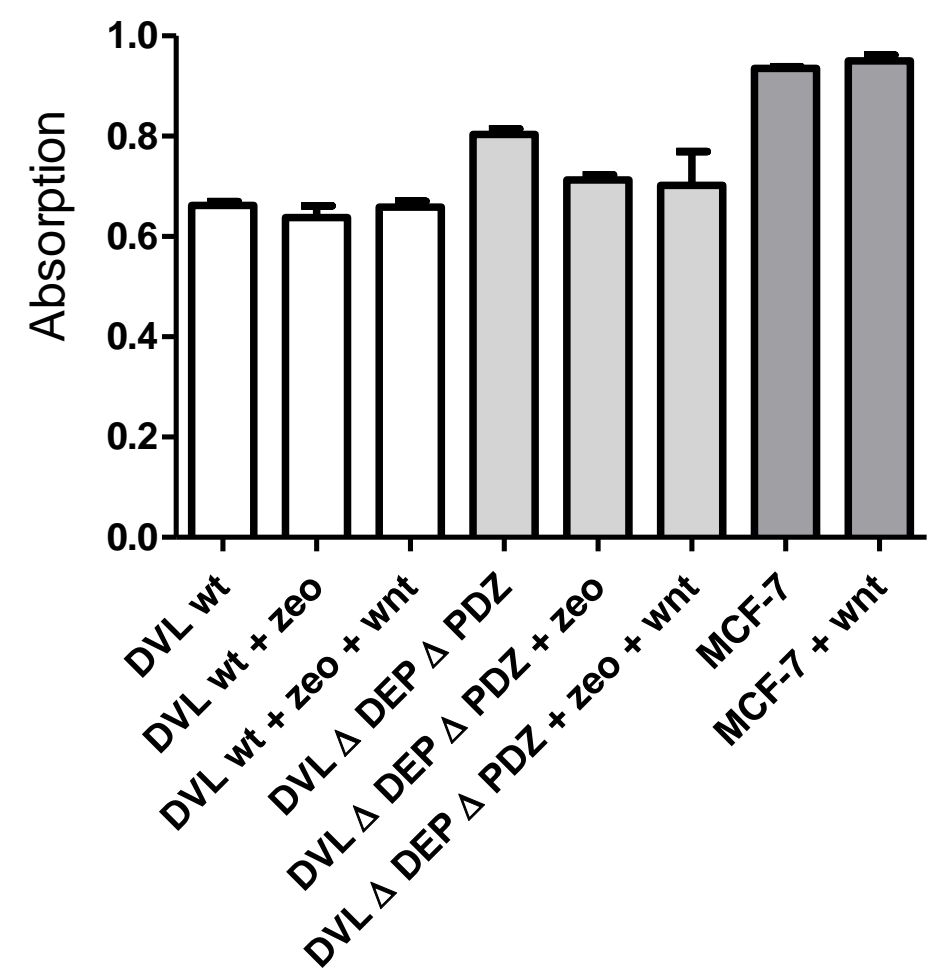

Abbildung 3.5: Viabilitätsrate von DVL wt, DVL $\triangle$ PDZ $\triangle$ DEP und MCF-7 im MTT-Test.

Pro Versuchsansatz $1 \times 10^{5}$ Zellen $+/$ - Antibiotikum und $+/$ - Wnt. $(+$ zeo $)=$ mit Zeocin $^{T M}$, (+ $z e o+w n t)=$ mit Zeocin $^{T M}$ und Wnt 5a. $M W+/-S D$ aus triplikaten Versuchsansätzen. Die Viabilitätsrate innerhalb eines Zellklons mit und ohne Stimulation sowie mit und ohne Antibiotikum unterschied sich nicht signifikant $(p>0,05)$. 


\subsubsection{Zellzählung der stabil transfizierten Zellen}

Um nachzuweisen, dass die Stimulation mit Wnt 5a keinen starken Einfluss auf die Zellproliferation ausübt, wurde die Anzahl der Zellen nach 96h Inkubation bestimmt. Es wurden jeweils drei Zellzählungen der Konstrukte im Zellmedium mit dem Selektionsantibiotikum Zeocin ${ }^{T M}\left(x+z e o ; x\right.$ steht für das jeweilige Konstrukt), mit Zeocin ${ }^{T M}$ und Wnt $5 a(x+$ wnt + zeo) und im Zeocin-freien Zellmedium ohne Wnt-Stimulation $(x)$ sowie von MCF-7-Kontrolle mit und ohne Wnt-Stimulation ausgewertet. Die Proliferationsrate der stabilen Klone + / - Selektionsantibiotikum und unter Wnt-Stimulation als auch die der MCF7-Kontrolle + / - Wnt-Stimulation ergab keinen signifikanten Unterschied.

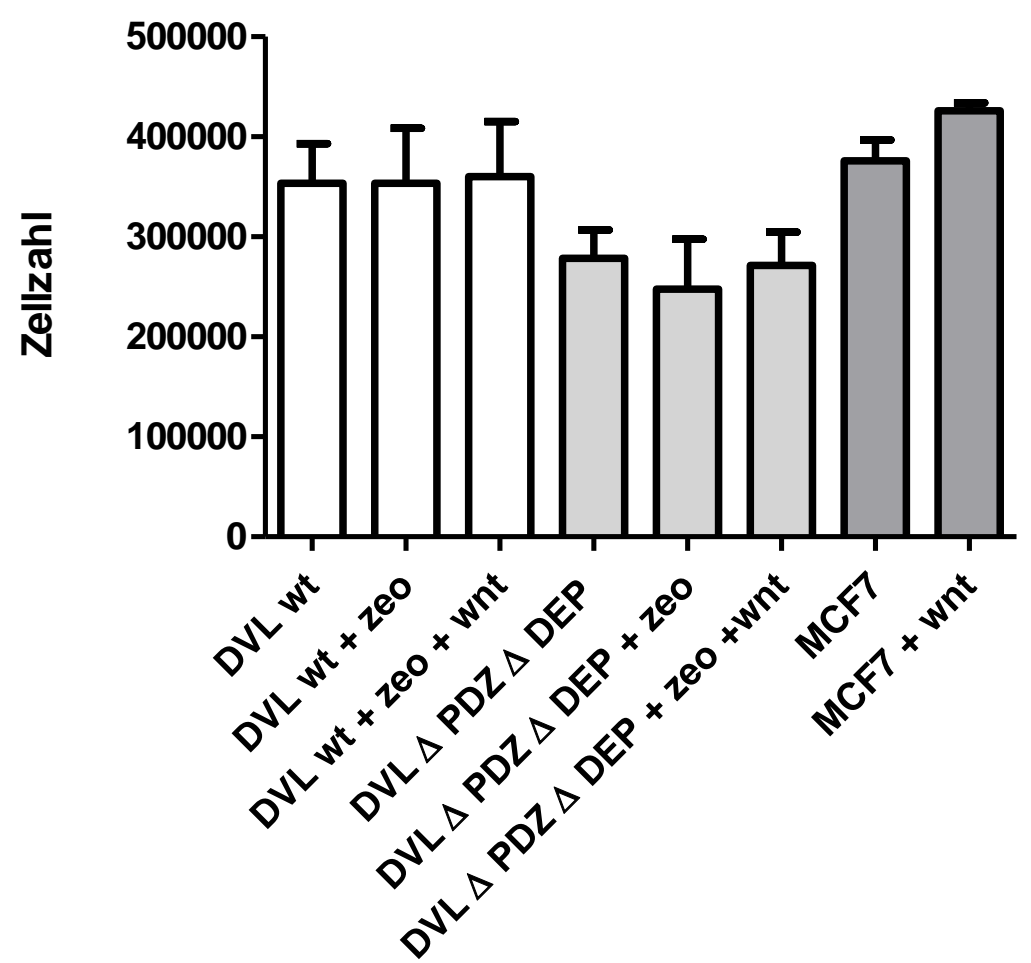

Abbildung 3.6: Proliferationssrate von DVL wt, DVL $\triangle$ PDZ $\triangle$ DEP und MCF-7-Kontrolle nach 96h. Pro Versuchsansatz $1 \times 10^{5}$ Zellen +/ - Antibiotikum und +/ - Wnt 5a. MW + / - SD aus triplikaten Versuchsansätzen. Die Proliferationsrate innerhalb eines Zellklons mit und ohne Stimulation sowie mit und ohne Antibiotikum unterschied sich nicht signifikant $(p>0,05)$. 


\subsection{Einsatz der Zellen in der modifizierten Boyden-Kammer}

Zur Invasivitätsbestimmung wurde der in 2.2 .5 beschriebene Boyden-Assay durchgeführt.

Wie in Abbildung $3.7 \mathrm{zu}$ sehen, zeigten alle mit Wnt 5 a stimulierten Zellen eine signifikante relative Invasivitätszunahme im Vergleich zu den nicht stimulierten Zellen. Klon DVL wt wies die höchste relative Invasivitätszunahme auf ca. $330 \%$ unter Wnt 5 a auf. Klon DVL $\Delta$ PDZ $\Delta$ DEP verhielt sich ähnlich zur MCF-7-Kontrolle: Die Invasivität von DVL $\triangle$ PDZ $\triangle$ DEP stieg nach Stimulation auf ca. $180 \%$, die Invasivität von MCF-7-Kontrolle auf ca. $230 \%$ an. Es werden die Ergebnisse von jeweils drei repräsentativen Versuchen dargestellt. Es konnte gezeigt werden, dass rekombinantes Wnt 5 a einen signifikanten invasionssteigernden Effekt auf die MCF-7-Kontrolle und die beide Klone DVL wt und DVL $\triangle$ PDZ $\triangle$ DEP ausübte.
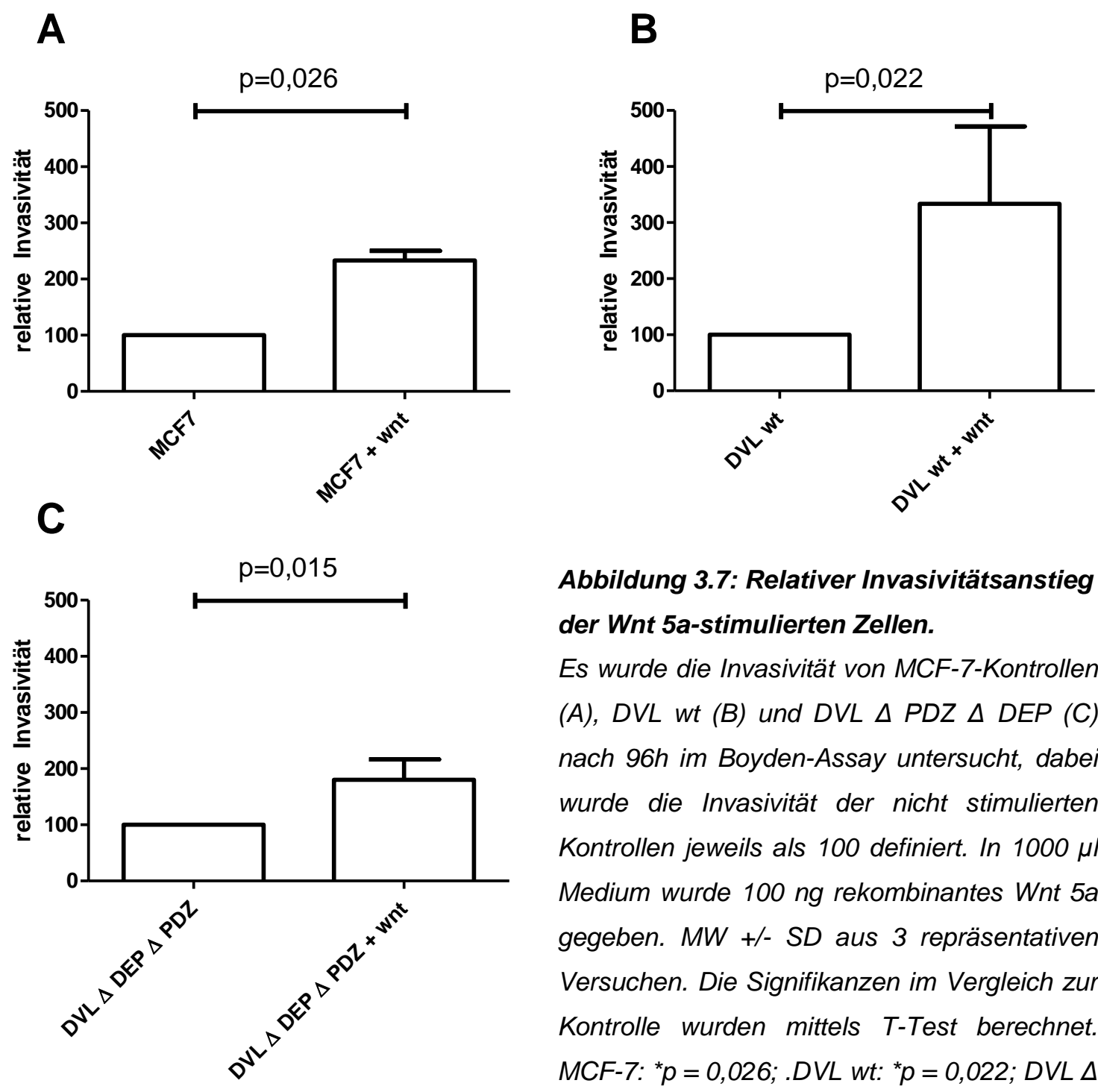

Abbildung 3.7: Relativer Invasivitätsanstieg
der Wnt 5a-stimulierten Zellen.

Es wurde die Invasivität von MCF-7-Kontrollen (A), DVL wt (B) und DVL $\triangle P D Z \triangle D E P$ (C) nach $96 h$ im Boyden-Assay untersucht, dabei wurde die Invasivität der nicht stimulierten Kontrollen jeweils als 100 definiert. In $1000 \mu$ I Medium wurde 100 ng rekombinantes Wnt $5 a$ gegeben. $M W+/-S D$ aus 3 repräsentativen Versuchen. Die Signifikanzen im Vergleich zur Kontrolle wurden mittels T-Test berechnet. MCF-7: * $p=0,026$; . DVL wt: * $p=0,022 ; D V L \Delta$ $P D Z \triangle D E P:{ }^{*} p=0,015$. 


\subsection{Subzelluläre Lokalisation der einzelnen Dishevelled-Konstrukte}

\subsubsection{Cytospin-Färbung der Wnt 5a-stimulierten Zellen nach Durchlaufen der Boyden-}

\section{Kammer}

Um zu untersuchen, ob sich der Anteil an transfizierten Zellen zu den nicht-transfizierten Zellen eines Klons nach Durchlaufen der Boyden-Kammer verändert hat, wurden nach Ablauf der Invasivitätsuntersuchungen Cytospins durchgeführt. Die Zellen, die im modifizierten Boyden-Assay unter Wnt 5a eine Invasivitätszunahme zeigten, wurden mittels Cytospin fixiert und die Konstrukte DVL wt und DVL $\triangle$ PDZ $\triangle$ DEP wie in 2.2.4.1 beschrieben detektiert. Abbildung 3.8. zeigt beispielhaft jeweils einen Cytospin von DVL wt, DVL $\triangle$ PDZ $\Delta$ DEP und MCF-7. $90 \%$ der Zellen wiesen ein Signal auf. Auffallend war allerdings die unterschiedliche Expression der Signale: Bei DVL wt war das flag-getaggte Konstrukt homogen im Zytoplasma verteilt, bei DVL $\triangle$ PDZ $\triangle$ DEP akkumulierte es zu punktartigen Konglomeraten.

A

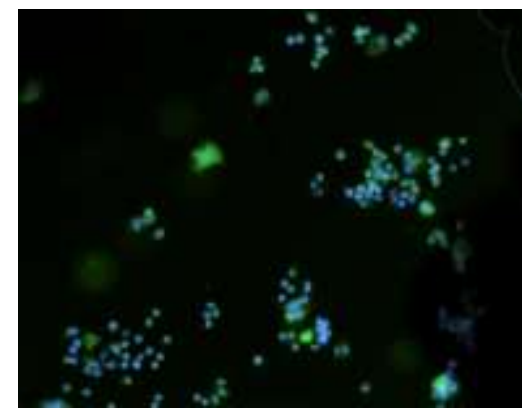

B

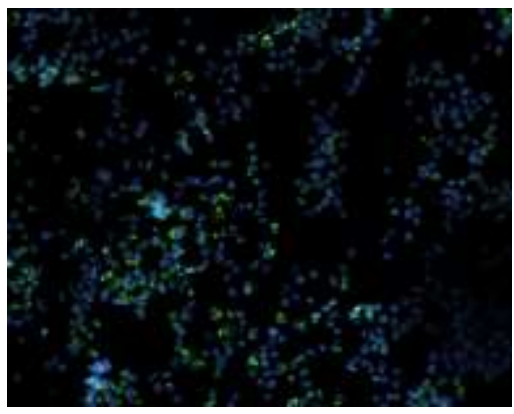

C

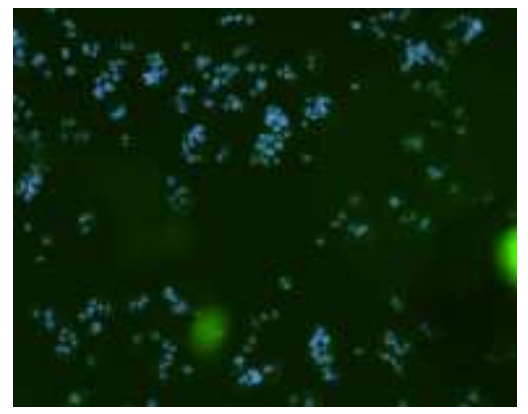

Abbildung 3.8: Invasionsrate von DVL wt, DVL $\triangle P D Z \triangle D E P$ und MCF-7-Kontrolle. CytospinFärbungen der durch die Boyden-Kammer gelaufenen, mit Wnt-5a-stimulierten Zellen. Die Zellen wurden auf ihre flag-getaggten Konstrukte hin detektiert (grün). Zellkerne wurden mit DAPI sichtbar gemacht (blau). Flag-Antikörper 1:1000. A: DVL wt, B: DVL $\triangle$ PDZ $\triangle D E P$, C: MCF-7.

\subsubsection{Subzelluläre Lokalisation der DVL-Konstrukte in stabil transfizierter MCF-7}

Im Zellklon DVL $\triangle$ PDZ $\triangle$ DEP wurde, wie in 1.6. beschrieben, ein DVL-Konstrukt überexprimiert, bei dem die für die Signaltransduktion des PCP-Signalwegs DishevelledDomänen PDZ und DEP fehlten. Deshalb stellte sich die Frage, warum DVL $\triangle$ PDZ $\triangle$ DEP trotzdem - ebenso wie Klon DVL wt und MCF-7-Kontrolle - eine Invasivitätszunahme unter Wnt 5a-Stimulation zeigte. Nach den Ergebnissen der Cytospin-Färbungen wurden deswegen die beiden Zellklone DVL wt und DVL $\triangle$ PDZ $\triangle$ DEP mittels Immunfluoreszenz detektiert und unter dem konfokalen Laser-Scanning-Mikroskop untersucht. Wie zuvor schon 
in den Cytospins zu erkennen, war bei Klon DVL wildtyp und Klon DVL $\triangle$ PDZ $\triangle$ DEP eine starke Expression der Dishevelled-Proteine in ca. 80 bis $90 \%$ der Zellen zu sehen.

Das intrazelluläre Verteilungsmuster der Signale glich den Ergebnissen der CytospinFärbungen. DVL wt zeigte eine homogene rote Anfärbung im Zytoplasma, was dort auf eine gleichmäßige Verteilung des Konstrukts schließen ließ. Dagegen wiesen die Zellen von Klon DVL $\Delta$ PDZ $\triangle$ DEP mehrere punktartige Signale auf, die paranukleär und nukleär lokalisiert waren. Fast jede der DVL $\triangle$ PDZ $\Delta$ DEP-Zellen zeigte eine größere Akkumulation am Zellkernrand, die sich von den zahlreichen kleineren Strukturen abhob. Viele dieser Signalansammlungen besaßen einen Fortsatz in einen Hohlraum im Kerninneren. Bei einigen Zellen von Klon DVL $\Delta$ PDZ $\Delta$ DEP zeigte zudem der gesamte Kern - aber mit deutlich schwächerem Signal - eine homogene Fluoreszenz.

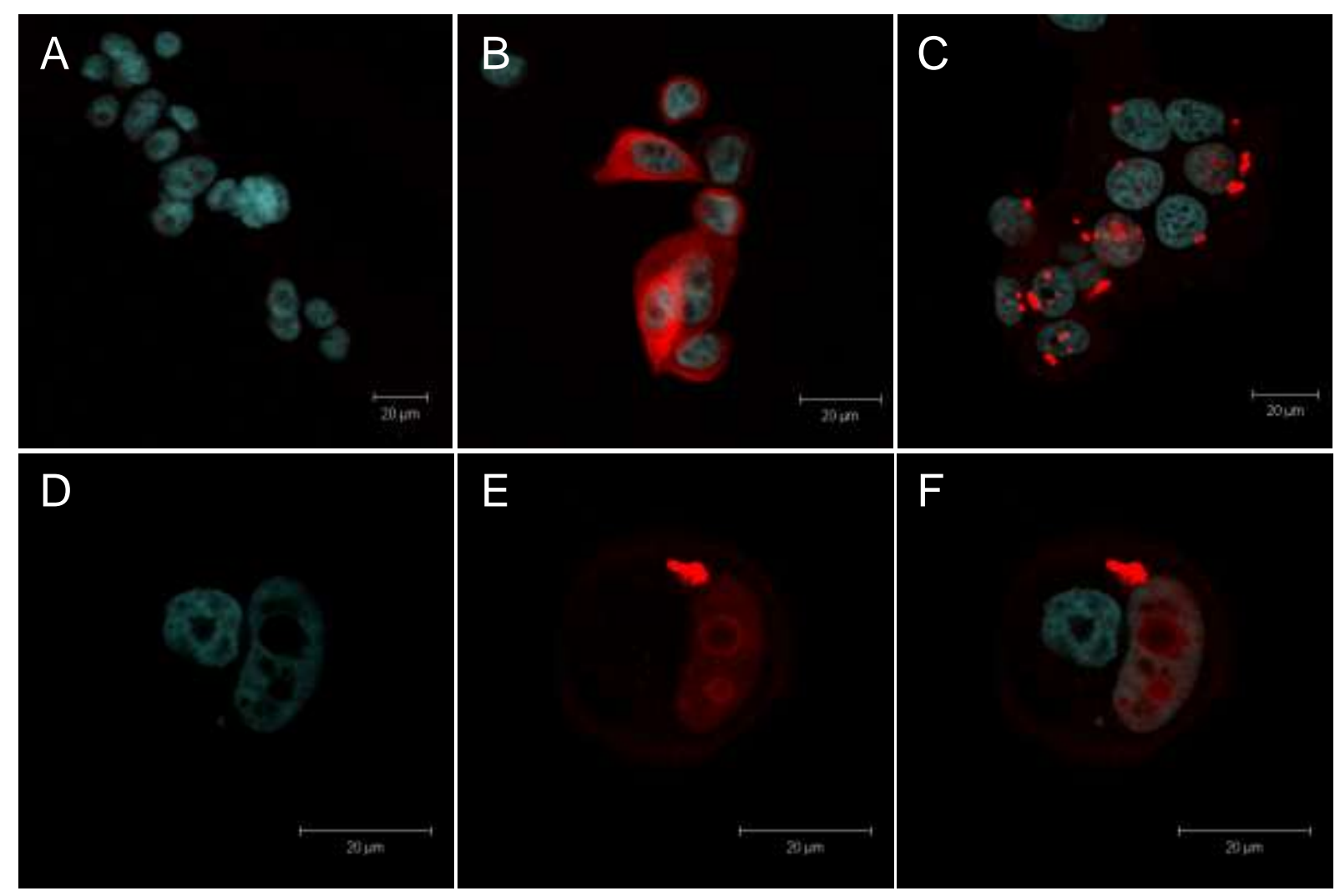

Abbildung 3.9: Subzelluläre Lokalisation der flag-getaggten Konstrukte von DVL wt und DVL $\Delta$ PDZ $\triangle$ DEP. Die stabilen Klone wurden auf ihre flag-getaggten Konstrukte hin detektiert (rot). Zellkerne wurden mit DAPI sichtbar gemacht (blau). $10^{5}$ Zellen wurden auf Deckgläschen ausgesät, Nach 24h Inkubation fand die Immunfluoreszenzfärbung statt.

A: Negativkontrolle: MCF-7-Kontrolle, B: DVL wt: Homogenes Signal von DVL wt im Zytoplasma, C: DV L $\triangle P D Z \triangle D E P$ : Paranukleäre und intranukleäre Konglomerate. D - F: DVL $\triangle P D Z \triangle D E P$ : Das para- und intranukleäre Signal von DVL $\triangle P D Z \triangle D E P$ ist nach Auftrennen der Färbungen deutlich zu erkennen. (D: Nur DAPI-Färbung der Zellkerne, E: Nur DVL $\triangle P D Z \triangle D E P$, F: Detektion von Zellkern und Konstrukt) 


\subsubsection{Subzelluläre Lokalisation der einzelnen DVL-Konstrukte in transient transfizierten} Zellen

Es stellte sich die Frage, ob eine bestimmte Kombination der Dishevelled-Domänen DIX, PDZ und DEP nicht nur für die Aktivierung von Signalwegen eine Rolle spielt, sondern eventuell auch die Lokalisation des Proteins beeinflusst. Wie schon bekannt, ist die Primärstruktur von DVL wt aus allen drei Domänen aufgebaut, DVL $\Delta$ PDZ $\Delta$ DEP dagegen besitzt nur die DIX-Domäne. Um zu überprüfen, ob bestimmte Domänen der DVL-Mutanten deren Lokalisation im Zytoplasma beeinflussen, wurden MCF-7-Zellen mit allen in 3.1.1. beschriebenen Plasmiden transient transfiziert. Auch DVL wt und DVL $\Delta$ PDZ $\Delta$ DEP wurden noch einmal transient in die Zellen gebracht, um auszuschließen, dass die Lokalisation der Konstrukte durch die stabile Transfektion beeinflusst worden sein könnte. Die Schemazeichnung der Konstrukte befindet sich auf Seite 26. Die Aufnahmen (Abbildung 3.10) zeigen, dass bei DVL wt und DVL $\triangle$ PDZ $\triangle$ DEP kein Unterschied in der DVLLokalisation zwischen transient transfizierter und stabil transfizierter Zelle besteht. Weiterhin zeigen die Aufnahmen, dass alle Konstrukte, bei denen die DEP-Domäne ausgeknockt worden war, eine nukleäre und paranukleäre Lokalisation besitzen. Die Konstrukte, welche DEP enthalten, zeigen dagegen eine homogene Verteilung im Zytoplasma. Das Vorhandensein von DIX und PDZ scheint keine entscheidende Rolle zu spielen. 


\section{Konstrukte mit DEP-Domäne Konstrukte ohne DEP-Domäne}
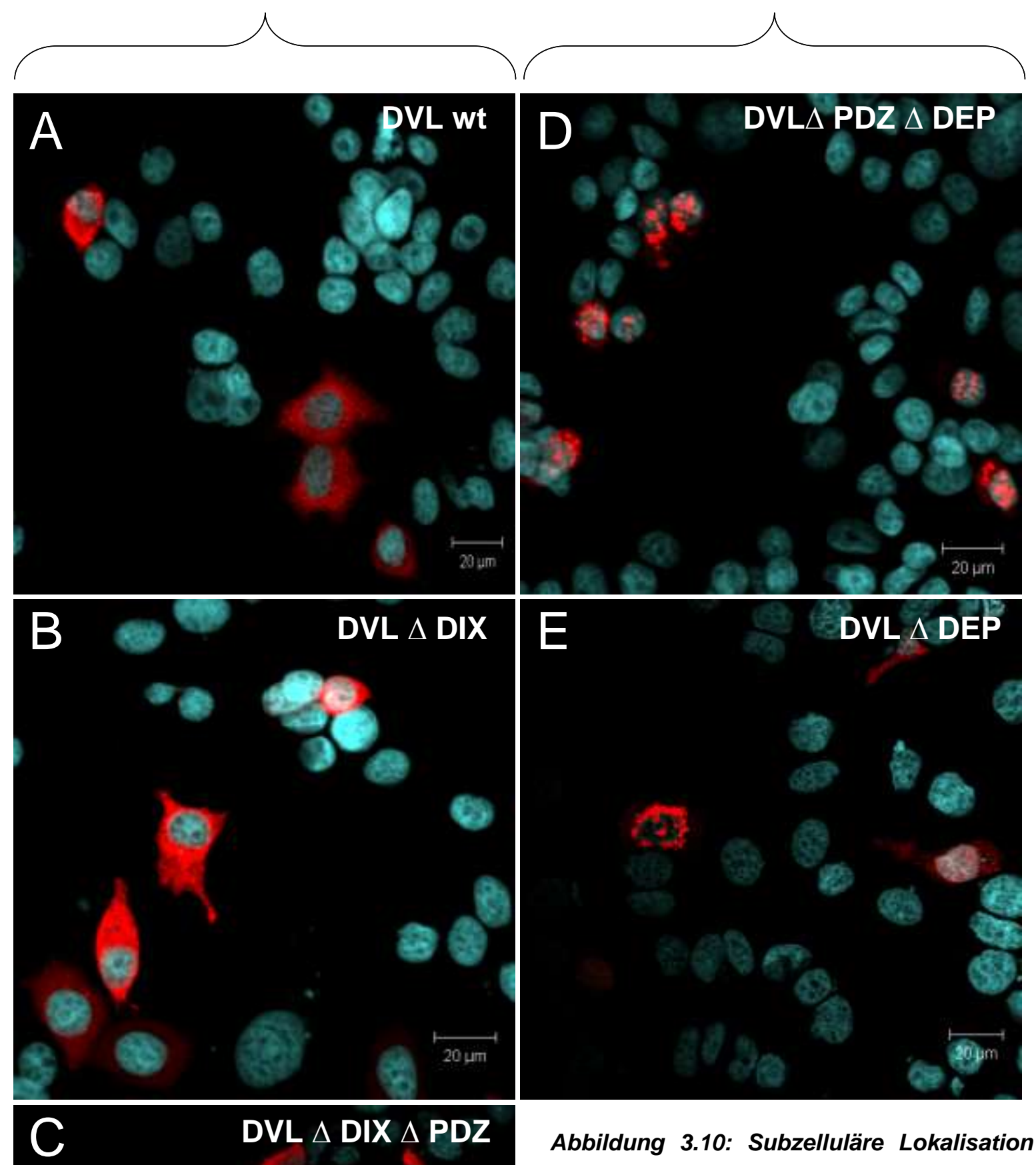

Abbildung 3.10: Subzelluläre Lokalisation aller transient in MCF-7 gebrachten DVLKonstrukte. A. DVL wt, B: DVL $\triangle D I X, C: D V L$ $\triangle D I X \triangle P D Z, D: D V L \triangle P D Z \triangle D E P, E: D V L \triangle$ $D E P$. Die Zellen wurden auf ihre flaggetaggten Konstrukte hin detektiert (rot). Zellkerne wurden mit DAPI sichtbar gemacht (blau). Flag-Antikörper 1:1000. 


\subsubsection{Subzelluläre Lokalisation der Konstrukte nach Wnt-5a-Stimulation}

Um zu überprüfen, ob Wnt 5a einen Einfluss auf die Lokalisation von Dishevelled ausübt, wurden Aufnahmen von den Klonen nach 5 und nach 30 minütiger Inkubation mit Wnt $5 \mathrm{a}$ gemacht und mit den jeweils unstimulierten Kontrollen verglichen (Abbildung 3.11). Es konnte kein Unterschied zwischen den stimulierten und unstimulierten Zellen nachgewiesen werden. Als Beispiel werden repräsentative Bilder nach 30 min Wnt-Inkubation gezeigt.

\section{Unstimuliert}

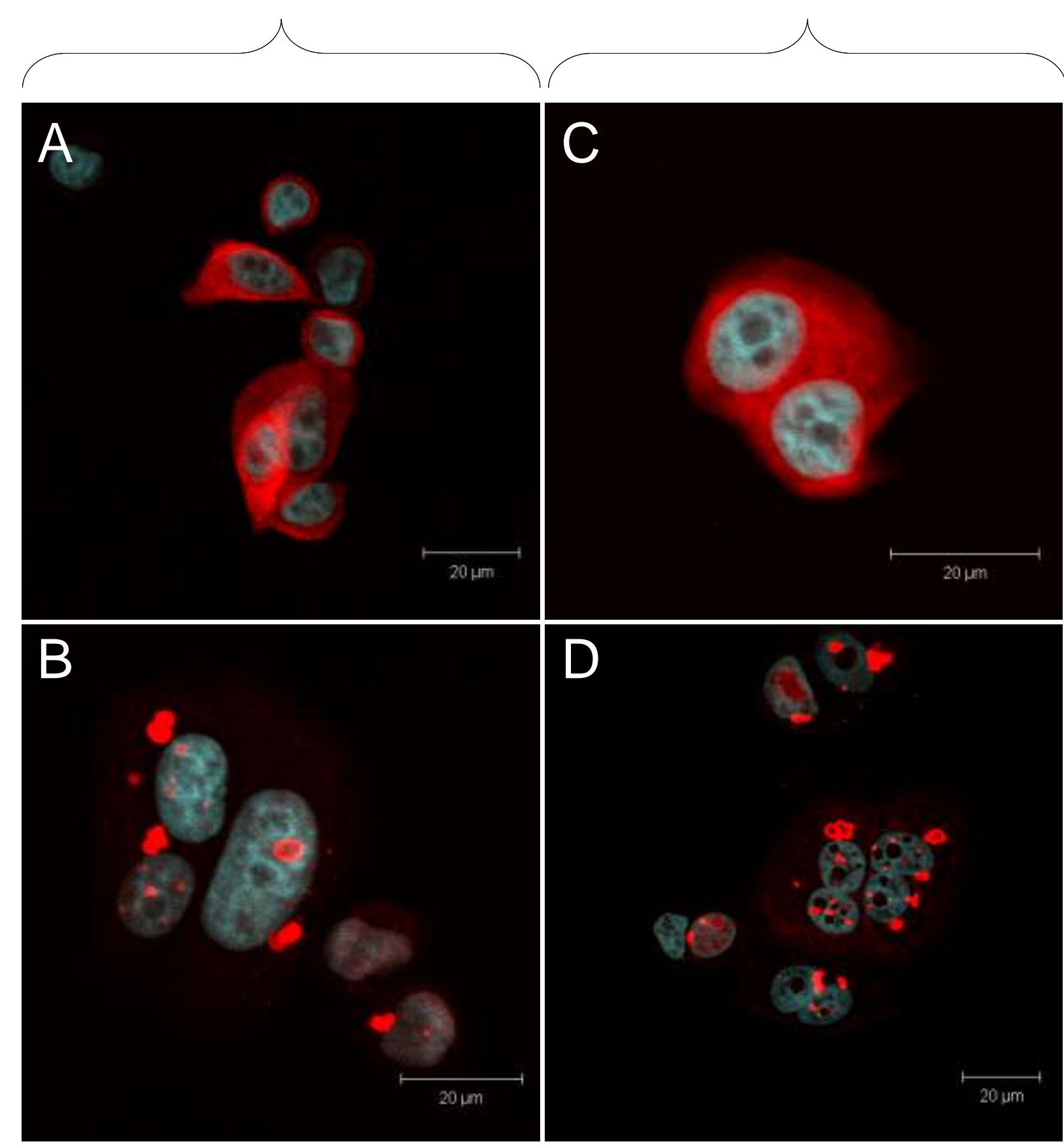


Abbildung 3.11: Lokalisation der Konstrukte nach 30 min Wnt 5a-Inkubation im Vergleich zu Kontrollzellen ohne Wnt 5a-Stimulation. Die Zellen wurden auf ihre flag-getaggten Konstrukte hin detektiert (rot). Zellkerne wurden mit DAPI sichtbar gemacht (blau). A: DVL wt, B: DVL wt + Wnt 5a, C: DVL $\triangle P D Z \triangle D E P, D: D V L \triangle P D Z \triangle D E P+$ Wnt $5 a$.

\subsubsection{Expression von exogenem Konstrukt und endogenem DVL-3 in stabil transfizierten Zellklonen}

Es stellten sich nun zwei weitere Fragen: 1) War genug endogenes DVL vorhanden, das trotz scheinbar dominant-negativem Konstrukt eine Wnt 5a-induzierte Invasivitätssteigerung vermitteln konnte? 2) Führte die Transfektion des dominant-negativen Konstrukts zu einer Hochregulation von endogenem DVL? Die Expression des Proteins sollte mittels Western Blot detektiert werden. Da es leider nicht möglich war, endogenes Dishevelled völlig unabhängig von den Dishevelled-Proteinen von DVL wt und DVL $\triangle$ PDZ $\triangle$ DEP darzustellen, wurde zur Detektion ein Antikörper ausgewählt, bei dem es die geringsten Überschneidungen aller Dishevelled-Proteine gab. Bei MCF-7 werden endogenes Dishevelled-1 und Dishevelled-3 exprimiert (Schlange et al. 2007). Die Plasmide aus dem Labor von R.T. Moon sind auf Dishevelled-3 aufgebaut, weswegen ein Dishevelled-3Antikörper ausgewählt wurde (Angers et al. 2006). Der Dishevelled-3-Antikörper (DVL-3Antikörper) bindet am C-Terminus von Dishevelled, somit sollte er nur das endogene Dishevelled und exogenes DVL wt erkennen. Da bei DVL $\Delta$ PDZ $\Delta$ DEP der C-Terminus fehlt, kann es durch diesen Antikörper nicht dargestellt werden. Parallel dazu wurde die Expression der stabilen Konstrukte mittels polyklonalem flag-Antikörper nachgewiesen. Die Detektion der flag-getaggten Konstrukte in Blot A zeigt bei DVL wt (1) mehrere Banden zwischen 120 und $80 \mathrm{kDa}$ und bei DVL $\triangle \mathrm{PDZ} \triangle \mathrm{DEP}(2)$ mehrere Banden zwischen 34, 00 und 49,00 kDa (siehe Abbildung 3.12. A, Pfeile a und b). Damit können die ähnlich starken Signale den korrekten Größenverhältnissen der Konstrukte zugeordnet werden. Bei der DVL3-Detektion in Blot B zeigen DVL $\triangle$ PDZ $\triangle$ DEP (2) und MCF-7-Kontrolle (3) jeweils zwischen 90 und 120 kDa ein ähnlich starkes Signal (siehe Abbildung 3.12.B, Pfeil b), das endogenem DVL entspricht, welches wie in der Literatur beschrieben ungefähr $93 \mathrm{kDa}$ groß ist. DVL wt (1) zeigt im gleichen Größenbereich ein deutlich stärkeres Signal, was - wie zuvor beschrieben - für eine gleichzeitige Detektion von Konstrukt und endogenen DVL-3 spricht (siehe Abbildung 3.12.B, Pfeil a), die Dishevelled-Proteine lassen sich in diesem WesternBlot nicht differenzieren.

Die Ergebnisse zeigen, dass in den mit DVL $\Delta$ PDZ $\Delta$ DEP transfizierten Zellen ähnlich viel endogenes DVL vorhanden ist wie in der MCF-7-Kontrolle. Da erstere eine Invasivitätssteigerung unter Wnt 5 a zeigten, erscheint es somit wahrscheinlich, dass 
endogenes DVL im Zellklon DVL $\Delta$ PDZ $\Delta$ DEP ausreichend war, um eine Invasivitätssteigerung zu erklären. Dafür spricht die ähnlich starke Signalintensität von endogenem DVL-3 in MCF-7-Kontrolle und DVL $\triangle$ PDZ $\triangle$ DEP in Blot B, die zu den Ergebnissen der Boyden-Kammer-Versuche passt, wo beide Zellen eine ähnlich starke Invasivitätszunahme zeigten. In DVL $\Delta$ PDZ $\Delta$ DEP kann somit eine Hochregulation von endogenem DVL ausgeschlossen werden. Die DVL wt-Zellen wurden in ihrer Invasivitätszunahme am stärksten beeinflusst, da diese am meisten DVL (endogenes und exogenes DVL) besitzen, die das Wnt-induzierte Signal weiterleiten konnten.
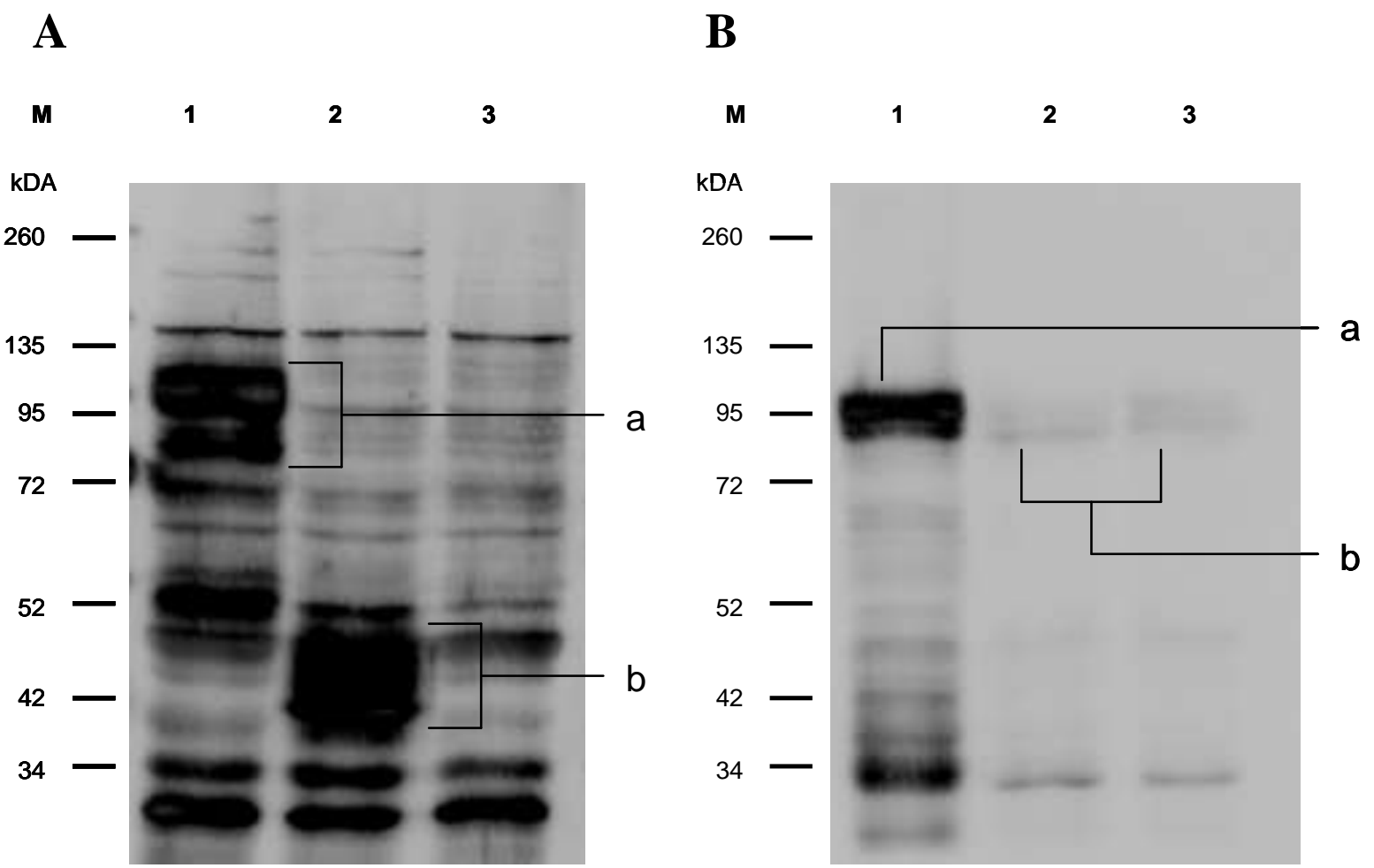

Abbildung 3.12: A: Expression der exogenen Konstrukte in stabil transfizierten MCF-7.

B: Expression von endogenem DVL-3 in DVL wt, DVL $\triangle$ PDZ $\triangle$ DEP und MCF-7-Kontrolle A: FlagDetektion der stabil in MCF-7 gebrachten Konstrukte 1: DVL wt, 2: DVL $\triangle P D Z \triangle D E P$, 3: MCF-7Kontrolle (a: Expression von FLAG-getaggtem DVL wt; b: Expression vom FLAG-getaggtem DVL $\Delta$ $P D Z \triangle D E P)$. B: C-Terminal DVL-3-Detektion in den Zellklonen und in MCF-7-Kontrolle.

1: DVL wt, 2: DVL $\triangle P D Z \triangle D E P$, 3: Unbehandelte MCF-7 (a: Expression von DVL wt und endogenem DVL-3; b: Endogenes DVL-3). Flag-Antikörper 1:500. DVL-3-Antikörper 1:1000.

\subsubsection{Gleichzeitige Lokalisation von endogenem DVL-3 und exogenem Konstrukt}

Zur gleichzeitigen Bestimmung der subzellulären Lokalisation von endogenem DVL-3 und der exogenen Konstrukte wurde bei den Klonen DVL wt und DVL $\triangle$ PDZ $\triangle$ DEP eine Doppel- 
Immunfluoreszenzfärbung durchgeführt. Für die Detektion der Proteine wurde ein monoklonaler M5-flag-Antikörper und monoklonaler DVL-3-Antikörper verwendet, der allerdings ein anderer war als derjenige, der für die DVL-3-Detektion im Western Blot ausgewählt wurde. Dies hat folgenden Grund: In den Zellen sollen sowohl endogenes DVL als auch die flag-getaggten Konstrukte dargestellt werden. Erforderlich ist dafür ein DVLAntikörper, der die gesamte DVL-Verteilung (also exogenes und endogenes DVL) innerhalb der Zellen darstellen kann; im Summationsbild lässt sich dann durch gleichzeitige Anregung von flag- und DVL-Antikörper endogenes und exogenes DVL voneinander differenzieren. Es wurde deswegen ein N-terminal bindender DVL-Antikörper gewählt, der durch seine Bindungsstelle für den Nachweis sowohl von endogenem Dishevelled-3 als auch der beiden exogenen Konstrukte geeignet war. Durch Anregung mit verschiedenen Wellenlängen können die einzelnen Signale detektiert werden. Endogenes DVL-3 gibt ein grünes Signal, DVL wt und DVL $\triangle$ PDZ $\triangle$ DEP fluoreszieren durch die Antikörperwahl rot. Wenn gleichzeitig endogenes DVL-3 und die Konstrukte dargestellt werden sollen, kommt es zu einer Signalsummation der beiden Antikörper. DVL wt und DVL $\triangle$ PDZ $\triangle$ DEP, die sowohl durch den flag-Antikörper als auch durch den N-terminal bindenden DVL-3-Antikörper nachgewiesen werden können, exprimieren dann ein gelbes Signal. Eine Kreuzreaktion des M5-flag-Antikörpers mit endogenem DVL-3 konnte durch die Färbungen ausgeschlossen werden. In Abbildung 3.13 zeigt sich eine homogene Verteilung von endogenem DVL-3 im Zytoplasma von MCF-7. Exogenes DVL wt verteilt sich entsprechend endogenem DVL-3 homogen im Zytoplasma, intranukleär sind keine Signalanreicherungen zu sehen (Abbildung 3.14). DVL $\triangle$ PDZ $\triangle$ DEP ist - wie in den vorherigen Abbildungen schon beschrieben - in punktartigen para- und intranukleären Strukturen verteilt (Abbildung 3.15). Die Signalintensität von endogenem DVL-3 in stabil mit DVL wt und DVL $\triangle$ PDZ $\triangle$ DEP transfizierter MCF-7 ist ähnlich stark im Vergleich zu DVL-3 in der MCF-7-Kontrolle. Durch die Aufnahmen kann nachgewiesen werden, dass es durch den DVL-3-Antikörper nur dann zu einer Signalsteigerung kommt, wenn gleichzeitig endogenes DVL und exogenes Konstrukt detektiert werden, da DVL wt und DVL $\triangle$ PDZ $\triangle$ DEP dieselbe Bindungsstelle wie DVL-3 besitzen. Eine Überexpression von endogenem DVL-3 in DVL $\Delta$ PDZ $\Delta$ DEP kann ausgeschlossen werden und bestätigt damit die Ergebnisse aus dem Western Blot. 


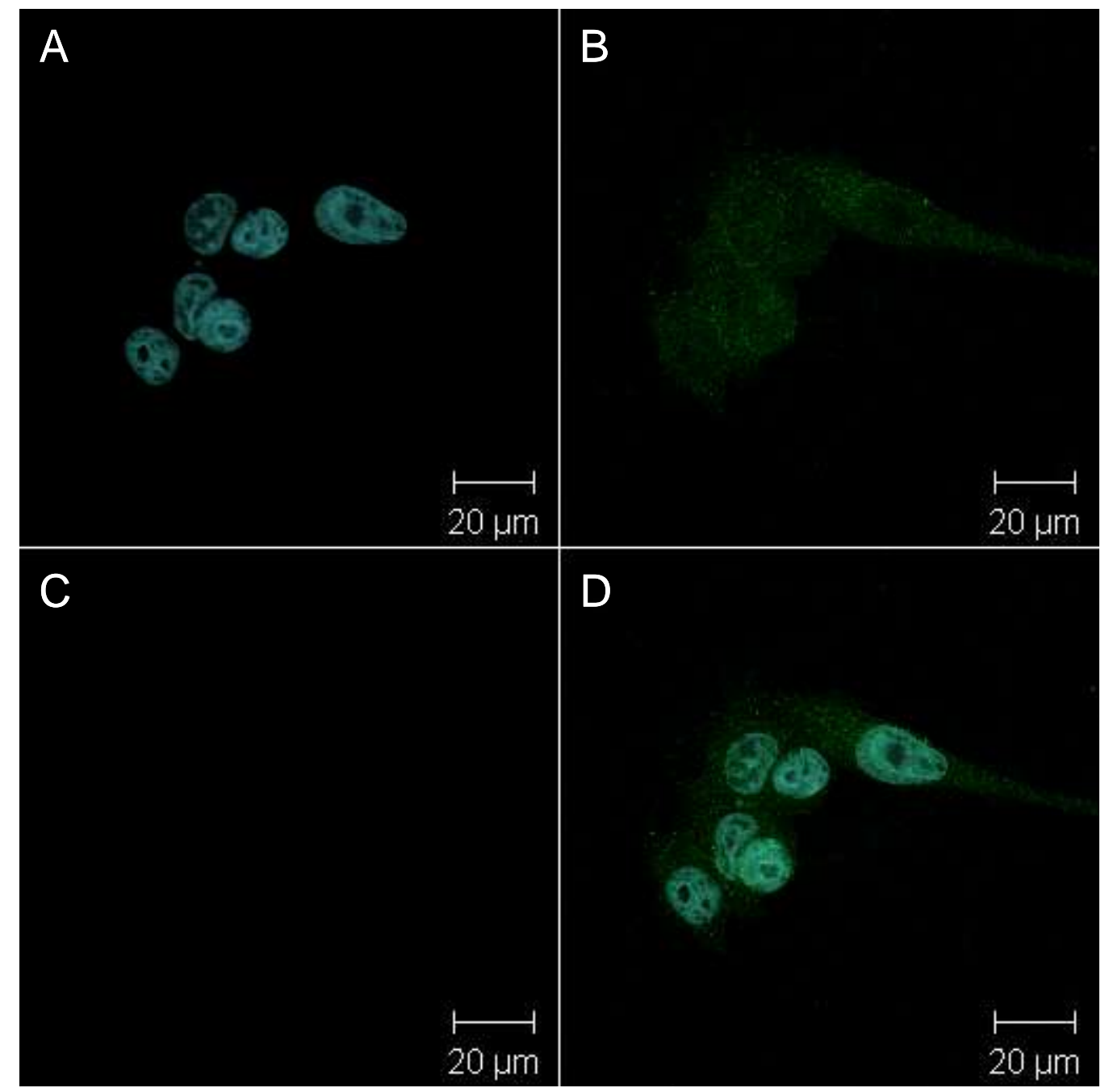

Abbildung 3.13: Lokalisation von endogenem DVL-3 bei MCF-7. Zellkerne wurden mit DAPI sichtbar gemacht (blau); flag-getaggte Konstrukte gaben über TRITC ein rotes Signal; N-terminal $D V L-3$ fluoreszierte durch $H+L$ grün. Flag-Antikörper 1:500, DVL-3-Antikörper 1:50.

A: DAPI-Färbung der Zellkerne. B: Anti-DVL-3, C: Anti-flag M5, D: Summationsbild: Darstellung der Zellkerne und von endogenem DVL-3 Es lässt sich keine Kreuzreaktion mit dem flag-getaggten Antikörper nachweisen. 


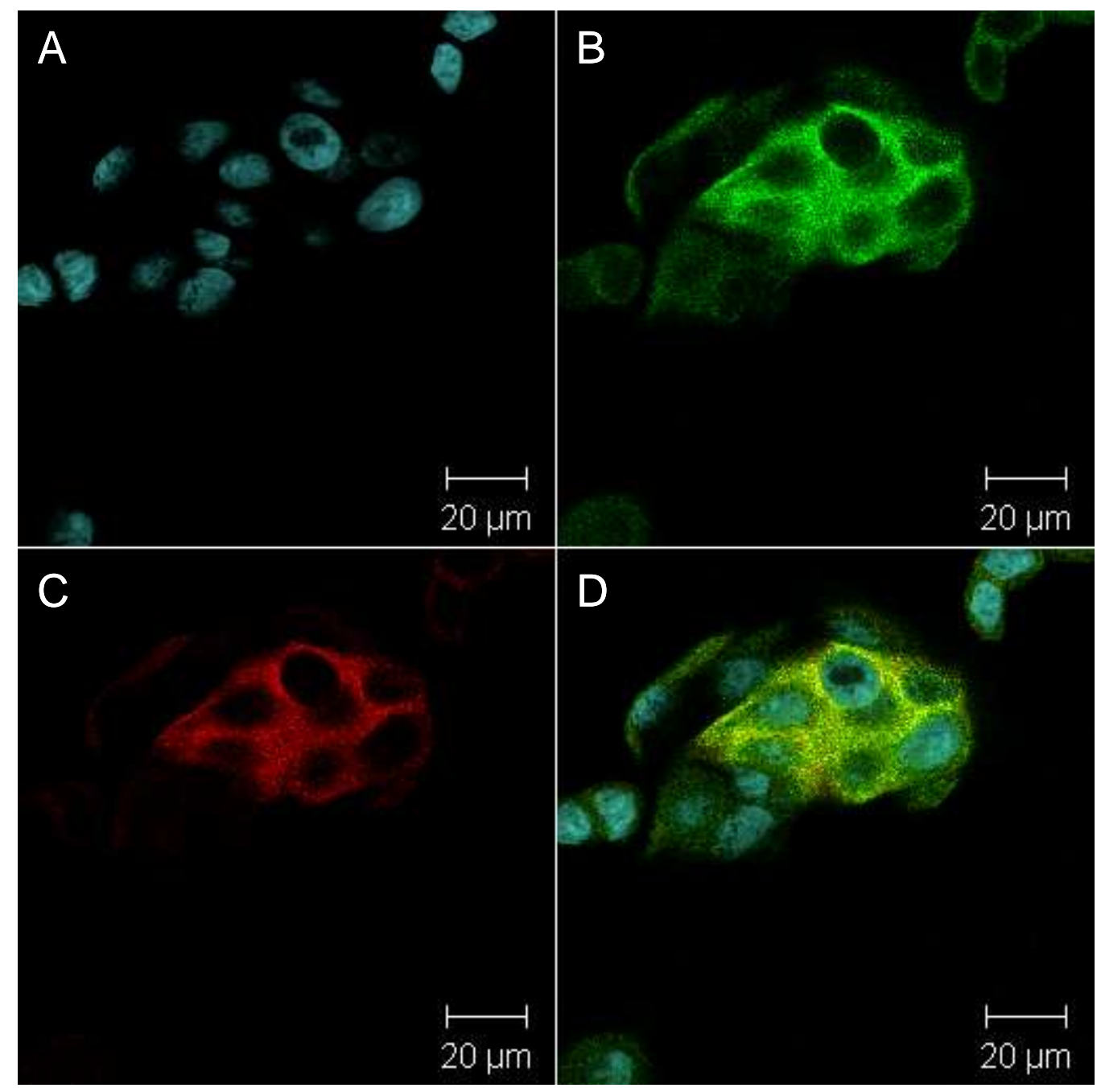

Abbildung 3.14: Lokalisation von endogenem DVL-3 und DVL wt bei stabil mit DVL wt transfizierter MCF-7. Zellkerne wurden mit DAPI sichtbar gemacht (blau); flag-getaggte Konstrukte gaben über TRITC ein rotes Signal; $N$-terminal DVL-3 fluoreszierte durch $H+L$ grün. Flag-Antikörper 1:500, DVL-3-Antikörper 1:50.

A: DAPI-Färbung der Zellkerne. B: Anti-DVL-3, C: Anti-flag M5, D: Summationsbild: Darstellung der Zellkerne, endogenem DVL-3 und DVL wt. Gleichzeitige Detektion von endogenem DVL-3 und DVL wt durch Anregung beider Antikörper gibt ein gelbes Signal. 


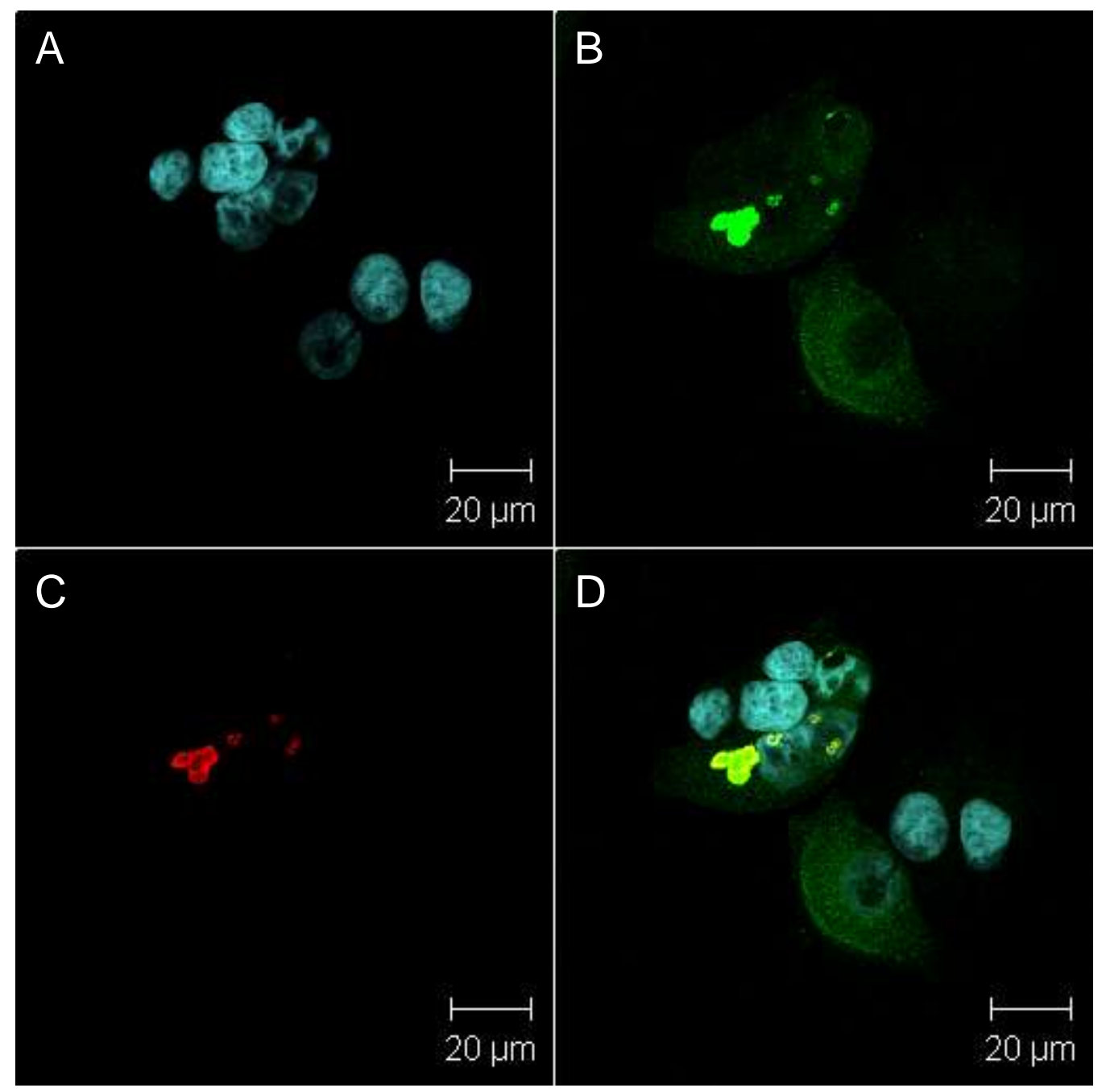

Abbildung 3.15: Lokalisation von endogenem DVL-3 und DVL $\triangle P D Z \triangle D E P$ bei stabil mit DVL $\triangle P D Z \triangle D E P$ transfizierter MCF-7.:

Zellkerne wurden mit DAPI sichtbar gemacht (blau); flag-getaggte Konstrukte gaben über TRITC ein rotes Signal, N-terminal DVL-3 fluoreszierte durch $H+L$ grün. Flag-Antikörper 1:500, DVL-3Antikörper 1:50. A: DAPI-Färbung der Zellkerne. B: Anti-DVL-3, C: Anti-flag M5, D: Summationsbild: Darstellung der Zellkerne, endogenem DVL-3 und DSH $\triangle P D Z \triangle D E P$. Gleichzeitige Detektion von endogenem DVL-3 und DVL $\triangle P D Z \triangle D E P$ gibt ein gelbes Signal. Durch Auftrennung der Farben ist die Verteilung von endogenem DVL-3 und exogenem Konstrukt gut zu erkennen. 


\section{Diskussion}

Im Rahmen dieser Arbeit habe ich die beiden Dishevelled-Mutanten DVL wt und DVL $\triangle$ PDZ $\triangle$ DEP stabil in die Brustkrebszellinie MCF-7 transfiziert, um das invasive Verhalten der entstandenen Zellklone unter Wnt 5a-Stimulation zu untersuchen. Ziel meiner Arbeit war es, herauszufinden, ob der über Dishevelled kanalisierte PCP-Signalweg die Invasivität der Brustkrebszelllinie MCF-7 beeinflusst.

\subsection{Untersuchung der Invasivität}

Nach Inkubation mit Wnt 5a fand sowohl bei der MCF-7-Kontrolle als auch bei beiden Klonen DVL wt und DVL $\triangle$ PDZ $\triangle$ DEP ein Anstieg der Invasivität statt. DVL wt zeigte dabei die größte Invasivitätszunahme, MCF-7-Kontrolle und DVL $\triangle$ PDZ $\Delta$ DEP wiesen eine zueinander ähnlich starke, aber im Vergleich zu DVL wt geringere Invasivitätszunahme auf. Wie bei Pukrop et al. kam es bei MCF-7 unter Wnt $5 a$ zu einem erwarteten Invasivitätsanstieg (Pukrop et al. 2006). Der im Vergleich größere Anstieg bei DVL wt ist durch die absolute Zunahme von DVL gut erklärbar (endogenes und exogenes DVL). Erstaunlich war allerdings die gezeigte Invasivitätszunahme bei DVL $\triangle$ PDZ $\triangle$ DEP. Ein erster Erklärungsansatz für den Invasivitätsanstieg von DVL $\Delta \mathrm{PDZ} \Delta \mathrm{DEP}$ wäre, dass möglicherweise nicht transfizierte Zellen im Klon das Ergebnis beeinflusst haben könnten. Rekombinantes Wnt $5 \mathrm{a}$ habe in den untransfiziert gebliebenen Zellen im Klon - im Gegensatz zu den Zellen, die DVL $\triangle$ PDZ $\triangle$ DEP enthalten - den nicht-kanonischen Signalweg aktiviert. Dadurch könnte eine Selektion stattgefunden haben mit dem Resultat, dass nur die nicht-transfizierten Zellen auf das Stimulans mit einer gesteigerten Invasivität reagiert hätten. Durch Immunfluoreszenz der flag-getaggten Konstrukte bei den zwei stabilen Zellklonen konnte ein Einbau von DVL wt bzw. - für die Fragestellung von besonderer Bedeutung - DVL $\triangle$ PDZ $\triangle$ DEP in je etwa $90 \%$ der Zellen nachgewiesen werden. Cytospins von den Zellen, die nach Ablauf der 96 Stunden durch die Boyden-Kammer gelaufen sind, zeigten keine Abweichung zu der Ausgangseffizienz und damit keine relative Abnahme an transfizierten Zellen. Somit sind die Ergebnisse der Boyden-Versuche nicht auf im Klon untransfiziert gebliebene Zellen zurückzuführen. Überraschenderweise lieferte die Immunfluoreszenz aber einen anderen Hinweis für den unerwarteten Invasivitätsanstieg bei DVL $\triangle$ PDZ $\triangle$ DEP: Die beiden Klone unterschieden sich hinsichtlich ihrer Lokalisation in den Zellen. Während DVL wt wie schon beschrieben eine homogene Verteilung im Zytoplasma zeigte, wiesen die Zellen von DVL $\triangle$ PDZ $\triangle$ DEP zahlreiche Konglomerate auf. Diese Strukturen befanden sich vorwiegend am und auch im Kern. Letzteres konnte durch Schichtfotographie im konfokalen Laser-Scanning-Mikroskop nachgewiesen werden. Bei einigen Zellen zeigte sich zudem eine schwache aber homogene Bindung des Flag- 
Antikörpers im gesamten Zellkern. Es gibt zahlreiche Publikationen, die zeigen, dass Dishevelled die Fähigkeit besitzt, zytoplasmatische Konglomerate zu bilden (Axelrod et al. 1998; Chen et al. 2003; Kishida et al. 1999; Rothbacher et al. 2000; Smalley et al. 1999; Yang-Snyder et al. 1996). Diese Konglomerate wurden sowohl bei full-length-Konstrukten als auch bei endogenem Dishevelled in Drosophila, im Krallenfrosch Xenopus, im Fadenwurm Caenorhabditis elegans, und bei Mäuse-Embryonen beobachtet (Schwarz-Romond et al. 2005). Diese Dots waren allerdings meistens im gesamten Zytoplasma verteilt - und nicht para- oder sogar intranukleär. Konträr zu den Ergebnissen meiner Doktorarbeit traten die Ansammlungen außerdem vorwiegend bei überexprimierten wildtyp-Konstrukten auf wie zum Beispiel Dishevelled-2. Eine homogene und nicht punktartige Verteilung im Zytoplasma, so wie ich sie bei DVL wt beobachtet habe, resultierte bei Dishevelled-2 erst durch Ausknocken von DIX als Mediator für die Bildung der Dots (Schwarz-Romond et al. 2005). Allerdings ist DIX bei meinen Konstrukten sowohl in DVL wt als auch in DVL $\triangle$ PDZ $\triangle$ DEP vorhanden und scheint damit bei den humanen DVL-Konstrukten nicht ursächlich für deren unterschiedliche Lokalisation zu sein. Nach Transfektion und anschließender Immunfluoreszenz sämtlicher Konstrukte ließ sich ein von DIX-abhängiges, subzelluläres Verteilungsmuster ausschließen. Ein weiterer Unterschied zu meinem Versuchsaufbau ist, dass die verwendeten Konstrukte der oben zitierten Autoren EGFP/GFP-getaggt waren, während DVL wt und DVL $\triangle$ PDZ $\Delta$ DEP flag-getaggt sind. Somit können auch unterschiedliche Affinitäts-tags die zytoplasmatische Verteilung von Dishevelled beeinflusst haben. Aufgrund der Tatsache, dass Dishevelled-Konstrukte unterschiedlicher Herkunft und mit unterschiedlichen Affinitätstags verwendet worden sind, lassen sich diese Beschreibungen als Erklärungsgrundlage für meine Ergebnisse nur schwer heranziehen.

\subsection{Ursache und Konsequenz der Zelllokalisationen}

DVL wt und DVL $\triangle$ PDZ $\triangle$ DEP unterscheiden sich hinsichtlich des Vorhandenseins zweier Domänen. Um zu überprüfen, ob eine fehlende Domäne ausschlaggebend für die Lokalisation von Dishevelled ist, habe ich die vorhandenen Dishevelled-Konstrukte DVL wt, DVL $\Delta$ DIX, DVL $\Delta$ PDZ $\Delta$ DIX, DVL $\Delta$ PDZ $\Delta$ DEP und DVL $\Delta$ DEP transient in MCF-7 transfiziert und diese anschließend mittels Immunfluoreszenz detektiert. Die Färbungen von DVL wt, DVL $\Delta$ DIX, DVL $\Delta$ PDZ $\Delta$ DIX zeigten eine homogene Verteilung von Dishevelled im Zytoplasma. Fehlte dagegen die DEP-Domäne, trat das punktartige paranukleäre und nukleäre Muster auf, wie bei DVL $\triangle \mathrm{PDZ} \Delta \mathrm{DEP}$ und DVL $\triangle \mathrm{DEP}$ zu sehen. Damit scheint die DEP-Domäne in Dishevelled dessen Position in der Zelle zu beeinflussen.

Eine Kernlokalisation von Dishevelled wurde erst vor kurzem in der Literatur beschrieben. Itoh et al lieferten 2005 Hinweise dafür, dass das bis dahin als rein zytoplasmatisch bekannte Protein Dishevelled zwischen Kern und Zytoplasma hin und her zirkulieren kann. Die Forschergruppe um Itoh konnte dabei innerhalb der DEP-Domäne von im Versuch 
verwendeten Xenopus-Dishevelled eine Aminosäuresequenz ausmachen, die als Nuclear Export Signal (NES) für Dishevelled dient. Dieses Leucin-reiche NES befindet sich bei Xenopus-Dishevelled an Position 513 bis 515 mit der Sequenz Leucin-x-Leucin, wobei x eine beliebige Aminosäure repräsentiert (Itoh et al. 2005). Die gleiche Sequenz liegt beim humanen Dishevelled-3 zwischen Position 504 bis 506. Da DVL $\triangle$ PDZ $\triangle$ DEP aus den Aminosäuren 1-247 und DVL $\Delta$ DEP aus den Aminosäuren 1-442 aufgebaut sind, besitzen sie diese Sequenz nicht, was als ein möglicher Grund für die Lokalisation in Betracht kommt. Auffällig an den Färbungen ist allerdings, dass nur zum Teil im Kern eine homogene Konstruktansammlung detektiert werden konnte. Deutlich mehr Zellen bei Klon DVL $\Delta$ PDZ $\Delta$ DEP zeigten zusätzlich oder unabhängig von dieser gleichmäßigen Kernanfärbung paranukleäre Konglomerate. Bei einem ausgeknockten Export-Signal in DVL $\triangle$ PDZ $\Delta$ DEP und DVL $\triangle$ DEP wäre eher zu erwarten, dass die Konstrukte im Zellkern akkumulieren. Neben dem NES-Signal gibt es bei Xenopus-Dishevelled auch ein Nuclear Localisation Signal (NLS) zwischen PDZ und DEP an Position 333 bis 381 der Aminosäuresequenz, welches den Transport von Dishevelled in den Zellkern reguliert. Dabei ist besonders die Sequenz aus den Aminosäuren Isoleucin-x-Leucin-Threonin an Position 333 bis 337 (x steht wieder für eine beliebe Aminosäure) von Bedeutung, deren Ausschaltung bei XenopusDishevelled einen Transport in den Nukleus verhindert (Itoh et al. 2005). Die Sequenz befindet sich bei humanem Dishevelled-3 in der Konsensus-Sequenz an Position 329 bis 332. NLS ist damit nur noch bei DVL wt und bei DVL $\triangle$ DEP vorhanden, dagegen weder bei DVL $\Delta$ PDZ $\Delta$ DEP noch bei DVL $\Delta$ DIX. Da sich unter diesem Aspekt keine Gemeinsamkeiten im zytoplasmatischen Verteilungsmuster der Konstrukte finden lassen, scheint NLS in meinen Untersuchungen vermutlich keinen Einfluss auf die zelluläre Lokalisation auszuüben. So waren bei DVL $\triangle$ PDZ $\triangle$ DEP trotz im Konstrukt fehlenden NLS intranukleäre Ansammlungen $\mathrm{zu}$ sehen. Itoh et al. konnten nachweisen, dass eine Kernlokalisation von Dishevelled für den PCP-Signalweg - im Gegensatz zum Wnt/BCateninsignalweg - nicht von Bedeutung ist und dieser auch dann noch stattfinden kann, wenn das Nuclear Localization Signal durch Aminosäureaustausch wirkungslos geworden ist (Itoh et al. 2005). Es stellt sich dann aber die Frage, ob der PCP-Signalweg noch durchlaufen werden kann, wenn Dishevelled durch seine intra- und paranukleären Akkumulation nicht mehr fähig ist, an die Zellmembran zu binden. Die Ergebnisse der Immunfluoreszenz lassen vermuten, dass DVL $\triangle$ PDZ $\triangle$ DEP aufgrund seiner ungewöhnlichen Lage den PCP-Signal nicht antagonisieren konnte und damit gar nicht funktionstüchtig gewesen ist. Pan, Pang et al. konnten zeigen, dass die DEP-Domäne für die Membran-Translokation von Maus-Dishevelled-1 in HEK 293-Zellen verantwortlich ist. Bei gleichzeitiger Kotransfektion mit einem Frizzled-7-Rezeptor-Konstrukt verteilten sich nur fulllength-Dishevelled und DVL-DEP an der Zellmembran. Konstrukte ohne DEP-Domäne 
translozierten in den Zellkern, zeigten aber nicht die punktartigen Strukturen para- und intranukleär, wie ich sie bei meinen Zellen beobachtet habe (Pan et al. 2004). Neben der DEP-Domäne beinhaltet auch die PDZ-Region bei Dishevelled eine Bindungssequenz für die Zellmembran. Wong et al fanden heraus, dass Dishevelled mittels seiner PDZ-Domäne am C-Terminus vom Frizzled-Rezeptor schwach bindet. Diese Sequenz scheint aber im Vergleich zur DEP-Region einen geringeren Stellenwert aufzuweisen, was auch meinen IFResultaten entspricht (Wong et al. 2003): Das Konstrukt DVL $\Delta$ DIX $\Delta$ PDZ, bei dem die DEP-Domäne noch vorhanden war, PDZ aber ausgeschaltet worden ist, zeigte eine homogene Verteilung im Zytoplasma und an der Zellmembran. Somit muss die DEPDomäne den entscheidenden Anteil an der Membranbindung von Dishevelled einnehmen, während PDZ zwar diesbezüglich eher eine untergeordnete Bedeutung einnimmt, für die Weiterleitung der Wnt-Signalwege aber Voraussetzung ist. DEP scheint mit seiner stärkeren Bindung an die Membran der Sicherstellung der Signaltransduktion zu dienen (Wong et al. 2003). Unter physiologischen Bedingungen muss Dishevelled an die Zellmembran binden können, um dort über den Frizzled-Rezeptor das durch Wnt $5 \mathrm{a}$ generierte Signal zu empfangen. Dishevelled, dass durch Mutation von DEP nicht an die Zellmembran binden kann, geht mit einem beeinträchtigten PCP-Signalweg einher (Axelrod et al. 1998; Boutros et al. 1998).

Befindet sich DVL $\triangle \mathrm{PDZ} \triangle \mathrm{DEP}$ nicht am Frizzled-Rezeptor, läuft das Wnt-Signal entweder ins Leere oder über endogenes DVL und bekräftigt die Überlegung, dass DVL $\triangle$ PDZ $\triangle$ DEP deswegen auf den PCP-Signalweg gar nicht negativ regulierend eingewirkt haben konnte. Interessante Ergebnisse dazu liefern Simons und Gault. Ihre Untersuchungen mit DEPmutierten Domänen in DVL-Konstrukten bekräftigen den Verdacht, dass diese Domäne für die Zellbindung und damit für einen funktionstüchtigen PCP-Signalweg über DVL zuständig ist. Durch Austausch von basischen Aminosäuren gegen negativ geladene Aminosäuren in der DEP-Domäne konnte Dishevelled nicht mehr an die negativ geladene Innenseite der Zellmembran binden. Die durch Frizzled übermittelte Membranlokalisation fand nicht mehr statt und Dishevelled zeigte daraufhin ein zu meinen DEP-freien Konstrukten sehr ähnliches Bild paranukleärer Ansammlungen. Diese Konglomerate wurden von den Autoren als Fehlrekrutierung von Dishevelled interpretiert mit der Konsequenz, dass der PCP-Signalweg nicht mehr ausführbar war (Simons et al. 2009). Obwohl DVL $\Delta$ PDZ $\Delta$ DEP somit das durch Wnt $5 a$ erzeugte Signal gar nicht weiterleiten konnte, fand dennoch eine Invasivitätszunahme in diesen Zellen statt. Aus den zuvor erwähnten Schlussfolgerungen ergibt sich, dass sich das Konstrukt DVL $\triangle$ PDZ $\Delta$ DEP vermutlich nicht kompetitiv zu endogenem DVL verhalten und das Wnt-Signal weiterleiten konnte. Der Invasivitätsanstieg von DVL $\triangle$ PDZ $\triangle$ DEP könnte durch endogenes DVL erzeugt worden sein. Endogenes DVL befindet sich neben dem stabil transfizierten Konstrukt immer noch in den Zellen und könnte 
als Reaktion auf die ungewöhnliche Lage von nicht funktionierendem DVL $\Delta$ DIX $\Delta$ PDZ hochreguliert worden sein. Um zu überprüfen, ob endogenes DVL den Invasivitätsanstieg bei DVL $\Delta$ DIX $\Delta$ PDZ verursacht haben könnte, wurden sowohl endogenes DVL als auch die flag-getaggten Konstrukte noch einmal im Western Blot und in einer DoppelImmunfluoreszenzfärbung detektiert. Schlange et al. zeigten 2007, dass MCF-7 hauptsächlich DVL-1 und DVL-3 exprimiert. Da unsere Konstrukte aus DVL-3 aufgebaut sind, wurde ein DVL-3 detektierender Antikörper verwendet (Schlange et al. 2007). Im Western Blot zeigten DVL wt und DVL $\triangle$ PDZ $\triangle$ DEP eine ähnlich starke Expression ihrer Konstrukte. Die Expression von endogenem DVL-3 bei einer MCF-7-Kontrolle und bei DVL $\Delta$ PDZ $\triangle$ DEP wies ebenso keinen Unterschied auf, womit eine reaktive Hochregulierung von DVL-3 ausgeschlossen werden konnte. Eine Doppel-Immunfluoreszenzfärbung der flaggetaggten Konstrukte und endogenem DVL-3 bestätigte, dass endogenes DVL-3 bei DVL $\Delta$ PDZ $\triangle$ DEP im Vergleich zu MCF-7-Kontrolle nicht hochreguliert worden war. Endogenes Dishevelled war bei allen Zellen homogen im Zytoplasma verteilt und zeigte keine Konglomeratbildung. Es muss allerdings nicht unbedingt eine Überexpression von DVL-3 vorgelegen haben, um den Invasivitätsanstieg bei Klon DVL $\Delta$ PDZ $\Delta$ DEP erklären zu können. Da das Konstrukt DVL $\triangle$ PDZ $\Delta$ DEP weder an die Zellmembran binden noch vermutlich weitere Funktionen ausüben konnte, war es schlussfolgernd auch gar nicht in der Lage, trotz seiner Überexpression kompetitiv zu endogenem DVL-3 am PCP-Signalweg einzugreifen. Der zu MCF-7-Kontrolle vergleichbar starke Invasivitätsanstieg als auch die ähnliche starke Expression von endogenem DVL-3 in DVL $\triangle$ PDZ $\triangle$ DEP und MCF-7Kontrolle bestärken die Überlegung, dass die normale Menge an endogenem DVL-3 in einer MCF-7-Zelle den Invasivitätsanstieg bei DVL $\triangle$ PDZ $\triangle$ DEP bewirkt haben könnte. Weiterhin muss berücksichtigt werden, dass Wnt 5 a ein Ligand ist, der nicht exklusiv über die nichtkanonischen Signalwege wirkt. Wnt 5a kann ebenso den kanonischen Signalweg als auch Zielprodukte der nicht-kanonischen Signalwege unter Umgehung von DVL aktivieren: So induziert Wnt $5 \mathrm{a}$ bei Vorhandensein von Fz 4 und LRP 5 die über $\beta$-Catenin-gesteuerte Transkriptionsaktivität in humanen Embryo-Nierenzellen. Ebenso kann Wnt $5 a$ über den Tyrosin-Kinase-Rezeptor Ror 2 und damit unter Umgehung von DVL und des PCPSignalweges die Jun-N-Terminal-Kinase aktivieren (Liu, Y. et al. 2008; Mikels und Nusse 2006b; Mikels und Nusse 2006a; Oishi et al. 2003; Schambony und Wedlich 2007). Sowohl im kanonischen Signalweg über den Transkriptionsfaktor TCF/LEF als auch über JNK als Effektorprotein des PCP- und des Ror 2-Signalwegs werden c-Jun und AP-1 aktiviert, zwei weitere entscheidende Mediatoren für die Invasivität (Le Floch et al. 2005). Für eine Wnt -5ainduzierte Invasivitätssteigerung in Tumorzellen kommen somit mehrere Signalwege in Betracht, die allerdings auch vom Zelltyp abhängig zu sein scheinen (McDonald und Silver 2009). So konnte von Pukrop et al. bei der Brustkrebszelllinie MCF-7 eine Wnt-5a-generierte 
Aktivierung des kanonischen Signalwegs zwar ausgeschlossen werden. Trotzdem war ein prinzipiell funktioneller kanonischer Signalweg notwendig für eine Wn-5a-induzierte Zunahme der Invasivität (Pukrop et al. 2006). Noch nicht überprüft wurde allerdings, ob Ror 2 bei MCF-7 einen Invasivitätsanstieg bewirkt. Schlussfolgernd könnte Ror 2 - ebenso wie endogenes Dishevelled - den Invasivitätsanstieg bei DVL $\triangle$ PDZ $\Delta$ DEP verursacht haben. Dies verdeutlicht noch einmal die komplexen Interaktionen der Wnt-Signalwege. Die Schwierigkeit besteht darin, einzelne Kaskaden zu überprüfen, ohne dass das Ergebnis durch andere, nebenher ablaufende Signalwege in den Zellen beeinflusst wird. In Abbildung 4.1 werden die verschiedenen Angriffspunkte von Wnt 5a und die Verknüpfungen der Signalkaskaden zusammenfassend dargestellt:

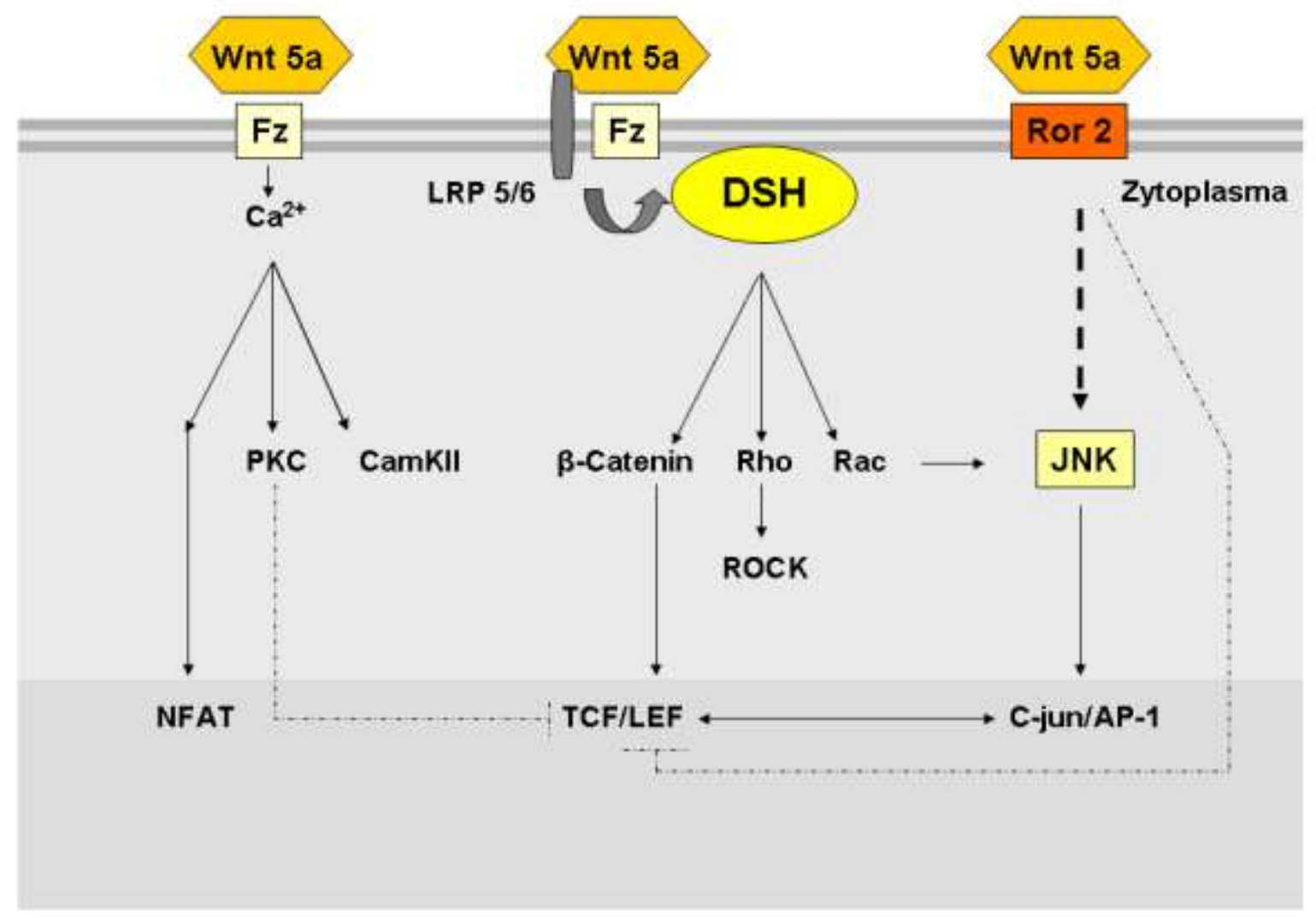

Abbildung 4.1: Wnt-5a als Aktivator zahlreicher Signalwege (Abbildung nach Pukrop und Binder, 2008, S. 260):

Wnt 5a aktiviert den Wnt/Ca ${ }^{2+}$-Signalweg (links im Bild). Über bestimmte Fz/LRP-RezeptorKombination kann einerseits durch Wnt $5 a$ der Wnt/3-Catenin-Signalweg als auch der PCPSignalweg aktiviert werden (Bildmitte). Neuere Studien zeigen, dass auch der Tyrosin-KinaseRezeptor Ror 2 über Wnt 5a JNK aktiviert wird (rechts im Bild). Camkll als Downstream-Effector des Wnt/Ca ${ }^{2+}$-Signalweg inhibiert den kanonischen Signalweg durch Hemmung den Transkriptionskomplexes TCF/LEF. Die Abbildung verdeutlicht die komplexen Interaktionen mehrerer Signalkaskaden, die alle durch den gleichen Wnt-Liganden Wnt 5a ausgelöst werden. 
Wie zuvor beschrieben müssen für zukünftige Untersuchungen der Wnt-5a-generierten Signalwege somit zahlreiche Einflussfaktoren berücksichtigt werden:

Endogenes DVL wird immer kompetitiv zu den exogenen Konstrukten wirken und die Versuchsergebnisse beeinflussen. Aufgrund seiner zahlreichen Funktionen in der Zellhomöostase kann die Bildung von endogenem DVL allerdings nicht komplett ausgeschaltet werden, ohne dass es zu einem Zelltod käme. Der Einsatz von exogenen Konstrukten bringt weitere Schwierigkeiten mit sich: So müsste zum Beispiel überprüft werden, ob die verwendeten Affinitäts-tags der Konstrukte einen Einfluss auf die subzelluläre Verteilung nehmen. Um solche Einflussfaktoren zu umgehen, sollte die Signaltransduktion durch den PCP-Signalweg deswegen durch andersartige Inhibitoren unterbrochen werden. Da ab DVL zwei parallel ablaufende und voneinander unabhängige Signalwege aktiviert werden, bietet sich - wenn technisch möglich - die Inhibition von deren Effektoren Rho und Rac an (Wallingford und Habas 2005). Das hätte den Vorteil, dass mit endogenem DVL gearbeitet werden kann. Um eine zusätzlich erfolgende Signaltransduktion über Ror 2 auszuschließen, müsste dieser Rezeptor in den Zellen durch ein dominant-negatives Konstrukt ausgeschaltet werden. Interessant wäre außerdem zu sehen, ob es bei einem DVL-Konstrukt mit fehlender DIX-Domäne (z.B. DVL $\Delta$ DIX) zu einer Invasivitätssteigerung unter Wnt 5a kommt. Da DVL $\Delta$ DIX die Signaltransduktion des kanonischen/ $\beta$-CateninSignalwegs über DVL unterbrechen sollte, könnte mit diesem Konstrukt dessen Einfluss auf die Wnt-5a-induzierte Invasivitätszunahme bei MCF-7 überprüft werden. 


\section{Zusammenfassung}

In dieser Arbeit wurde die Invasivität von MCF-7-Zellklonen untersucht, die entweder ein Dishevelled-wildtyp-Konstrukt (DVL wt) oder eine Dishevelled-Mutante mit ausgeknockten PDZ- und DEP-Domänen (DVL $\triangle$ PDZ $\triangle$ DEP) überexprimierten. Laut unserer Arbeitshypothese sollte der PCP-Signalweg im dominant-negativen Konstrukt DVL $\triangle$ PDZ $\Delta$ DEP nicht mehr weitergeleitet werden und dadurch eine Invasivitätssteigerung unter Wnt-5aStimulation nicht mehr stattfinden können. Die Annahme basiert auf Erkenntnissen, die u.a. von Pukrop et al. 2006 veröffentlicht wurden. Diese konnten zeigen, dass die Invasivität der Brustkrebszellinie MCF-7 durch den kanonischen Wnt/B-Catenin-Signalweg und den nichtkanonischen PCP-Signalweg gesteigert wurde. Ersterer übte dabei eher einen permissiven Part aus, während der PCP-Signalweg den aktiven Anteil zu übernehmen schien.

In den im Rahmen meiner Arbeit durchgeführten Versuchen nahm die Invasivität von DVL $\Delta$ PDZ $\triangle$ DEP im Boyden-Assay unter Wnt-5a-Stimulation im Vergleich zur nichtstimulierten Kontrolle zu. Mittels Immunfluoreszenz konnte gezeigt werden, dass das Konstrukt von DVL $\Delta$ PDZ $\Delta$ DEP in Zellkernnähe und teilweise auch intranukleär akkumulierte, jedoch nie membranständig war. Dagegen verteilte sich das Konstrukt von DVL wt - entsprechend dem Verteilungsmuster von endogenem DVL - homogen im Zytoplasma. Sehr wahrscheinlich war das Fehlen der DEP-Domäne ausschlaggebend für die atypische Lokalisation von DVL $\Delta$ $\mathrm{PDZ} \triangle \mathrm{DEP}$. Eine Membranbindung ist für DVL $\Delta \mathrm{PDZ} \Delta \mathrm{DEP}$ allerdings Voraussetzung, um als kompetitiver Antagonist zu endogenem DVL das Wnt-generierte Signal zu inhibieren. DVL wt zeigte in den Boyden-Versuchen die höchste Invasivitätszunahme, da die Quantität an Dishevelled (endogenes DVL und exogenes DVL wt) in diesen Zellen am höchsten war. Die Invasivität von MCF-7-Kontrolle stieg nach Wnt-Stimulation in einem etwas geringeren Prozentsatz an, die Signaltransduktion erfolgte dabei vermutlich über endogenes DVL. Da DVL $\triangle$ PDZ $\triangle$ DEP einen der MCF-7-Kontrolle ähnlich hohen Invasivitätsanstieg aufwies, schien hier ebenso endogenes DVL für die Signaltransduktion verantwortlich zu sein. Anhand nachfolgender Untersuchungen konnte ausgeschlossen werden, dass endogenes DVL in DVL $\triangle$ PDZ $\triangle$ DEP hochreguliert wurde: Sowohl im Western Blot als auch mittels Immunfluoreszenz wurde bestätigt, dass der normale Zellgehalt an endogenem DVL bei DVL $\triangle \mathrm{PDZ} \triangle \mathrm{DEP}$ ausreichend war, um einen Invasivitätsanstieg unter Wnt $5 \mathrm{a}$ zu bewirken.

Zusammenfassend zeigen die Ergebnisse, dass das Konstrukt DVL $\triangle$. PDZ $\triangle$ DEP zur Überprüfung meiner Arbeitshypothese ungeeignet war. Es konnten jedoch interesssante Erkenntnisse über die Bedeutung der subzellulären Lokalisation von Dishevelled gewonnen werden, die in Zukunft weiter verfolgt werden sollten. Ein weiteres Ziel ist die Klärung der genauen Natur der Wnt-5a-vermittelten Signaltransduktion durch alternative Methoden, welche die zahlreichen Interaktionen innerhalb der Wnt-Signalkaskaden so gut wie möglich berücksichtigen. 


\section{Abkürzungsverzeichnis}

AP-1

APC

$\mathrm{Ca}^{2+}$

CamK II

DAAM-1

DAG

DEP

DIX

Dkk

DVL

E.Coli

ECM

FCS

FITC

$\mathrm{Fz}$

GSK-3 $\beta$

JNK

LEF

LRP

MCF-7

MMP

NES

NLS

PCP

PDZ

rpm

RAC
Activator Protein-1

Adenomatosis Polyposis Coli (Tumor-

Suppressor-Protein)

Kalzium

$\mathrm{Ca2+/Calmodulin-abhängige} \mathrm{Protein-Kinase}$ II

Dishevelled-associated activator of morphogenesis 1

Diacylglycerin

Dishevelled/EGL-10/Pleckstrin protein

Dishevelled/Axin protein

Dickkopf

Dishevelled

Escherichia coli

Extrazellulärmatrix

Fetales Kälberserum

Fluoresceinisothiocyanat

Frizzled

Glykogen-Synthase-Kinase-3 $\beta$

c-Jun-N-terminal-Kinase

Lymphocyte enhanced factor

Lipoprotein-Receptor-Related Protein

Humane, hormonabhängige

Mammakarzinomzelllinie

Michigan Cancer Foundation

Matrix Metallo-Protease

Nuclear Export Signal

Nuclear Localisation Signal

Planar Cell Polarity

Postsynaptic density protein/Drosophila disc large tumor suppressor,/Zonula occludens-1 protein

Umdrehungen pro Minute (rounds per minute)

Ras-Like Protein 
ROCK

TAM

TCF

TNF- $\alpha$

TRITC

Wnt

wt

$\mathrm{xDSH}$

$(\mathrm{v} / \mathrm{v})$

$(w / v)$
RHO-Associated Coiled-Coil-Containing

Protein Kinase 1

Tumor-assoziierte Makrophagen

T-Cell Factor

Tumor-Nekrose-Faktor- $\alpha$

Tetramethylisothiocyanat

Wingless-type MMTV integration site family

Wildtyp

Xenopus Dishevelled

Volume/Volume

Weight/Volume 


\section{Literaturverzeichnis}

Aberle H, Bauer A, Stappert J, Kispert A and Kemler R (1997): beta-catenin is a target for the ubiquitin-proteasome pathway. EMBO J 16(13): 3797-804.

Adler PN (1992): The genetic control of tissue polarity in Drosophila. Bioessays 14(11): $735-$ 41.

Angers S, Thorpe CJ, Biechele TL, Goldenberg SJ, Zheng N, MacCoss MJ and Moon RT (2006): The KLHL12-Cullin-3 ubiquitin ligase negatively regulates the Wnt-beta-catenin pathway by targeting Dishevelled for degradation. Nat Cell Biol 8(4): 348-57.

Aplin AE, Howe A, Alahari SK and Juliano RL (1998): Signal transduction and signal modulation by cell adhesion receptors: the role of integrins, cadherins, immunoglobulin-cell adhesion molecules, and selectins. Pharmacol Rev 50(2): 197-263.

Axelrod JD, Miller JR, Shulman JM, Moon RT and Perrimon N (1998): Differential recruitment of Dishevelled provides signaling specificity in the planar cell polarity and Wingless signaling pathways. Genes Dev 12(16): 2610-22.

Boutros M, Paricio N, Strutt DI and Mlodzik M (1998): Dishevelled activates JNK and discriminates between JNK pathways in planar polarity and wingless signaling. Cell 94(1): 109-18.

Boutros M, Mihaly J, Bouwmeester T and Mlodzik M (2000): Signaling specificity by Frizzled receptors in Drosophila. Science 288(5472): 1825-8.

Bryja V, Schulte G, Rawal N, Grahn A and Arenas E (2007): Wnt-5a induces Dishevelled phosphorylation and dopaminergic differentiation via a CK1-dependent mechanism. $\mathrm{J}$ Cell Sci 120(Pt 4): 586-95.

Cadigan KM and Nusse R (1997): Wnt signaling: a common theme in animal development. Genes Dev 11(24): 3286-305. 
Capelluto DG, Kutateladze TG, Habas R, Finkielstein CV, He X and Overduin M (2002): The DIX domain targets dishevelled to actin stress fibres and vesicular membranes. Nature 419(6908): 726-9.

Chen W, ten Berge D, Brown J, Ahn S, Hu LA, Miller WE, Caron MG, Barak LS, Nusse R and Lefkowitz RJ (2003): Dishevelled 2 recruits beta-arrestin 2 to mediate Wnt5Astimulated endocytosis of Frizzled 4. Science 301(5638): 1391-4.

Chiang AC and Massague $\mathbf{J}$ (2008): Molecular basis of metastasis. N Engl J Med 359(26): 2814-23.

Coleman MP, Alexe D-M, Albreht T and McKee $\mathbf{M}$ in Responding to the challenge of cancer in Europe Institute of Public Health of the Republic of Slovenia, Ljubljana, Slovenia, (2008)

Crawford HC, Fingleton BM, Rudolph-Owen LA, Goss KJ, Rubinfeld B, Polakis P and Matrisian LM (1999): The metalloproteinase matrilysin is a target of beta-catenin transactivation in intestinal tumors. Oncogene 18(18): 2883-91.

De Koninck P and Schulman H (1998): Sensitivity of CaM kinase II to the frequency of Ca2+ oscillations. Science 279(5348): 227-30.

DeNardo DG, Johansson M and Coussens LM (2008): Immune cells as mediators of solid tumor metastasis. Cancer Metastasis Rev 27(1): 11-8.

Dolmetsch RE, Xu K and Lewis RS (1998): Calcium oscillations increase the efficiency and specificity of gene expression. Nature 392(6679): 933-6.

Du SJ, Purcell SM, Christian JL, McGrew LL and Moon RT (1995): Identification of distinct classes and functional domains of Wnts through expression of wild-type and chimeric proteins in Xenopus embryos. Mol Cell Biol 15(5): 2625-34.

Fahmy OG and Fahmy MJ (1959): Differential Gene Response to Mutagens in Drosophila Melanogaster. Genetics 44(6): 1149-71. 
Gordon MD and Nusse R (2006): Wnt signaling: multiple pathways, multiple receptors, and multiple transcription factors. J Biol Chem 281(32): 22429-33.

Habas R and Dawid IB (2005): Dishevelled and Wnt signaling: is the nucleus the final frontier? J Biol 4(1): 2.

Habas R, Dawid IB and He X (2003): Coactivation of Rac and Rho by Wnt/Frizzled signaling is required for vertebrate gastrulation. Genes Dev 17(2): 295-309.

Hagemann T, Robinson SC, Schulz M, Trumper L, Balkwill FR and Binder C (2004): Enhanced invasiveness of breast cancer cell lines upon co-cultivation with macrophages is due to TNF-alpha dependent up-regulation of matrix metalloproteases. Carcinogenesis 25(8): 1543-9.

Hanahan D and Weinberg RA (2000): The hallmarks of cancer. Cell 100(1): 57-70.

He X, Saint-Jeannet JP, Wang Y, Nathans J, Dawid I and Varmus H (1997): A member of the Frizzled protein family mediating axis induction by Wnt-5A. Science 275(5306): 1652-4.

He X, Semenov M, Tamai K and Zeng X (2004): LDL receptor-related proteins 5 and 6 in Wnt/beta-catenin signaling: arrows point the way. Development 131(8): 1663-77.

Itoh K, Brott BK, Bae GU, Ratcliffe MJ and Sokol SY (2005): Nuclear localization is required for Dishevelled function in Wnt/beta-catenin signaling. J Biol 4(1): 3 .

Kaplan RN, Riba RD, Zacharoulis S, Bramley AH, Vincent L, Costa C, MacDonald DD, Jin DK, Shido K, Kerns SA, Zhu Z, Hicklin D, Wu Y, Port JL, Altorki N, Port ER, Ruggero D, Shmelkov SV, Jensen KK, Rafii S and Lyden D (2005): VEGFR1-positive haematopoietic bone marrow progenitors initiate the pre-metastatic niche. Nature 438(7069): 820-7.

Kishida S, Yamamoto H, Hino S, Ikeda S, Kishida M and Kikuchi A (1999): DIX domains of Dvl and axin are necessary for protein interactions and their ability to regulate beta-catenin stability. Mol Cell Biol 19(6): 4414-22. 
Komiya Y and Habas R (2008): Wnt signal transduction pathways. Organogenesis 4(2): 6875.

Kumar V, Abbas AK, Fausto $\mathbf{N}$ and Mitchell RN: Neoplasia; in: Robbins Basic Pathology Saunders Elsevier, Philadelphia, PA, (2007)

Laemmli UK (1970): Cleavage of structural proteins during the assembly of the head of bacteriophage T4. Nature 227(5259): 680-5.

Lee AY, He B, You L, Xu Z, Mazieres J, Reguart N, Mikami I, Batra S and Jablons DM (2004): Dickkopf-1 antagonizes Wnt signaling independent of beta-catenin in human mesothelioma. Biochem Biophys Res Commun 323(4): 1246-50.

Le Floch N, Rivat C, De Wever O, Bruyneel E, Mareel M, Dale T and Gespach C (2005): The proinvasive activity of Wnt-2 is mediated through a noncanonical Wnt pathway coupled to GSK-3beta and c-Jun/AP-1 signaling. FASEB J 19(1): 144-6.

Liu G, Bafico A, Harris VK and Aaronson SA (2003): A novel mechanism for Wnt activation of canonical signaling through the LRP6 receptor. Mol Cell Biol 23(16): 5825-35.

Liu G, Bafico A and Aaronson SA (2005): The mechanism of endogenous receptor activation functionally distinguishes prototype canonical and noncanonical Wnts. Mol Cell Biol 25(9): 3475-82.

Liu Y, Rubin B, Bodine PV and Billiard J (2008): Wnt5a induces homodimerization and activation of Ror2 receptor tyrosine kinase. J Cell Biochem 105(2): 497-502.

Logan CY and Nusse R (2004): The Wnt signaling pathway in development and disease. Annu Rev Cell Dev Biol 20: 781-810.

Lukashev ME and Werb Z (1998): ECM signalling: orchestrating cell behaviour and misbehaviour. Trends Cell Biol 8(11): 437-41.

MacDonald BT, Tamai K and He X (2009): Wnt/beta-catenin signaling: components, mechanisms, and diseases. Dev Cell 17(1): 9-26. 
McDonald SL and Silver A (2009): The opposing roles of Wnt-5a in cancer. Br J Cancer 101(2): 209-14.

Medyouf H and Ghysdael J (2008): The calcineurin/NFAT signaling pathway: a novel therapeutic target in leukemia and solid tumors. Cell Cycle 7(3): 297-303.

Mikels AJ and Nusse R (2006a): Wnts as ligands: processing, secretion and reception. Oncogene 25(57): 7461-8.

Mikels AJ and Nusse R (2006b): Purified Wnt5a protein activates or inhibits beta-cateninTCF signaling depending on receptor context. PLoS Biol 4(4): e115.

Mikheev AM, Mikheeva SA, Liu B, Cohen P and Zarbl H (2004): A functional genomics approach for the identification of putative tumor suppressor genes: Dickkopf-1 as suppressor of HeLa cell transformation. Carcinogenesis 25(1): 47-59.

Nateri AS, Spencer-Dene B and Behrens A (2005): Interaction of phosphorylated C-Jun with TCF4 regulates intestinal cancer development. Nature 437(7056): 281-5.

Niehrs C (2006): Function and biological roles of the Dickkopf family of Wnt modulators. Oncogene 25(57): 7469-81.

Nomachi A, Nishita M, Inaba D, Enomoto M, Hamasaki M and Minami Y (2008): Receptor tyrosine kinase Ror2 mediates Wnt5a-induced polarized cell migration by activating c-Jun $\mathrm{N}$ terminal kinase via actin-binding protein filamin A. J Biol Chem 283(41): 27973-81.

Oishi I, Suzuki H, Onishi N, Takada R, Kani S, Ohkawara B, Koshida I, Suzuki K, Yamada G, Schwabe GC, Mundlos S, Shibuya H, Takada S and Minami Y (2003): The receptor tyrosine kinase Ror2 is involved in non-canonical Wnt5a/JNK signalling pathway. Genes Cells 8(7): 645-54.

Pan WJ, Pang SZ, Huang T, Guo HY, Wu D and Li L (2004): Characterization of function of three domains in dishevelled-1: DEP domain is responsible for membrane translocation of dishevelled-1. Cell Res 14(4): 324-30. 
Pukrop T and Binder C (2008): The complex pathways of Wnt $5 \mathrm{a}$ in cancer progression. $\mathbf{J}$ Mol Med 86(3): 259-66.

Pukrop T, Klemm F, Hagemann T, Gradl D, Schulz M, Siemes S, Trumper L and Binder C (2006): Wnt 5a signaling is critical for macrophage-induced invasion of breast cancer cell lines. Proc Natl Acad Sci U S A 103(14): 5454-9.

Reya T and Clevers H (2005): Wnt signalling in stem cells and cancer. Nature 434(7035): 843-50.

Robert-Koch-Institut in Verbreitung von Krebserkrankungen in Deutschland. Entwicklung der Prävalenzen zwischen 1990 und 2010.

Beiträge zur Gesundheitsberichterstattung des Bundes., RKI, Berlin, (2010)

Rothbacher U, Laurent MN, Deardorff MA, Klein PS, Cho KW and Fraser SE (2000): Dishevelled phosphorylation, subcellular localization and multimerization regulate its role in early embryogenesis. EMBO J 19(5): 1010-22.

Sambrook J, Fritsch EF and Maniatis T: Molecular Cloning; in: A Laboratory Manual. Cold Spring Habor, New York, Cold Spring Habor Laboratory Press, (1989)

Saneyoshi T, Kume S, Amasaki Y and Mikoshiba K (2002): The Wnt/calcium pathway activates NF-AT and promotes ventral cell fate in Xenopus embryos. Nature 417(6886): 2959.

Schambony A and Wedlich D (2007): Wnt-5A/Ror2 regulate expression of XPAPC through an alternative noncanonical signaling pathway. Dev Cell 12(5): 779-92.

Schlange T, Matsuda Y, Lienhard S, Huber A and Hynes NE (2007): Autocrine WNT signaling contributes to breast cancer cell proliferation via the canonical WNT pathway and EGFR transactivation. Breast Cancer Res 9(5): R63.

Schulte G and Bryja V (2007): The Frizzled family of unconventional G-protein-coupled receptors. Trends Pharmacol Sci 28(10): 518-25. 
Schwarz-Romond T, Merrifield C, Nichols BJ and Bienz M (2005): The Wnt signalling effector Dishevelled forms dynamic protein assemblies rather than stable associations with cytoplasmic vesicles. J Cell Sci 118(Pt 22): 5269-77.

Sharma RP and Chopra VL (1976): Effect of the Wingless (wg1) mutation on wing and haltere development in Drosophila melanogaster. Dev Biol 48(2): 461-5.

Shimizu H, Julius MA, Giarre M, Zheng Z, Brown AM and Kitajewski J (1997): Transformation by Wnt family proteins correlates with regulation of beta-catenin. Cell Growth Differ 8(12): 1349-58.

Simons M and Mlodzik M (2008): Planar cell polarity signaling: from fly development to human disease. Annu Rev Genet 42: 517-40.

Simons M, Gault WJ, Gotthardt D, Rohatgi R, Klein TJ, Shao Y, Lee HJ, Wu AL, Fang Y, Satlin LM, Dow JT, Chen J, Zheng J, Boutros M and Mlodzik M (2009): Electrochemical cues regulate assembly of the Frizzled/Dishevelled complex at the plasma membrane during planar epithelial polarization. Nat Cell Biol 11(3): 286-94.

Slusarski DC and Pelegri F (2007): Calcium signaling in vertebrate embryonic patterning and morphogenesis. Dev Biol 307(1): 1-13.

Slusarski DC, Corces VG and Moon RT (1997): Interaction of Wht and a Frizzled homologue triggers G-protein-linked phosphatidylinositol signalling. Nature 390(6658): 410-3.

Smalley MJ, Sara E, Paterson H, Naylor S, Cook D, Jayatilake H, Fryer LG, Hutchinson L, Fry MJ and Dale TC (1999): Interaction of axin and Dvl-2 proteins regulates Dvl-2stimulated TCF-dependent transcription. EMBO J 18(10): 2823-35.

Steeg PS (2006): Tumor metastasis: mechanistic insights and clinical challenges. Nat Med 12(8): 895-904.

Tamai K, Zeng X, Liu C, Zhang X, Harada Y, Chang Z and He X (2004): A mechanism for Wnt coreceptor activation. Mol Cell 13(1): 149-56. 
van Amerongen R, Mikels A and Nusse R (2008): Alternative wnt signaling is initiated by distinct receptors. Sci Signal 1(35): re9.

Wallingford JB and Habas R (2005): The developmental biology of Dishevelled: an enigmatic protein governing cell fate and cell polarity. Development 132(20): 4421-36.

Wallingford JB, Rowning BA, Vogeli KM, Rothbacher U, Fraser SE and Harland RM (2000): Dishevelled controls cell polarity during Xenopus gastrulation. Nature 405(6782): 815.

Wang $\mathbf{H}$, Lee $\mathbf{Y}$ and Malbon CC (2004): PDE6 is an effector for the Wnt/Ca2+/cGMPsignalling pathway in development. Biochem Soc Trans 32(Pt 5): 792-6.

Westermarck J and Kahari VM (1999): Regulation of matrix metalloproteinase expression in tumor invasion. FASEB J 13(8): 781-92.

Wong HC, Mao J, Nguyen JT, Srinivas S, Zhang W, Liu B, Li L, Wu D and Zheng J (2000): Structural basis of the recognition of the dishevelled DEP domain in the Wnt signaling pathway. Nat Struct Biol 7(12): 1178-84.

Wong HC, Bourdelas A, Krauss A, Lee HJ, Shao Y, Wu D, Mlodzik M, Shi DL and Zheng J (2003): Direct binding of the PDZ domain of Dishevelled to a conserved internal sequence in the C-terminal region of Frizzled. Mol Cell 12(5): 1251-60.

Wu J, Klein TJ and Mlodzik M (2004): Subcellular localization of frizzled receptors, mediated by their cytoplasmic tails, regulates signaling pathway specificity. PLoS Biol 2(7): E158.

Yamamoto H, Yoo SK, Nishita M, Kikuchi A and Minami Y (2007): Wnt5a modulates glycogen synthase kinase 3 to induce phosphorylation of receptor tyrosine kinase Ror2. Genes Cells 12(11): 1215-23.

Yang-Snyder J, Miller JR, Brown JD, Lai CJ and Moon RT (1996): A frizzled homolog functions in a vertebrate Wnt signaling pathway. Curr Biol 6(10): 1302-6. 


\section{DANKE}

... an Prof. Dr. med. Claudia Binder für die Überlassung dieses spannenden Themas, für die hervorragende Unterstützung als Doktormutter und für die beeindruckende und motivierende Begeisterung für ihren Fachbereich. Ihr habe ich mein Interesse an der Onkologie zu verdanken;

$\ldots$ an Dr. med. Tobias Pukrop für die intensive Betreuung meiner Dissertation. Er hatte immer Zeit für spannende wissenschaftliche Diskussionen und praktische Hinweise und sorgte dadurch von Anfang an, dass man sich als Doktorand sehr gut aufgehoben fühlte;

... an Matthias Schulz und Meike Schaffrinski, die jederzeit mit viel Rat und guter Tat zur Seite standen;

... an Florian Klemm für seine Hilfsbereitschaft und Unterstützung im Labor;

... an meine netten Mitdoktoranden, dass die Fertigstellung einer Promotion nur halbes Leid und doppelte Freude ist. Hier geht insbesondere ein großer Dank an Eugenia Chuang, Raphaela Lohaus und Julia Schoenen für die schöne Zeit seit Beginn der Dissertation;

... an alle weiteren Mitarbeiter für die gute Stimmung im Labor;

... ein besonderer Dank an Dr. Thierry Rolling. 